\title{
The Energy Efficiency and Living Comfort of a Stabilized Rammed Earth Dwelling in Comparison with a Traditional Stud Frame Building
}

David C. Johnson III

WVU, dcj0007@mix.wvu.edu

Follow this and additional works at: https://researchrepository.wvu.edu/etd

Part of the Civil Engineering Commons

\section{Recommended Citation}

Johnson, David C. III, "The Energy Efficiency and Living Comfort of a Stabilized Rammed Earth Dwelling in Comparison with a Traditional Stud Frame Building" (2020). Graduate Theses, Dissertations, and Problem Reports. 7533.

https://researchrepository.wvu.edu/etd/7533

This Problem/Project Report is protected by copyright and/or related rights. It has been brought to you by the The Research Repository @ WVU with permission from the rights-holder(s). You are free to use this Problem/Project Report in any way that is permitted by the copyright and related rights legislation that applies to your use. For other uses you must obtain permission from the rights-holder(s) directly, unless additional rights are indicated by a Creative Commons license in the record and/ or on the work itself. This Problem/Project Report has been accepted for inclusion in WVU Graduate Theses, Dissertations, and Problem Reports collection by an authorized administrator of The Research Repository @ WVU. For more information, please contact researchrepository@mail.wvu.edu. 
The Energy Efficiency and Living Comfort of a Stabilized Rammed Earth Dwelling in Comparison with a Traditional Stud Frame Building

\author{
David Johnson
}

\author{
Problem Report submitted \\ to the Statler College of Engineering and Mineral Resources \\ at West Virginia University \\ in partial fulfillment of the requirements for the degree of \\ Civil Engineering in \\ Department of Civil and Environmental Engineering
}

\author{
Hota GangaRao, Ph. D., Chair \\ Ruifeng Liang, Ph. D. \\ Karl Barth, Ph. D. \\ Hailin Li, Ph. D.
}

\title{
Morgantown, West Virginia \\ 2020
}

Keywords: stabilized rammed earth, thermal performance, living comfort, geothermal mass, Hakka Tulou, sustainable construction, Green building, eQUEST

\section{Copyright 2020 David Johnson III}




\begin{abstract}
The Energy Efficiency and Living Comfort of a Stabilized Rammed Earth Dwelling in

Comparison with a Traditional Stud Frame Building
\end{abstract}

\author{
David Johnson
}

\begin{abstract}
During the last several decades, rammed earth construction has received renewed attention due to its many desirable characteristics. For construction, use, and end of life treatment, rammed earth construction has shown in research to reduce the embodied energy of residential building construction by $66-85 \%$ compared to building methods that use fired brick and concrete members. Research thus far also indicates that rammed earth construction may indeed be more energy efficient since the building material has a very high thermal inertia, henceforth, the rammed earth walls absorb thermal energy from the sun and release it into the building to reduce the total volume of energy needed from external utilities. This paper reports the data and conclusions from an ongoing project being conducted by West Virginia University (WVU) in collaboration with the United States Department of Housing and Urban Development (HUD), Aleutian Housing Authority (AHA) in Anchorage, Alaska, and The North American Rammed Earth Builders Association (NAREBA). The project includes the construction and monitoring of a stabilized rammed earth (SRE) dwelling in Butte, Alaska that is compared in real-time to the performance of a traditional stick frame house located within a half-mile from the original SRE building. Live temperature, relative humidity (RH), and dew point (DP) data are used in conjunction with utility bills for both homes to determine the thermal performance of each home. When normalizing the energy being used to heat both homes to $71 \mathrm{~F}$, it was found that heating one square foot in the stud construction home (STUD) costs $\sim 2.3$ times as much compared to an SRE house. This represents a cost savings of $56 \%$ for the SRE home compared to the STUD home. By replacing one stick frame home with an SRE home with an approximate size of $1,788 \mathrm{ft}^{2}$, the released greenhouse gasses are reduced by 67 tons of $\mathrm{CO}_{2}$ per decade. Virtual models using eQUEST and Alaskan state thermal models (AK Warm) have also been compared to the field data to validate the accuracy of the models. The eQUEST model was then able to reveal that the rammed earth walls improved the energy efficiency by $42 \%$, the high-performance windows by $22 \%$, the absence of a crawlspace by $8 \%$, and the lengthwise-southern orientation of the building by $7 \%$.
\end{abstract}




\section{ACKNOWLEDGEMENTS}

The research and development effort on rammed earth construction at WVU was initially funded by NSF from Jan 2009 to Dec 2011. The field work was funded by HUD for research and monitoring portion and by AHA for construction portion from Jan 2015 to Dec 2016. Additional funding is being provided by HUD to conduct the monitoring and on-site evaluation of the SRE housing from Sept 2018 to Dec 2021.

I would like to thank Dr. Hota for his guidance and review of this project to ensure that the highest level of quality was achieved while reporting our research at WVU.

I would like to thank Dr. Liang for his constant efforts to assist with the project, provide guidance, and direct involvement to help better understand the information that this project has gathered.

I would like to thank Dr. Barth for his commitment to excellence and teaching here at WVU and for his support in this project as a member of my committee.

I would like to thank Dr. Li who provided me with very helpful insights and advice on how to develop a working virtual model of the buildings discussed in this project.

I would like to thank Dan Duame, who although is retired, did not hesitate to help myself or the team here at WVU with any of our questions and was more than willing to assist and direct me with activities while in Alaska. Special thanks to his friend, the homeowner of the stud frame house, that was willing to volunteer her space to be used for the research and personally help us with our onsite needs.

I would like to thank Kennedy Serr who displayed a tremendous amount of hospitality to Dr. Liang and myself when traveling to Alaska. She was more than willing to provide me with 
answers, advice, and documentation while speaking in person in Alaska or from our own offices thousands of miles apart.

I would like to give a special thanks to the tenants of the SRE house were very

hospitable to the researchers from WVU and were more than willing to provide us with any information that we needed. 


\section{TABLE OF CONTENTS}

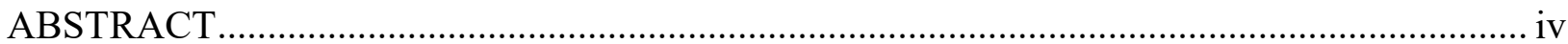

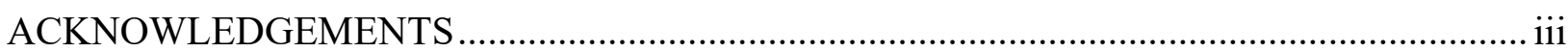

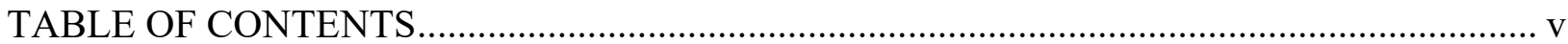

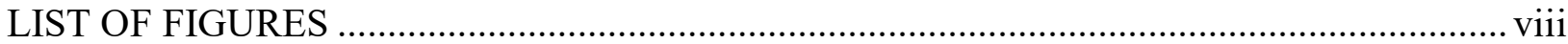

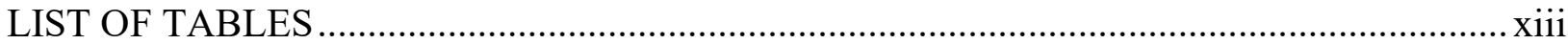

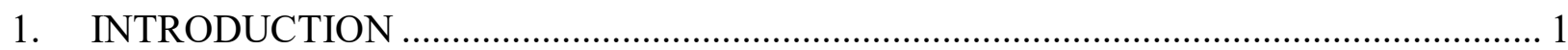

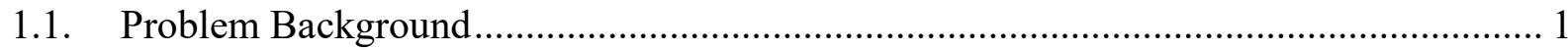

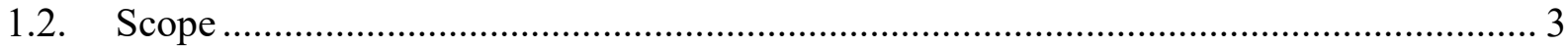

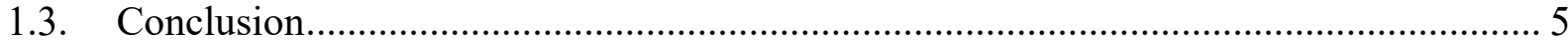

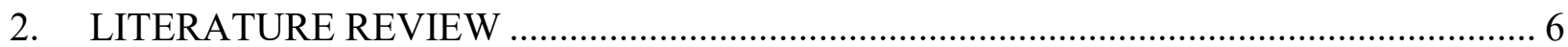

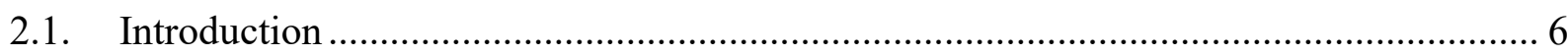

2.1.1. History of Rammed Earth Buildings............................................................ 6

2.1.2. The Advantages of Rammed Earth Buildings ............................................... 7

2.1.3. The Limitations of Rammed Earth Buildings ................................................. 8

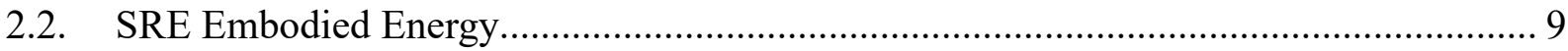

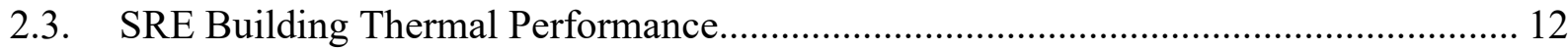

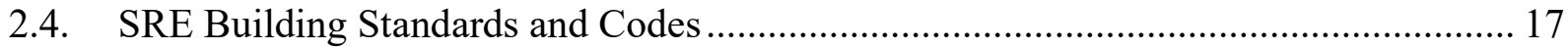

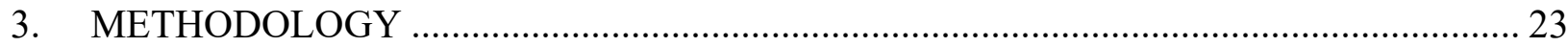

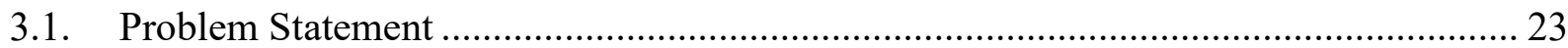




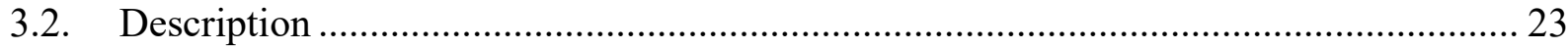

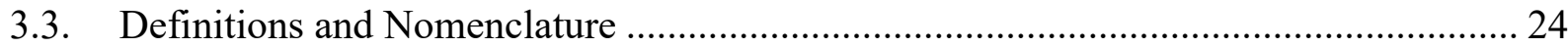

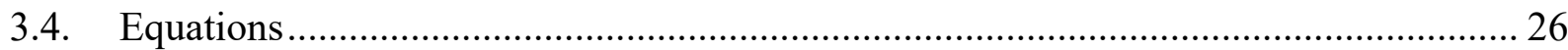

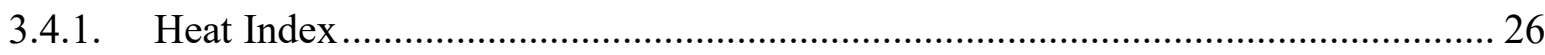

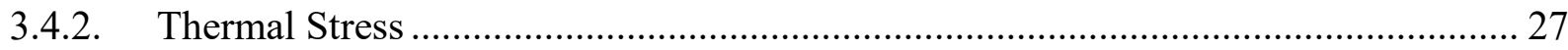

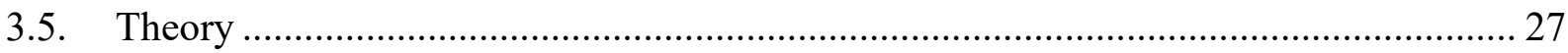

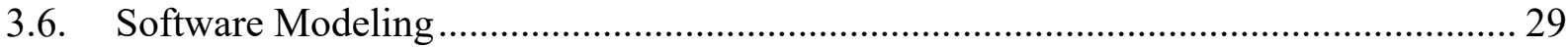

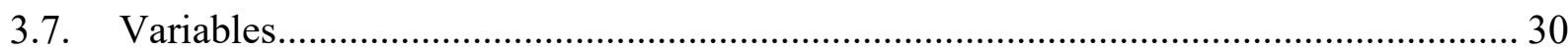

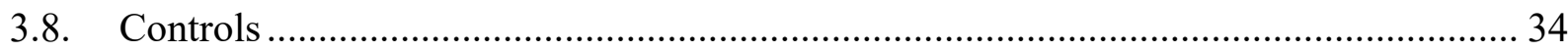

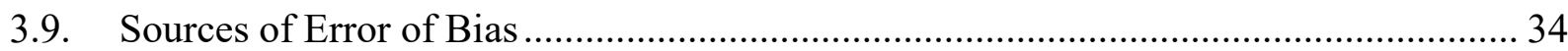

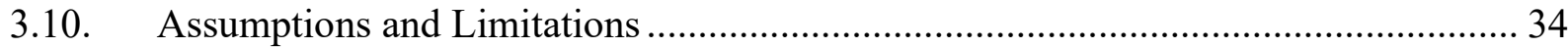

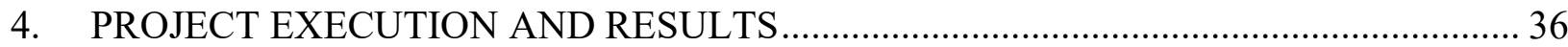

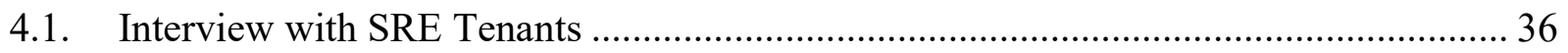

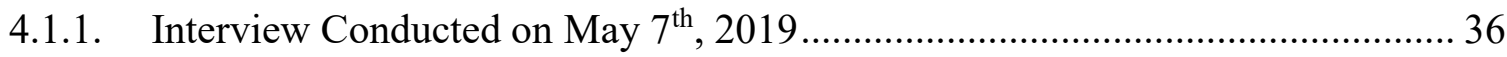

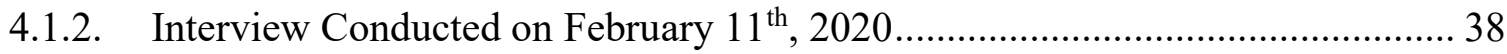

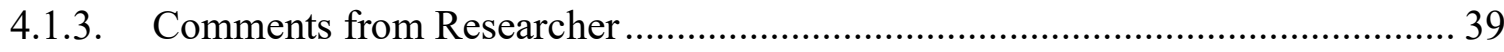

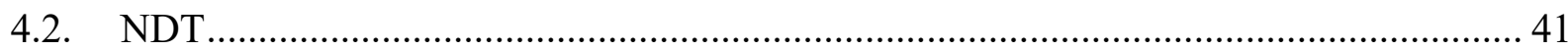

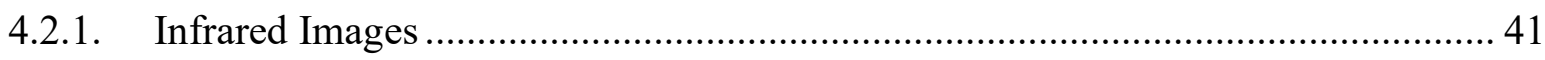

4.2.2. Infrared Images of SRE House ……………............................................... 41

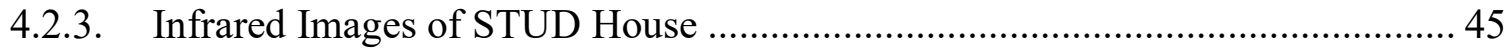


4.2.4. Ultrasound Tap Meter Results ............................................................................ 47

4.2.5. Visual Inspection of SRE Structure ……………............................................... 49

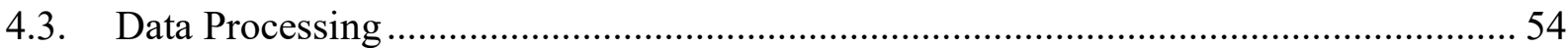

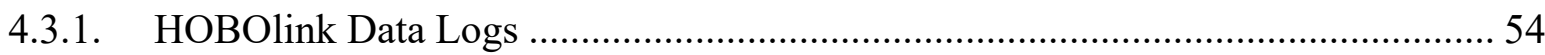

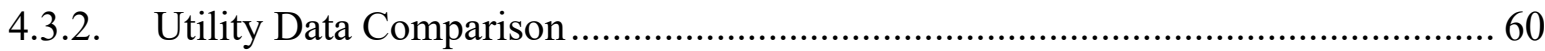

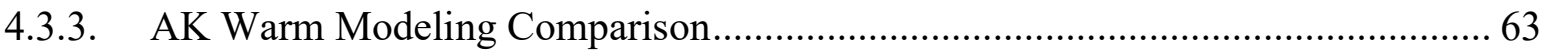

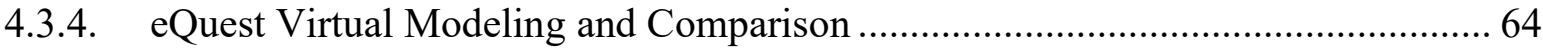

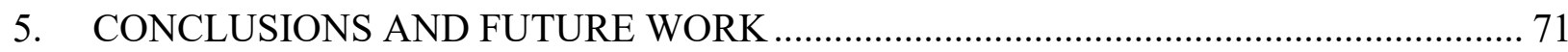

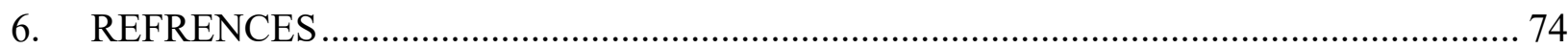

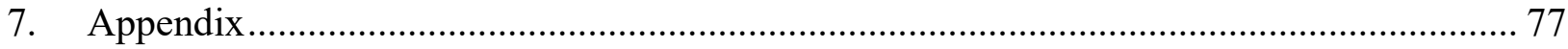

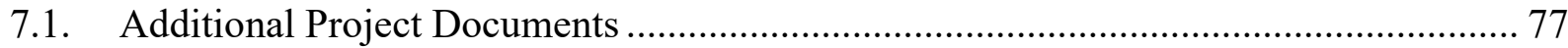

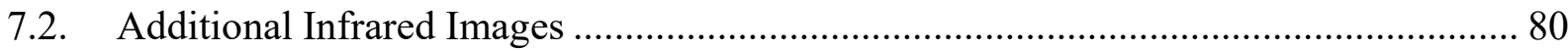

7.2.1. Infrared Photos Taken from inside of SRE house …............................................ 80

7.2.2. Infrared Photos Taken from Outside of the SRE House.......................................... 82

7.2.3. Infrared Photos Taken from Outside of STUD House.............................................. 85

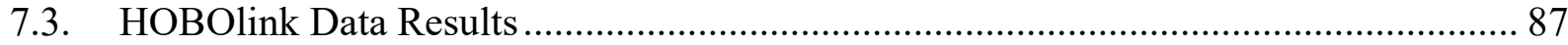

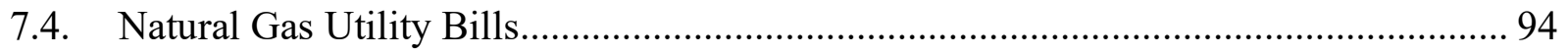




\section{LIST OF FIGURES}

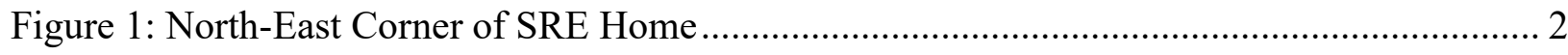

Figure 2: South-East Corner of SRE House ................................................................. 2

Figure 3: Reference Stick Frame House (STUD House) ................................................... 3

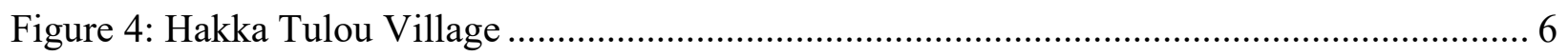

Figure 5: Comparison of Embodied Energy in Four Building Solutions (Pacheco et al. 2012)... 12

Figure 6: Definition of Seasons for this Paper.................................................................... 26

Figure 7: Summer and Winter Comfort Zones (Boduch et al 2009) ...................................... 29

Figure 8: SRE Floorplan with Location of Sensors …................................................... 33

Figure 9: STUD Floorplan with Location of Sensors ......................................................... 33

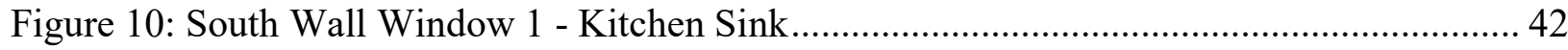

Figure 11: South Wall Sliding Glass Door 2 (Bottom)..................................................... 42

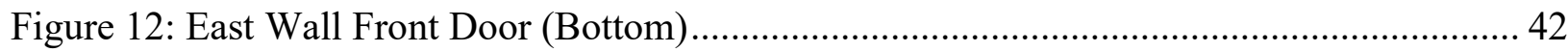

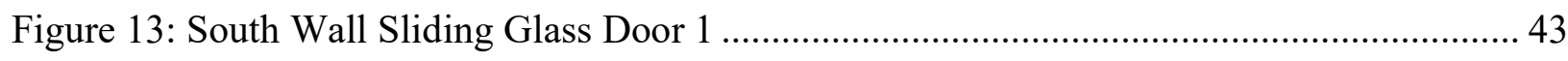

Figure 14: South Wall View of Wall-Slab Joint Outside ................................................. 43

Figure 15: North Wall Window 2 - Guest Bathroom ..................................................... 44

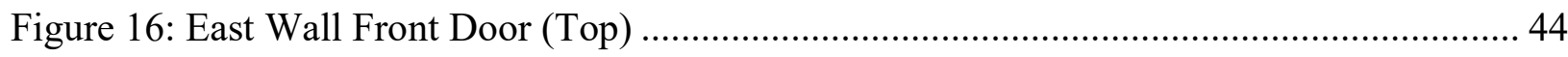

Figure 17: West Wall Window - Living Room ............................................................ 45

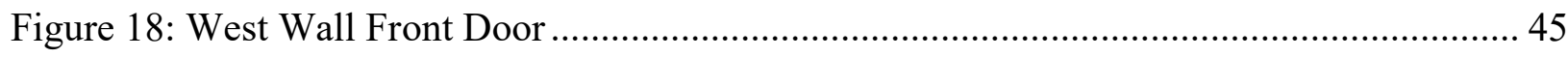

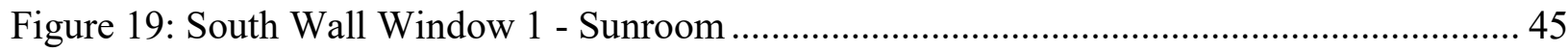

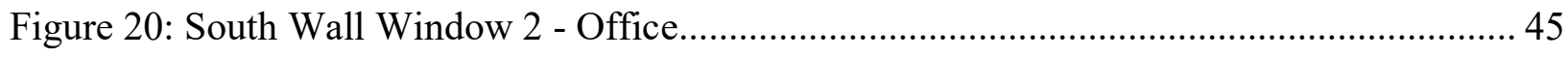

Figure 21: North Wall Leakage - Laundry Room ......................................................... 46

Figure 22: West Wall Overhead Garage Door..................................................................... 46 
Figure 23: $\mathrm{RD}^{3}$ Digital Tap Meter by Wichitech Industries . 47

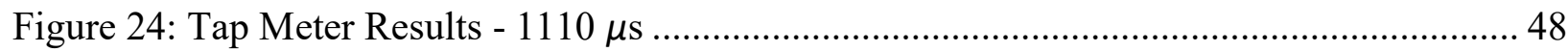

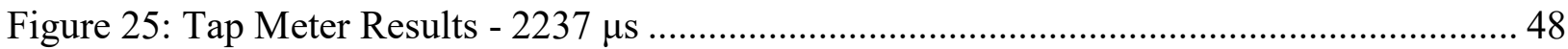

Figure 26: Tap Meter Results - $1117 \mu$ s ........................................................................... 48

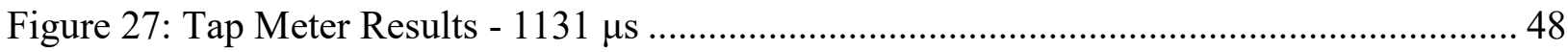

Figure 28: South Window 3 - Interior Delamination - Master Bedroom ............................... 49

Figure 29: Close up of South Window 3 - Interior Delaminations - Master Bedroom .............. 49

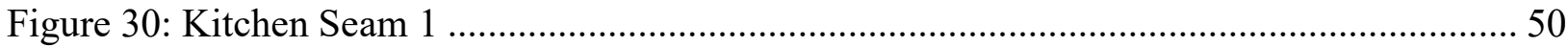

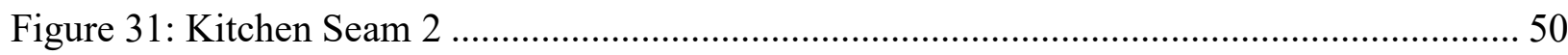

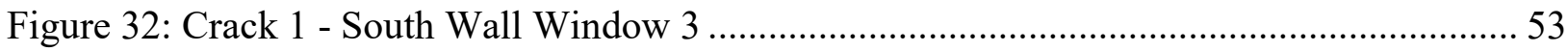

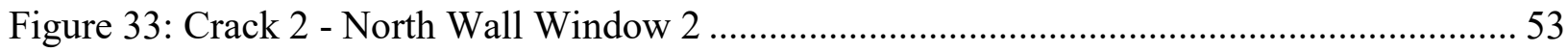

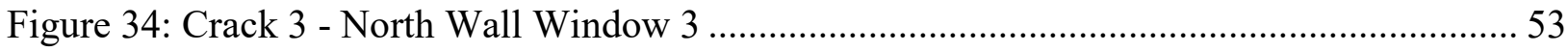

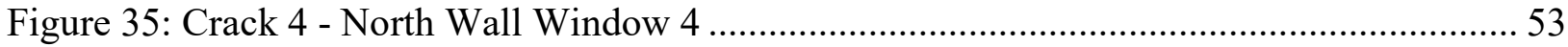

Figure 36: Average Seasonal Temperatures Measured in SRE house, Stud house, and Exterior 56

Figure 37: Max Temperatures Measured in SRE house, Stud house, and Exterior ................... 56

Figure 38: Min Temperatures Measured in SRE house, Stud house, and Exterior .................... 56

Figure 39: Winter of 2019 - Relative Humidity vs Temperature ........................................... 58

Figure 40: Summer of 2019 - Relative Humidity vs Temperature .......................................... 59

Figure 41: Summary of SRE Apparent Temperatures during Summer Months of 2019 ........... 60

Figure 42: Vol. of Natural Gas Used in SRE house and Stud house and Predicted Vol. of Natural

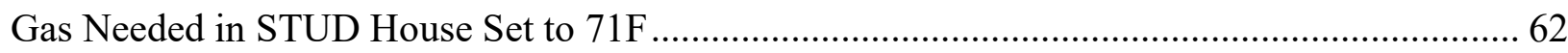

Figure 43: SRE Gas Consumption Chart from eQUEST.................................................. 66

Figure 44: SRE Gas Consumption Table from eQUEST ....................................................... 67 
Figure 45: STUD Gas Consumption Chart from eQUEST

Figure 46: STUD Gas Consumption Table from eQUEST ................................................. 68

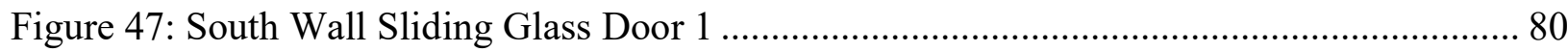

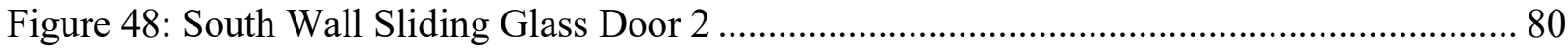

Figure 49: South Wall Sliding Glass Door 2 (Bottom Corner View)...................................... 80

Figure 50: North-East Interior Ceiling Corner - Guest Bedroom .......................................... 80

Figure 51: South Wall Sliding Glass Door 1 .................................................................. 81

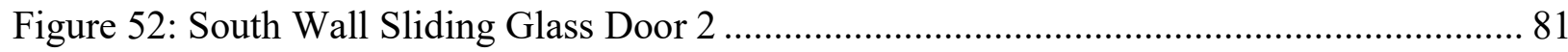

Figure 53: South Wall Sliding Glass Door 2 (Bottom Corner View)...................................... 81

Figure 54: North-East Interior Ceiling Corner - Guest Bedroom ........................................ 81

Figure 55: South Wall Window 3 - Master Bedroom Window ............................................. 82

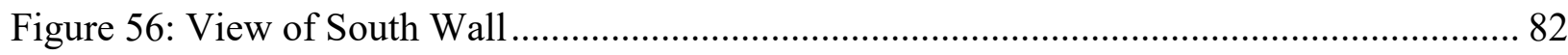

Figure 57: South Wall Window 2 - Master Bathroom Window .............................................. 82

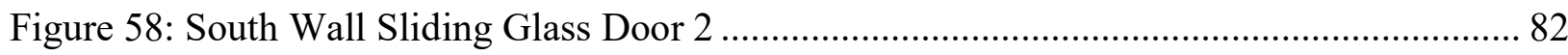

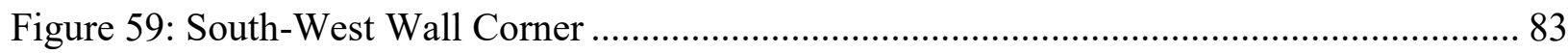

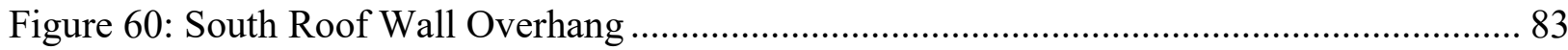

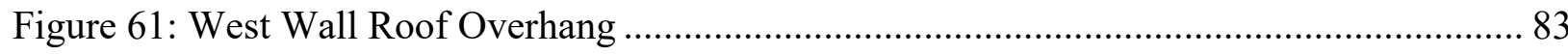

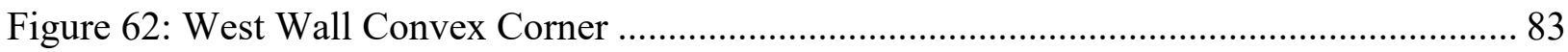

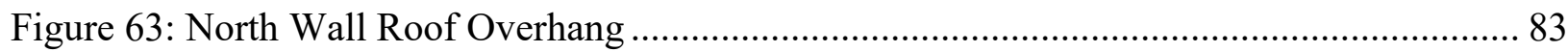

Figure 64: North Wall Window 1 - Guest Bedroom........................................................ 83

Figure 65: North Wall Window 4 - Entryway Window 1 ................................................... 84

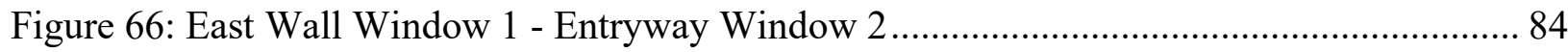

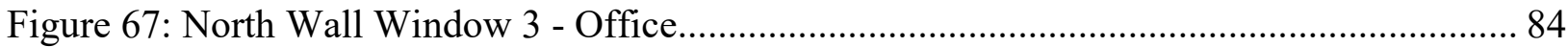




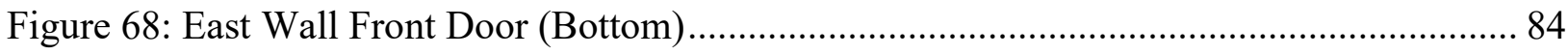

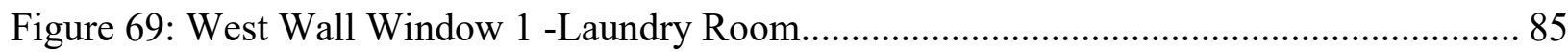

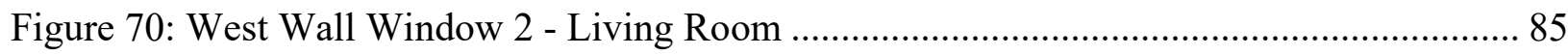

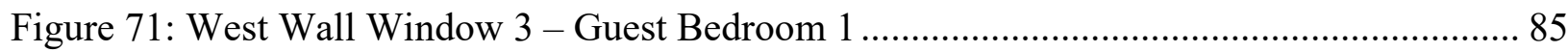

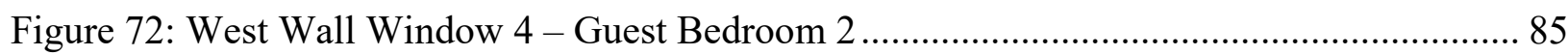

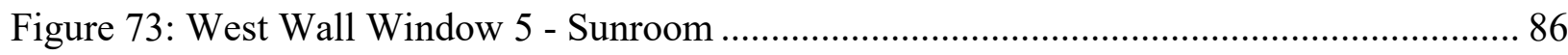

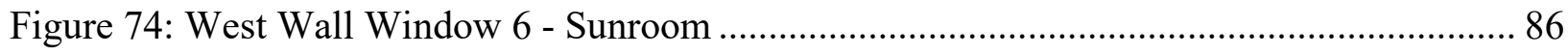

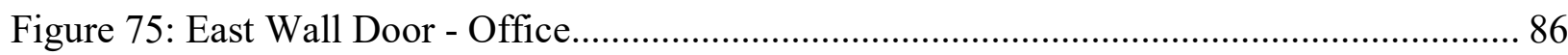

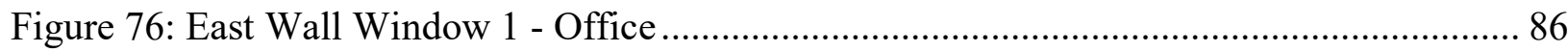

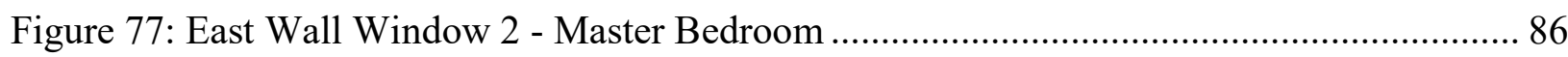

Figure 78: East Wall Back Patio - Sliding Glass Door, Kitchen Window, Kitchen Door............. 86

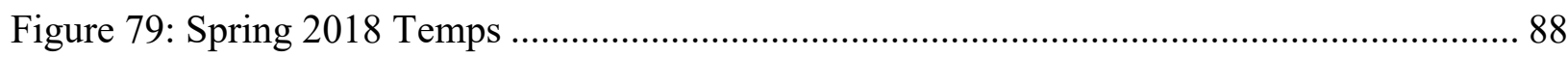

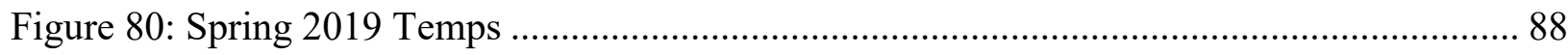

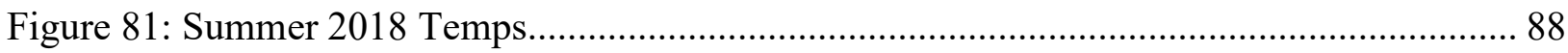

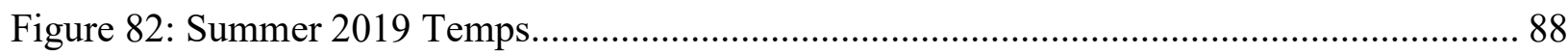

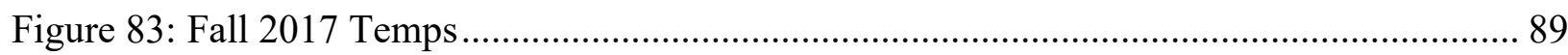

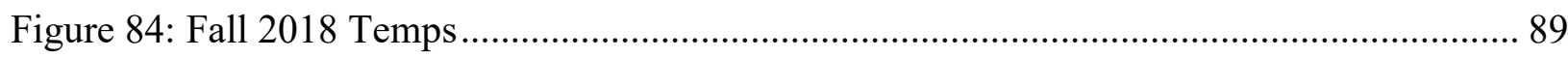

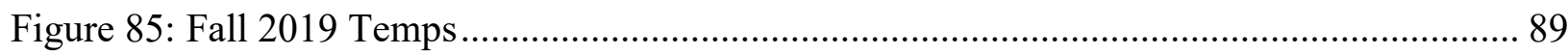

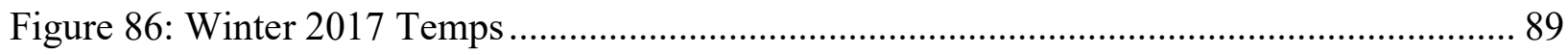

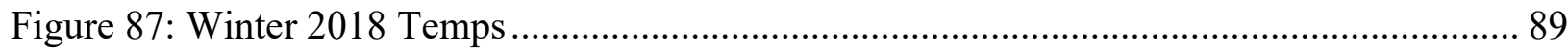

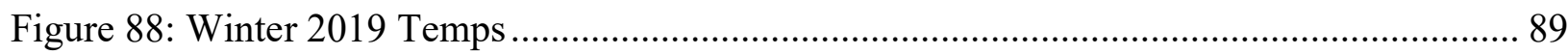

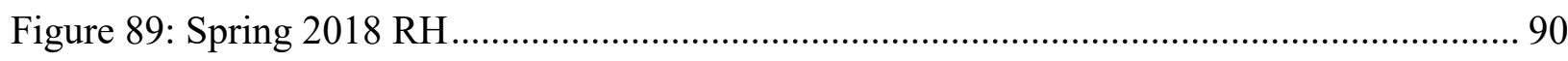

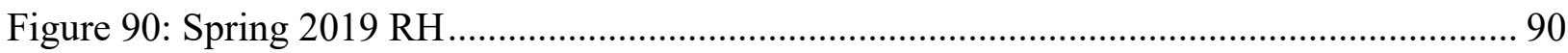




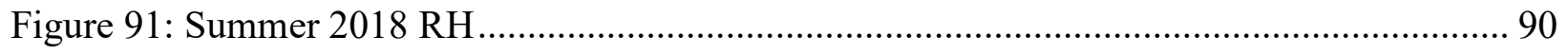

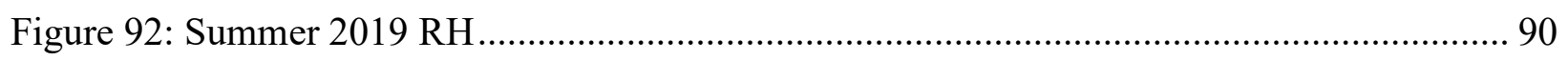

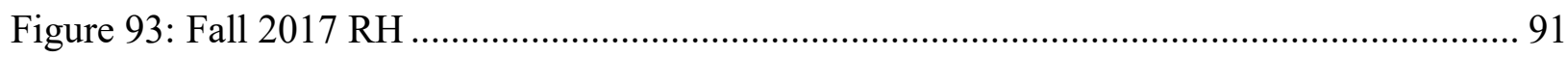

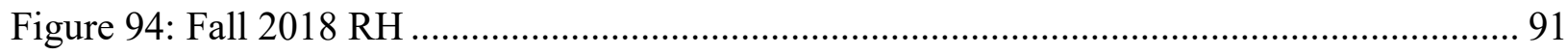

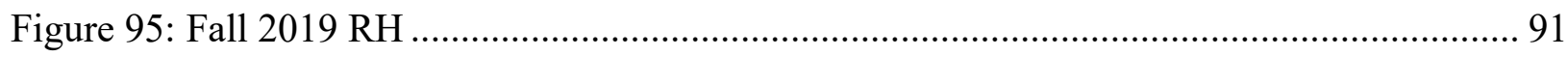

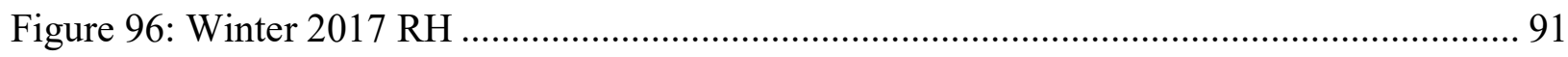

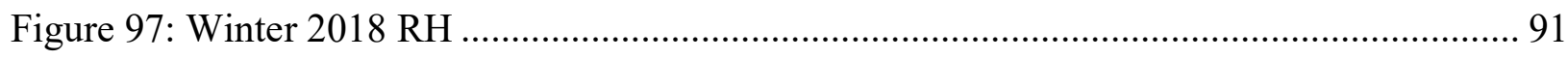

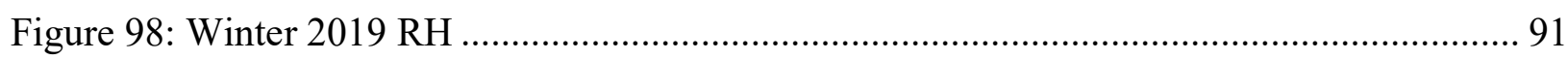

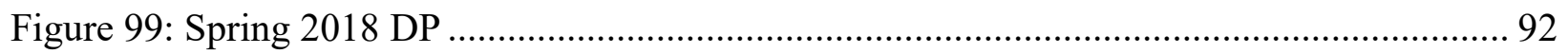

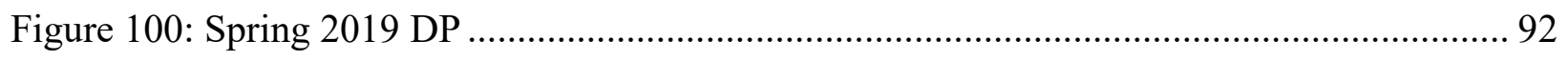

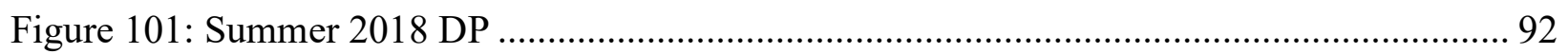

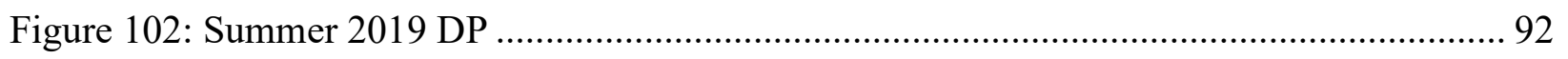

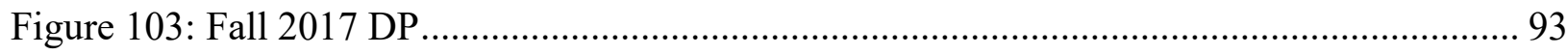

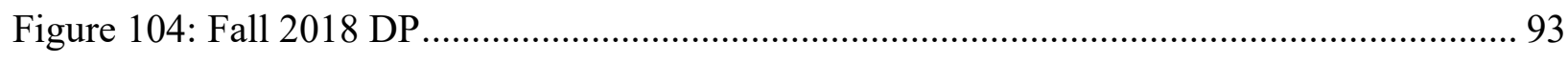

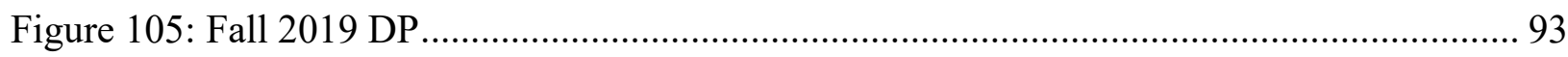

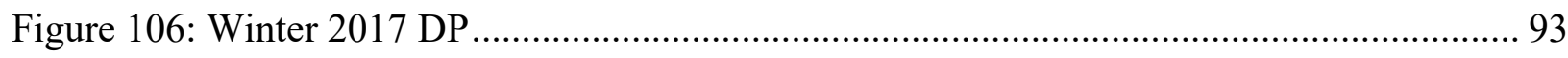

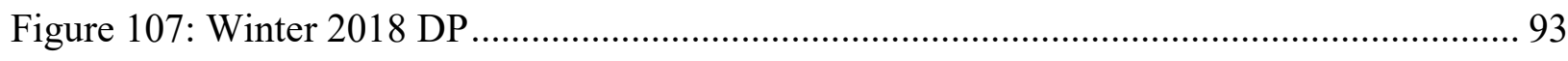

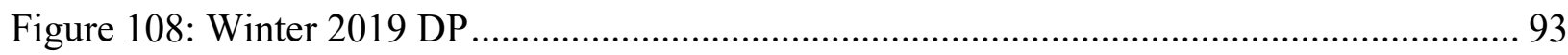




\section{LIST OF TABLES}

Table 1: Total Energy Consumption Comparison (Serrano et al. 2016) ……............................... 15

Table 2: Column Load Factor Reductions (Maniatidis et al. 2008) ............................................ 21

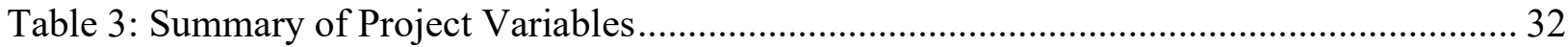

Table 4: Summary of Common Interior Temperatures in SRE Building ..................................... 42

Table 5: Summary of Common Exterior Temperatures on SRE Building ................................... 44

Table 6: Summary of Common Exterior Temperatures STUD Building ...................................... 46

Table 7: Summary of Seasonal HOBOlink Temperature, RH, and DP Data ................................ 55

Table 8: Standard Deviations for Seasons from Recorded Temperature, RH, and DP Data........ 57

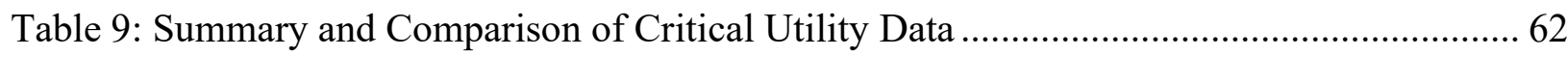

Table 10: Summary of AK Warm Data in Comparison with Measured Utilities.......................... 64

Table 11: Gas Consumption Comparison to Prove eQUEST Model Accuracy ………………..... 68

Table 12: Influence of Specific Building Properties on the Energy Demand of the Model

Structure

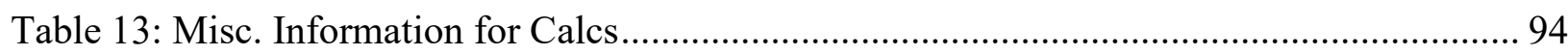

Table 14:Sample SRE Natural Gas Utility Information ............................................................... 94

Table 15: Sample of STUD Natural Gas Utility Information................................................... 95 


\section{INTRODUCTION}

\subsection{Problem Background}

The Department of Housing and Urban Development (HUD), Aleutian Housing Authority (AHA), and The North American Rammed Earth Builders Association (NAREBA) in collaboration with West Virginia University (WVU) has constructed a stabilized rammed earth (SRE) residential dwelling for the purpose of studying the thermal efficiency of the structure as well as developing materials for the purpose of training others on how to best use SRE to maximize thermal performance. SRE buildings are made from walls that are composed of compacted layers of sand, soil, stone, occasionally natural fibers, and a lime or cement hardener. The layers are compacted one on top of the other using a slip formwork resulting in a wall that acts as a load bearing wall and a geothermal mass. SRE construction has received a renewed attention over the last several decades because it proposes an affordable construction method in many third world countries that uses environmentally friendly materials that may thermally outperform conventional building methods available in the market today (see LITERATURE REVIEW for additional background information). For additional documentation regarding the long term history of this project see the appendix where a list of references has been gathered to recognize previous contributions to this project.

The rammed earth building in this project was constructed in Alaska in December of 2016 by Bly Windstorm of NAREBA with the help of John Harper and a team of volunteer WVU students. Since the majority of the work for building the SRE house was done by volunteers, the exact cost of constructing an SRE house is unknown because hours spent on this project were not tracked. The structure was then connected to utilities in November 2017 and occupied by tenants in January 2018. The temperature and humidity data inside the building, outside the building, 
and within the walls have been collected since November 21,2017. The data from these sensors is routed to a data logger located within the building and is then uploaded to an encrypted site where researchers at WVU can gain access to the live transmission of the data and export historical data.

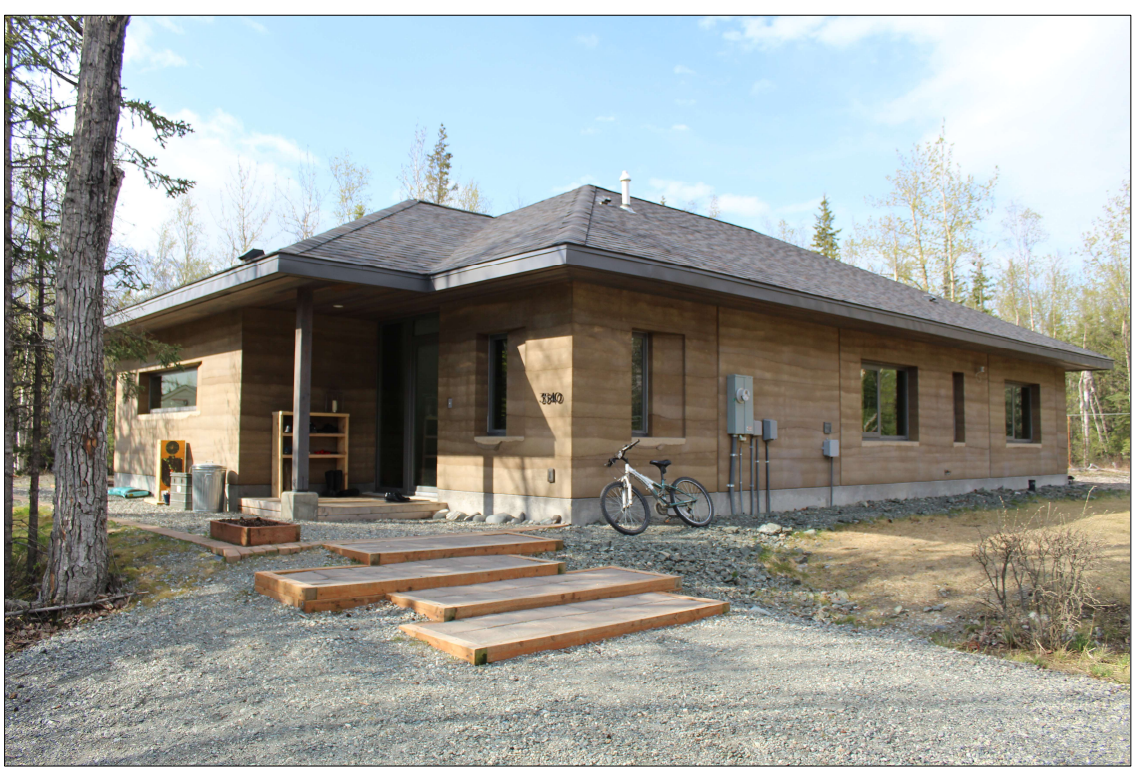

Figure 1: North-East Corner of SRE Home

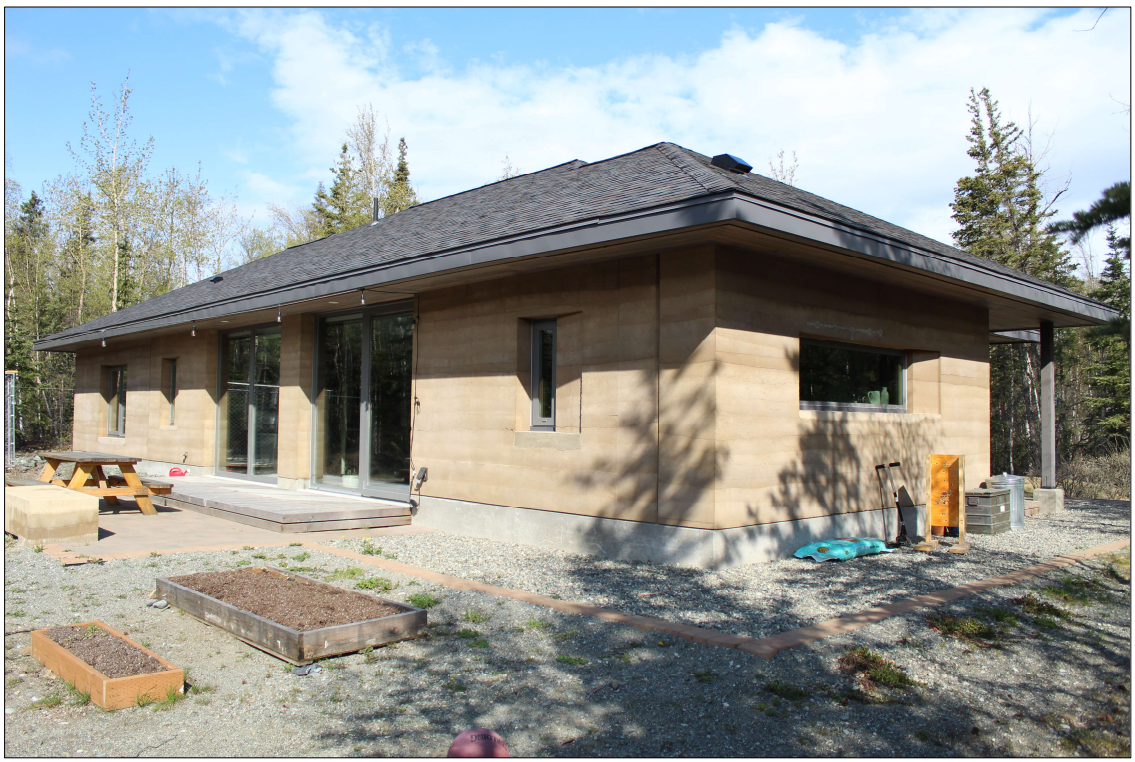

Figure 2: South-East Corner of SRE House 
A similar data logging system was installed and initiated on May 8, 2019, in a closely located "reference" building constructed using standard stick frame construction with fiberglass, batt insulation so that the researchers at WVU can have a live comparison of the thermal performance of the two buildings. In addition to the data being received from the two sites, researchers at WVU have created virtual models of both buildings to better understand the energy usage and propose modifications that can be made to either of these two structures that can further enhance the thermal performance.

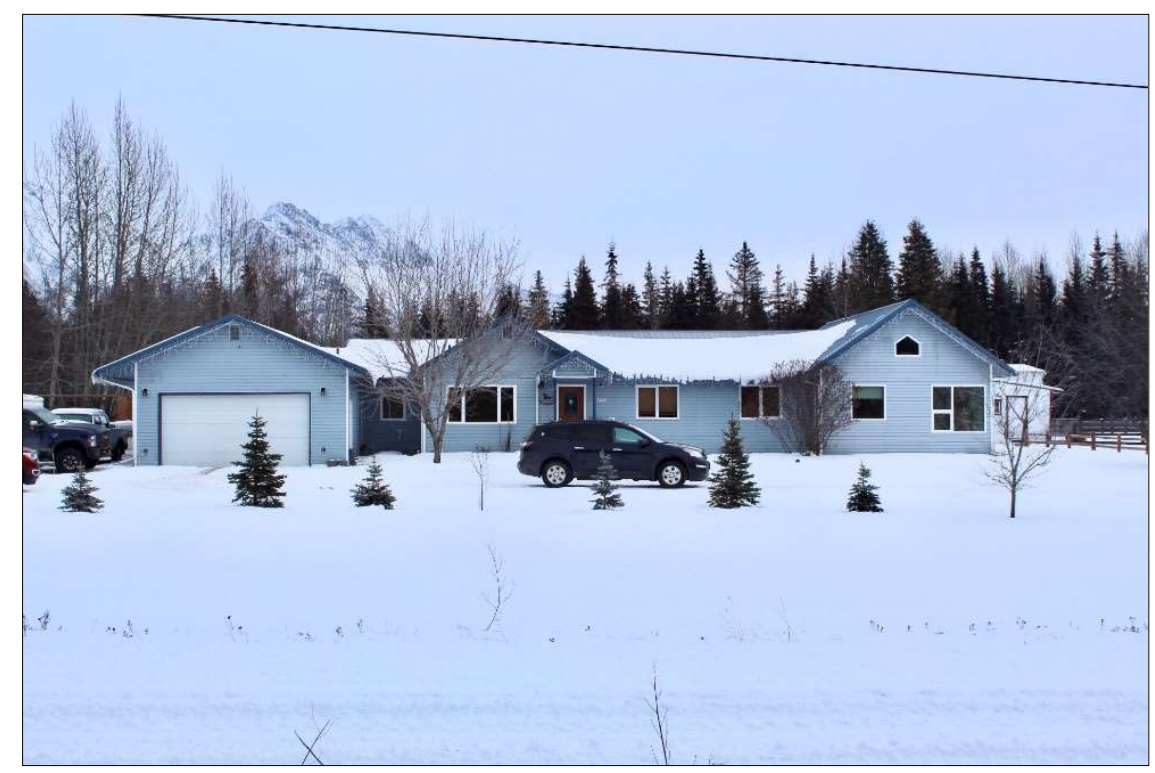

Figure 3: Reference Stick Frame House (STUD House)

\subsection{Scope}

The duration of this project has required quarterly collection and analysis of the data to understand how the buildings are behaving. Researchers at WVU have been downloading the new available data from the online portal and add it to an existing master spreadsheet that is able to generate time-temperature/relative humidity/dew point graphs inside the two homes, and 
statistical information from different seasons (summer, fall winter, spring), essentially providing clarity to see what the large volume of data is communicating.

Dr. Liang and Graduate Student, David Johnson, traveled to Butte, Alaska where the SRE house is located during May 2019. On this trip the researchers were able to meet with the tenants of both the houses and interview them on their experiences regarding living in a SRE house, thus far. The team was also able to conduct extensive non-destructive testing with an infrared camera and ultrasound tap-meter. The infrared camera was used to help detect if there were any leaks where cold air was getting in or warm air was escaping. The tap-meter was used to check the areas surrounding any cracks in the building to understand if they were growing or intrinsic to the layers of compacted soil in the walls were being constructed.

During the May 2019 trip, the researchers worked closely with members of the AHA team. Dan Duame, who recently retired from AHA, recommended that we use his previous home as a reference location to compare the energy efficiency of the SRE house, since it was located less than a half mile away, had a similar square footage, and was a good representation of standard stick frame construction method in the area. We were able to coordinate with the homeowner to install a data logger with various sensors located though the building - similar to the layout in the SRE building. Infrared photos were also taken at this location to better understand any thermal leakages that were present in the house around doors, windows, and the crawl space.

The data from both sites was then collected in three-month intervals and analyzed for energy consumption so that useful information could be derived. The author of this report (David Johnson) from WVU was then able to return to Alaska during February of 2020 to interview the tenants at the SRE house and to gather more NDT data from the SRE home. The infrared thermography data was much more successful this time since the ambient temperature was $0^{\circ} \mathrm{F}$ 
and there was no sun exposure. During this trip additional meetings were held with Dan and members of AHA to gather additional information about both homes in order to better develop eQUEST software models of the buildings. Final observations and research was concluded and summarized during the spring months of 2020 to deliver this up-to-date report on the project.

\subsection{Conclusion}

The following report uses the monitoring data, site information, utility information, and eQUEST virtual models of the SRE house and traditional stick frame house to provide an accurate description of the thermal performance of the two buildings and provide clarity to the question regarding whether or not SRE structures are more energy efficient than presently common construction methods. 


\section{LITERATURE REVIEW}

\subsection{Introduction}

\subsubsection{History of Rammed Earth Buildings}

The inspiration for researching the thermal performance of modern rammed earth construction comes from the Hakka Tulou structures in the southern and western parts of the Fujian Province, China (Liang 2013, Yelland et al 2013, Liang et al 2013, Liang et al 2011a, Liang et al 2011b). These structures have provided a case study for researchers at WVU - such as Daniel Stanislawski. The rammed earth structures in those regions have been dated to different construction efforts between $10^{\text {th }}$ and $20^{\text {th }}$ centuries and are now listed as UNESCO world heritage sites. Each structure was called a Tulou and represented a self-contained community that included schools, family dwellings, and places of worship all in one building. The structures were intentionally built around natural features, facing south, and in places that would minimize the wind loading on the building (Stanislawski 2011).

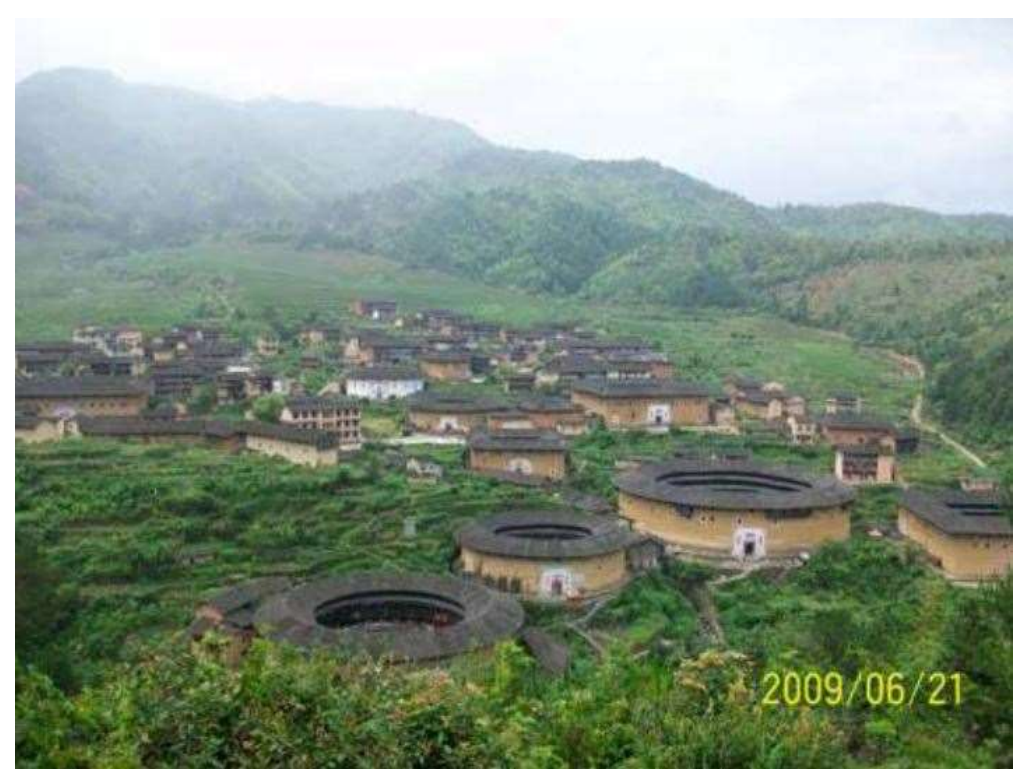

Figure 4: Hakka Tulou Village 
Over the years there have been several records of the material makeup of these structures but energy-dispersive X-ray spectroscopy (EDS) spectrums and interview reports indicate that the most likely constituents of the walls were all local materials such as stones, clay, mud, wood, and a compound called sanhetu - a mixture of earth, sand, and lime typically called "rammed earth". The structures from this region were typically $1,000 \mathrm{~m}^{2}$, but as large as $5,000 \mathrm{~m}^{2}$. Throughout this region there are estimated to be about 35,000 Tulous made with either a circular or rectangular footprint that could hold anywhere from 5 to 600 people (Stanislawski 2011).

The structure is made by creating a stone and clay perimeter foundation around the edge of the bottom footprint of the structure. This is then followed by a labor-intensive process to compact each layer of rammed materials from $\approx 20$ " to $15-16 "$. Each layer is allowed to dry and reach full hardness before the next layer is placed and the walls get thinner and thinner as the walls get higher. The rammed earth walls have had wood chips or bamboo added to provide reinforcement. The interior of the Tulou, that serves as dwelling places and other areas were constructed from timber trusses and interior partitions (Stanislawski 2011).

\subsubsection{The Advantages of Rammed Earth Buildings}

Rammed earth construction has become an attractive building method because it provides a practical way to reduce the overall cost and energy consumption of a regular dwelling place - a more precise discussion of the embodied energy of these structures will be found later in the report (Morel et al. 2001). Other benefits of rammed earth construction are that they may require less energy to manipulate the thermal conditions of the living space (Morel et al. 2001). This would reduce the annual consumption natural gas, electricity, or other local utilities used to heat and cool the space. The annual energy consumption issue will also be explored later in the literature review and then in the outcome of the problem investigated by this paper. Another 
major benefit of rammed earth dwellings are that rammed earth composite systems are known to be very stiff and provide a considerable amount of resistance to earthquake loads (Stanislawski 2011). The survival of the Tulou structures for hundreds of years in an earthquake prone region also provides a testimony to their structural durability (Stanislawski 2011).

Another advantage of rammed earth walls is the ease of construction. The skills required to build a rammed can be easily taught to someone without a formal education which is a benefit when attempting build an SRE structure in third world countries or very rural areas. Rammed earth walls constructed by hand are built by using slip forms and compacting one lift of soil at a time (approximately 12"-20" at a time). This process can be automated by using an onsite compacter that is installed close to the building site. This compacter would be filled with stock soil that is premixed with the correct ratios of cement, lime, sand, or other ingredients. This unit then would then be turned on and with the use of a simple motor and hydraulic pumps, the compactor would press the soil into a rammed earth block and this would be moved a short distance to its final resting place in the building plan.

\subsubsection{The Limitations of Rammed Earth Buildings}

One major limitation for rammed earth is that the construction tends to be very labor intensive (Stanislawski 2011). Another major limitation is that the geothermal mass that makes up the wall can force the residents to be unable to quickly manipulate the temperature of the living space. This may happen in situations when it is hot and sunny outside, and ventilation is limited in the structure and is one of the pressing issue that was discovered during this research project. Although this is an intrinsic challenge to rammed earth dwellings, there are several available solutions for problems like this. 


\subsection{SRE Embodied Energy}

The embodied energy is a term that describes the energy required for all the phases that a building can exist in - design, construction, and end of life (Serrano et al. 2016). As of a report published in 2010, the building sector is responsible for $19 \%$ of the total greenhouse gasses emitted into the atmosphere (Serrano et al. 2016). The control of the indoor living temperature of residential homes accounts for on average $34 \%$ of that building's energy consumption (Serrano et al. 2016). One of the best ways to improve the overall embodied energy that goes into a home is in properly selecting of materials for the different building elements (Serrano et al. 2016). Factors such as material availability, manufacturing, transportation, and end-of-life requirements all play a major factor in the embodied energy of a building and optimization of the material selection process has been shown to successfully reduce the used energy by $62 \%$ (Serrano et al. 2016).

SRE has become very attractive during the last couple of decades because of its low embodied energy due to the fact that the materials are cheap, locally sourced, involve low carbon emission processes, are recyclable, and are flexible for almost any building footprint (Venkatarama et al. 2010). Research from 2001 by G. Treloar, C. Owen, and R. Fay also concluded that the embodied energy of rammed earth systems is considerably lower relative to standard construction styles that use brick veneer and cavity brick. At the time of the publication, the embodied energy values for cement and brick systems were given an error of $\pm 30 \%$ which is not a great deal of accuracy. Even with these considerations, they were able to conclude from their experiments that rammed earth systems required $62.7 \%$ energy compared to brick veneer and $66.3 \%$ energy compared to cavity brick systems (Treloar et al. 2001). 
One of the major factors considered in the initial cost and environmental impact of any constructed building is the energy used to transport the materials to the site. By using materials located nearby, engineers in Cedex, France from the University of Bath were able to reduce the embodied energy for a single-family dwelling by 215 times. For this project, timber, stone, and soil were being sourced from local areas to build three homes with the different building materials such as: stone masonry with soil mortar, stone masonry with soil mortar and rammed soil, and concrete. The home built with the rammed earth building material reduced the embodied energy by $36 \%$ (Morel et al. 2001). Given that the materials required for rammed earth structures are readily available in most of the developed world, measures could be taken immediately to reduce the cost and carbon emissions of construction simply by building with local materials where they are readily available in rural areas similar to the common building practice in Chine between the $10^{\text {th }}$ and $20^{\text {th }}$ centuries.

Research conducted by B. Rebby and P. Kumar published in the Energy and Buildings Journal in 2010 compared the embodied energy of a rammed earth construction and a typical fired brick construction. They constructed several rammed earth walls with a portion of cement that were $5 \%, 8 \%$ and $12 \%$ respectively. They discovered that the difference in embodied energy between a wall with $0 \%$ cement and a wall with $12 \%$ cement is an increase in energy by $900 \%$. Although this is a considerable increase, they determined that it was negligible when considering the entire amount of embodied energy entering the system because the rammed earth wall with $12 \%$ cement still only required $25 \%$ of the embodied energy that is required to construct the fired brick wall of the same size. The rammed earth wall with only $5 \%$ of cement required only $15 \%$ of the embodied energy that was needed by the fired brick wall (Venkatarama et al. 2010). 
Research published in 2012 by F. Pacheco-Torgal, and S. Jalali in the Building Materials Journal explored the environmental impacts of various construction methods (Pacheco et al. 2012). The four specific "solutions" shown in Figure 5 include: (1) building with a reinforced concrete structure, hollow brick masonry, and a precast reinforced concrete roof, (2) rammed earth block walls topped with concrete beams and a wooden roof, (3) exterior walls made of rammed earth, adobe interior walls, and a wooden roof, and (4) reinforced concrete structure with adobe walls (Pacheco et al. 2012). The rammed earth blocks and walls were made from a mixture that contained 6-8\% cement (Pacheco et al. 2012). When comparing all four variations, items two and three that were made using the rammed earth systems contained less than half of the embodied energy that the other variations contained (Pacheco et al. 2012). Refer to Figure 5 to appreciate the embodied energy comparisons in all four variations from the publication (Pacheco et al. 2012). 


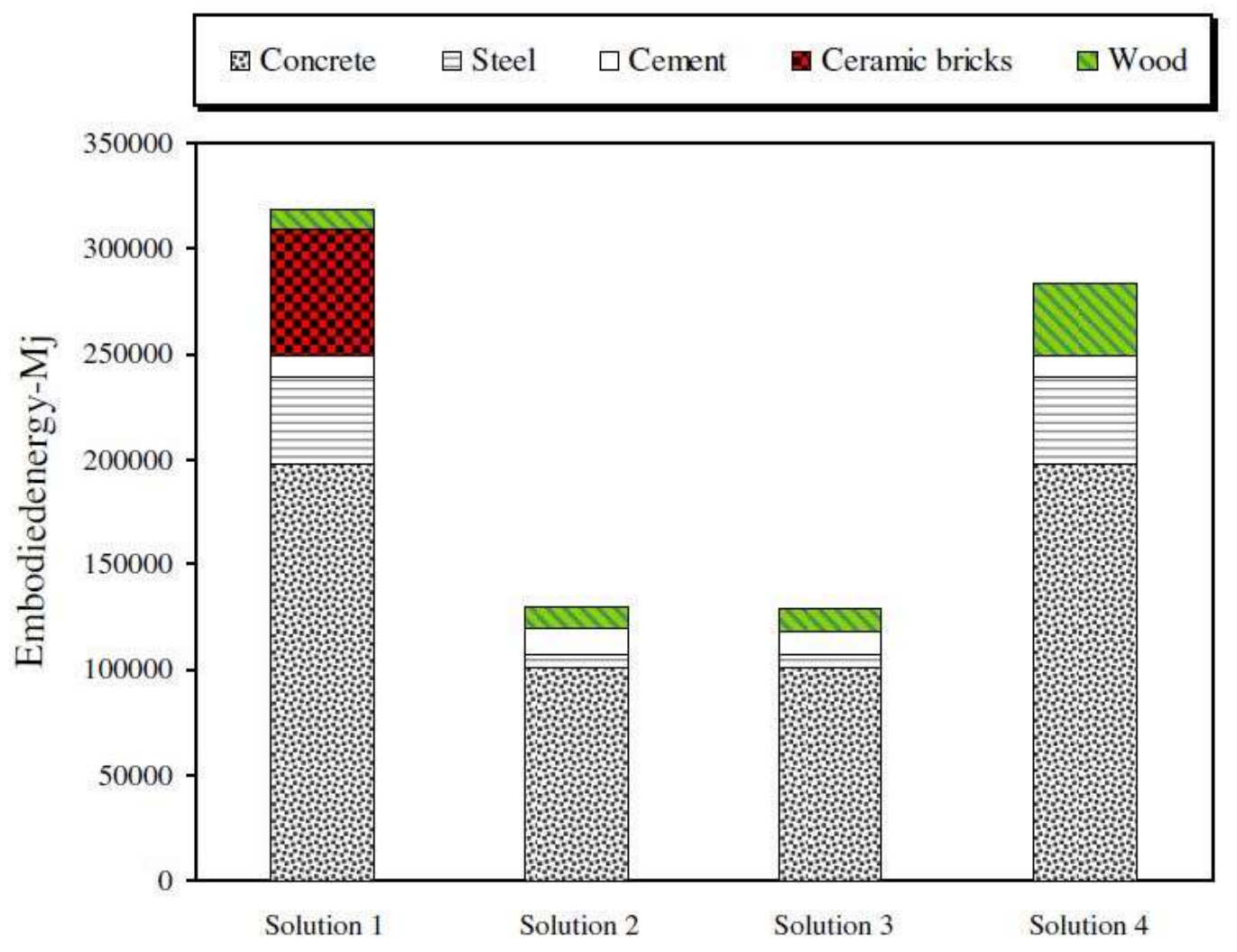

Figure 5: Comparison of Embodied Energy in Four Building Solutions (Pacheco et al. 2012)

Even before examining the embodied carbon, building cost, and other construction factors (included when considering a construction method), rammed earth appears to a be a viable solution due to the fact that its embodied energy is considerably lower than the other commonly available construction methods that are currently on the market. The design, construction, materials, and end-of-life use of rammed earth construction is the best rated method compared to other construction styles.

\subsection{SRE Building Thermal Performance}

One of the very attractive features of SRE construction is that the rammed earth walls naturally act not only as excellent insulators with a high R-value, but also as geothermal masses. 
Geothermal masses are useful because they have very high thermal inertia (Pacheco et al. 2012). This means that relative to other forms of construction, rammed earth walls require a lot more energy to change its thermal state (Pacheco et al. 2012). This is useful because the thermal masses are able store energy from the sun during the day, and then release it into the living space when it gets cooler during the night. There are even some cases where the building is designed to absorb thermal energy all summer long and then release it into the house for the duration of the winter so that the building can operate completely off the gird (IP et al. 2009). This particular use of rammed earth construction was coined "Earthships" and was made famous by well-known US architect, Michael Reynolds, and is in use in the US, Canada, England, Spain, and the UK (IP et al. 2009).

Researchers at the University of Adelaide in Australia in 2007 were able to publish a case study of the thermal performance of three structures - one being rammed earth, another having insulation with rammed earth, and the last being made from a reverse brick veneer masonry unit. All three of the structures were similar in construction having the same blueprint and north orientation. All three of the buildings were monitored with temperature sensors and then modeled in a thermal simulation software called ENER-WIN. The recorded physical data and the software model all confirmed that the temperature in the two rammed earth houses was cooler during the winter months than that of the brick building to. This did not confirm the hypothesis of the researchers so after additional investigations they reported the owner of the brick home used a space heater during the winter much more often than the owners of the other two homes. The researchers simply concluded that one of the biggest factors of building thermal performance that must be considered is that of the residents desired comfort level (Soebarto 
2007). Regardless, the question of which building behaved more thermally efficient was not addressed by these researchers.

During the same year, researchers at Charles Sturt University in Albury, Australia also published work regarding the thermal behavior of rammed earth construction, but this building was used as a two-story office space. These researchers wanted to answer the question if it was possible to use an affordable construction process like rammed earth while also being able to save on the cost of heating and cooling the space. After monitoring the building through all the seasons of the year they were able to determine that the building stayed within the thermal comfort level about $70 \%$ of the time during the winter $76 \%$ of the time during the summer (Taylor et al. 2008). These comfort levels are outstanding since the total greenhouse gas, carbon dioxide, emitted from this building was only $37 \%$ of a neighboring standard construction office building called the Gordon Beaven (Taylor et al. 2008). This research appears to indicate that rammed earth structures indeed outperform traditional buildings thermally while still being a comfortable place to work.

Researchers at the same University in Australia in 2009 explored the idea of whether a layer of insulation in a rammed earth wall would help with the thermal performance (Soebarto 2009). Builders were concerned that uninsulated rammed earth walls would require greater levels of heating that surpassed that of the brick insulated walls in order to reach the same comfort levels during the winter. After monitoring the buildings, they discovered that the rammed earth walls with the insulation allowed for $19-29 \%$ more time at a thermally comfortable level. This indicates that a rammed earth wall with insulation stays warmer during the winter months, but it is very interesting to note that the two homes that did not have insulation within the rammed earth walls consumed about $50 \%$ of the average energy use per person in the region (Soebarto 
2009). This is a result of the material that was used, but it also is a result of the desired comfort level of the resident (Soebarto 2009). Considering these results it would still be fairly safe to say that a rammed earth dwelling would require less energy to maintain thermally comfortable levels of living space compared to a standard building using fiberglass batt insulation and a weather barrier set to the same temperature.

The University of Lleida conducted research in Spain where they compared the summertime performance of five identical cubical structures with same north orientation whose only difference was the material that the walls were made of. The different structures could be described as follows: non-insulated rammed earth (RE) $-29 \mathrm{~cm}$ thick, insulated rammed earth (IRE) - same as RE but with additional $6 \mathrm{~cm}$ of natural wood fiber panels and $1 \mathrm{~cm}$ of natural clay and straw coating, reference cubical (REF) - made of conventional gypsum and brick members, polyurethane cubical (PU) - similar to REF but includes $3 \mathrm{~cm}$ of sprayed foam under the bricks, and polystyrene cubical (XPS) - similar to PU but with $3 \mathrm{~cm}$ of extruded polystyrene (Serrano et al. 2016). After a summer of observations, the researchers were able to record the following energy usage values per week (Serrano et al. 2016):

\begin{tabular}{|c|c|c|c|c|c|}
\hline Set Point $\left({ }^{\circ} \mathrm{C}\right)$ & IRE $(\mathrm{kWh})$ & RE $(\mathrm{kWh})$ & REF $(\mathrm{kWh})$ & PU $(\mathrm{kWh})$ & XPS $(\mathrm{kWh})$ \\
\hline 18 & 20.06 & 32.52 & 27.52 & 19.38 & 20.45 \\
\hline 21 & 15 & 28.56 & 21.81 & 13.01 & 14.46 \\
\hline 24 & 8.34 & 15.77 & 11.54 & 5.91 & 7.70 \\
\hline
\end{tabular}

Table 1: Total Energy Consumption Comparison (Serrano et al. 2016)

This data indicates that the IRE structure consumes about $45 \%$ less energy than the RE structure. With the use of the $6 \mathrm{~cm}$ wood fiber insulation, the researchers were able to develop a building that performed just as efficiently as the PU and XPS structures and more efficiently than the REF 
structure (Serrano et al. 2016). The advantage at this point is that the IRE structure is made from renewable and recyclable materials that have a much smaller embodied energy and environmental impact compared to the polyurethane and polystyrene solutions.

Heathcote conducted research in 2011 in Sydney, Australia to determine at what wall thickness the rammed earth material loses the beneficial properties of being a geothermal mass. They were able to compare the performance of two rammed earth constructions with that of an insulated brick veneer building under passive heating and cooling situations for an entire year. The research concluded that in order to have a large enough thermal mass that can lag the change of temperature for the occupants, the walls need to be at least $450 \mathrm{~mm}$ thick (Heathcote 2011). The thermal performance of the walls also increase rapidly as the thickness passes $600 \mathrm{~mm}$ (Heathcote 2011).

In 2008 researchers at the University of Nottingham in Nottinghamshire, UK conducted tests to determine if there was an optimal moisture content that derived a dry density of rammed earth that produced a desirable thermal conductivity (Hall et al. 2009). They discovered that the thermal conductivity and level of moisture in the rammed earth increased linearly with one another (Hall et al. 2009). They were able to conclude that the most important factor that influenced the thermal properties of SRE is inter-particle contact (Hall et al. 2009). The presence of moisture in the compacted soil appears to cause meniscuses to form between the soil particles that act as a mode of transportation for heat (Hall et al. 2009). The other factor that influences the inter-particle contact is the soil grading pre-compaction, but the explanation for this phenomenon is not clearly understood and hypothesized to be due to suction that develops between layers of differently graded soil sizes (Hall et al. 2009). 


\subsection{SRE Building Standards and Codes}

In May of 2003 DTi Partners at the Innovation Project in the UK assembled a literature review of the existing national rammed earth codes and what they contained (Maniatidas 2003). Australia was one of the first countries to write a national design for adobe, pressed block, and rammed earth buildings published in a document called the Bulletin 5 (Maniatidas 2003).

Bulletin 5 was first published in 1952 by the Commonwealth Experimental Building Station and then updated in 1976, 1981, and 1987 by the publisher CSIRO (Maniatidas 2003). After a failed joint effort with New Zeeland to produce a standalone code document in 1994, Australia successfully completed The Australian Earth Building Handbook in August of 2002 (Maniatidas 2003). This document detailed good practices and recommended design guidelines for light construction - one or two stories high (Maniatidas 2003).

Meanwhile in Germany, The Lehmbau Regeln in 1999, though lacking national DIN authority, published a reference document that detailed general building practices for rammed earth construction in chapter 1 (Maniatidas 2003). In 1998, New Zealand was able to complete three separate legal documents, New Zealand Standards, Engineering Design of Earth Buildings (NZS) 4297:1998, 4298:1998, and 4299:1998. The first dealt with buildings containing earthen walls up to a maximum height of $6.5 \mathrm{~m}$. The second dealt with buildings containing earthen walls with a maximum height of $3.3 \mathrm{~m}$ in an earthquake zone. The third document dealt with the necessary materials and workmanship that is required for buildings described in the first two documents (Maniatidas 2003). Spain completed their own national standard in 1992 where the Ministry of Transportation and Public Works gave guidance for the design and construction of earthen buildings (Maniatidas 2003). In the USA, the state of New Mexico developed its own building code that readily adopted the use of rammed earth buildings, but it was very limited in 
its guidance and only directly addressed soil suitability, moisture content, requirements for framework, methods for construction, and methods for curing rammed earth (Maniatidas 2003). In 2010, the American Society for Testing and Materials International (ASTM) created E2392/E2392M which gave a standardized guide for the design of earthen wall building systems (ASTM E2392/E2392M). This guide is drawn from the Australian Earth Building Handbook, California Historical Building Code, Chinese Building Standards, Ecuadorian Earthen Building Standards, German Earthen Building Standards, Indian Earthen Building Standards, International Building Code / provisions for adobe construction, New Mexico Earthen Building Materials Code, New Zealand Earthen Building Standards, and Peruvian Earthen Building Standards (ASTM E2392/E2392M). This ASTM guide directs the engineer to use the New Zealand Standards: NZS 4297:1998, NZS 4298:1998, and NZS 4299:1998 for all structural engineering design criteria (ASTM E2392/E2392M).

The authors of, The UK Rammed Earth Construction Review, summarized the various national codes to develop this summary of building codes for rammed earth buildings and contains the following topics: materials, structural design, architectural design, construction methods, quality control, foundations, and maintenance/repairs (Maniatidas 2003). The materials section of the review details the requirements for soil specification, particle size distribution, plasticity, dry density, compressive strength, tensile stress, bending stress, shear strength, durability, thermal properties, cement stabilization, lime stabilization, fiber stabilization, and sodium silicate stabilization (Maniatidas 2003). The structural design portion of the text outlined the requirements for compressive strength, flexural bending strength, shear strength, modulus of elasticity, deflection, shrinkage, water/frost penetration, and other combined loading effects. The architectural design required the consideration of the local climate, site topography, sunlight 
direction, wind direction, openings, roof support, and non-structural roof fixings. The construction methods considered the soil preparation, excavation, screening, pulverization, stockpiling, mixing, formwork, soil compaction styles, and horizontal joints. The quality control portion of the text addressed material quality, selection, weathering conditions, storage, preparation, density, compressive strength, erosion resistance, and surface defects. The foundation addressed details such as foundation types, drainage, details, and construction. The maintenance/repairs portion of the text outlines maintenance work, surface coating repairs, bulging defects, shrinkage cracking and spalling, structural cracking and under-scour, and renovations of old rammed earth buildings (Maniatidas 2003).

Researchers in UK in 2003 following the New Zealand Standards, Engineering Design of Earth Buildings, 1998 (NZS 4297:1998), conducted an experiment to see if novel rammed earth soil recipes could be derived through a process of blending graded quarry materials that could directly influence the dry density when a controlled amount of compressive energy was applied to each sample (Hall et al 2004). After standardizing a method for producing several rammed earth specimens with varying graded soils using the same compaction energy, they discovered that the dry density of the soil type was not directly related to the unconfined compressive strength of each sample (Hall et al 2004).

Researchers in Sri Lanka used UK's masonry unit building code, BS 5628: Part 1: 1992, as a guideline to test the structural integrity of modular rammed earth walls in order to determine how to optimize their compressive strength properties (Jayasinghe et al 2007). These researchers constructed many wall sections out of sandy, hard laterite, and clayey soils each with specimens that contained 6,8 , and 10\% cement content (Jayasinghe et al 2007). The results of the testing complimented the guidelines in the NZS 4297:1998 and revealed that the lowest performing soil 
type that was tested, hard laterite soils with $6 \%$ cement content, would still have performed with a factor of safety of 5 or more for single story buildings (Jayasinghe et al 2007). They stated with a great degree of confidence that cement stabilized rammed earth dwellings are a suitable building material for two story buildings as long as proper thickness dimensions are selected. These researchers recommended that builders use less than $20 \%$ of fines and $6 \%$ or more cement content in their soil recipes to maximize the compressive strength of the rammed earth walls. It is also important to note that since rammed earth is brittle material and fails compressively by local and global crushing, a safety factor of 5, which is required by the NZS 4297:1998, is highly recommended (Jayasinghe et al 2007).

Researchers in 2008 at the University of Bath in Bath, UK set out with the aim of investigating the validity of using masonry design rules for the design of rammed earth structural materials (Maniatidis et al. 2008). Using a novel experimentation method, the researchers tested full scale rammed earth columns to determine the effects of load eccentricity and slenderness on the strength reduction factors of combined axial compressive and bending loads. Basic strut theory was used to develop an analytical model that could further predict the capacity of rammed earth columns under concentric and eccentric loads (Maniatidis et al. 2008). Table 2 summarizes the actual and theoretical strength reduction factors for the various levels of eccentricity for the different column sizes: 


\begin{tabular}{|c|c|c|c|}
\hline $\begin{array}{l}\text { Column Height } \\
(\mathrm{mm})\end{array}$ & $\begin{array}{l}\text { Load Eccentricity } \\
(\%)\end{array}$ & $\begin{array}{l}\text { Experimental load } \\
\text { reduction factor }\end{array}$ & $\begin{array}{l}\text { Theoretical load } \\
\text { reduction factor }\end{array}$ \\
\hline \multirow{3}{*}{1800} & 0 & 1.00 & 1.00 \\
\hline & 10 & 0.79 & 0.81 \\
\hline & 30 & 0.57 & 0.39 \\
\hline \multirow{3}{*}{2400} & 0 & 1.00 & 1.00 \\
\hline & 10 & 0.75 & 0.81 \\
\hline & 30 & 0.71 & 0.39 \\
\hline \multirow{3}{*}{3000} & 0 & 1.00 & 1.00 \\
\hline & 10 & 1.75 & 0.81 \\
\hline & 30 & 0.55 & 0.39 \\
\hline
\end{tabular}

Table 2: Column Load Factor Reductions (Maniatidis et al. 2008)

The suspected reasons for the disparity between the actual and theoretical load reduction factors are due to the lack of consideration of internal tensile forces in the column as well as the idealized simplifications in the column-end conditions (Maniatidis et al. 2008). This research was able to confidently conclude that existing codes are successfully able to predict the structural capacity of rammed earth columns only with a load eccentricity of less than $10 \%$ (Maniatidis et al. 2008).

Researchers in 2011 at the University of Lyon in Nice, France conducted one of the first exploratory studies on the dynamic characteristics of rammed earth buildings (Bui et al. 2011). Presently, building codes describe the effects of an earthquake on a building as the equivalent static seismic force which is derived case-by-case by using natural frequencies and dampening ratios for specific buildings (Bui et al. 2011). In-situ dynamic measurements were recorded and compared to values derived by empirical equations found in Eurocode 8 to display that the code 
derived values sufficiently described the field results (Bui et al. 2011). The difference between the first natural period recorded in-situ in the $\mathrm{x}$ and $\mathrm{y}$ direction was very similar to the empirically derived values for the first natural period and it was concluded that the equations in Eurocode 8 were sufficient for providing an accurate estimate for these values (Bui et al. 2011). This helps with understanding the seismic resistance of currently standing rammed earth structures as well as providing conservative design estimates for newly constructed buildings (Bui et al. 2011).

Research conducted at WVU by Daniel Stanislawski in 2011 involved the extensive research through finite element modeling of the rammed earth Hakka Tulou structures in the Fujian Providence, China (Stanislawski 2011). Using historical seismic data from the region and the structural properties of the rammed earth buildings, the research was able to conclude that the design codes are extremely conservative and underestimate the strength of rammed earth buildings (Stanislawski 2011). According to ASTM Standard E2392/E2392M the height to thickness ratio should be limited to less than six times in high seismic risk zones and less than eight times in medium seismic risk zones (ASTM E2392/E2392M). According to this limitation, the $20 \mathrm{~m}$ high wall should have been $3.3 \mathrm{~m}$ thick in high risk seismic regions and $2.5 \mathrm{~m}$ thick in medium risk seismic regions when in reality the building has survived hundreds of years in a high risk region and has walls that are only $1.8 \mathrm{~m}$ thick - what the standard would consider to be a $46 \%$ thickness deficiency. 


\section{METHODOLOGY}

\subsection{Problem Statement}

The question that this project aims to answer is whether the SRE dwelling is more thermally efficient than a reference building that was constructed using a traditional stud method. In order to answer this question, the same following data has been collected from both homes. This data collection included: physical dimensions and properties, live stream temperature, $\mathrm{RH}$ and DP data, and utility usage information. NDT testing, such as infrared photos, also provide clarity to the situation being researched.

\subsection{Description}

Both dwelling places that are being researched in this paper are located within a half mile of one another in Butte, Alaska. Both homes have been suited with a HOBOlink data logger that is recording the temperature, $\mathrm{RH}$, and DP of the structures from various locations inside the house, inside the walls, and outside of the buildings. The data form the homes has been collected, processed, and compared to understand how both behave during the year. The utility information, namely the natural gas which is used for heating in both buildings, has also been collected and processed to best understand the energy input into both homes. Using a virtual modeling software called eQUEST, both homes were modeled for their energy efficiency to see if the field data could be replicated by a virtual model. Reports from Alaska's statewide project, AK Warm, was also provided to understand Alaska's thermal rating and expected energy efficiency of both homes. After collecting all this information, the data was compared to ensure that the field data, virtual model, and state predictions all coincided with one another. 


\subsection{Definitions and Nomenclature}

The following is a list of definitions that are pertinent to understand this technical report:

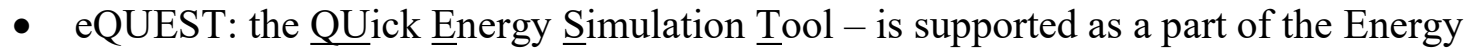
Design Resources program which is funded by California utility customers and administrated by Pacific Gas and Electric Company under auspices of the California Public Utilities Commission

- AK Warm: a software design tool for builders, designers, energy raters, lenders, and homeowners that can be used for energy design, retrofit, or determining an energy rating

- HOBOlink: an international company that produces and sells data sensing and logging devices that are using in residential and commercial settings every day around the world

- Geothermal mass: a volume of earthen material that is used to store energy from various inputs, such as solar, and slowly release that energy in a desired fashion usually into a living area

- Living comfort: the perception of a person's body heat transferring to the heat of the environment being influenced by five main factors: temperature, relative humidity, air movement, activity level, and clothing (see paragraph two in section 3.4, for standardized information regarding living comfort)

- Apparent Temperature: the temperature equivalent perceived by humans that is caused by the combined effects of temperature, relative humidity, and air velocity (heat index and wind chill) 
- Relative Humidity (RH): the amount of water vapor present in air expressed as a percentage of the amount needed for saturation at the same temperature

- Dew Point (DP): the atmospheric temperature, varying according to pressure and humidity, below which water droplets begin to condense, and dew can form

- Batt insulation: the most common form of residential insulation, also known as "blanket," insulation that is typically made of fiberglass

- In-Floor Radiant Heating: a relatively new style of heating residential living spaced by pumping hot water through the concrete slab so that the heat radiates up into the living space

- R-Value: described the resistance to heat flow - in practice, the larger the R-value, the better the insulation

- U-Value: The measure of the rate of heat transfer - in practice, the lower the U-value, the better the glass/window

- Air Leakage: this is a unit of measure that describes how many times the entire volume of air inside of a building is replace by air from outside of the building in one hour - typically measure at 50 pascals (with HVAC equipment on) and 0 pascals (with HVAC equipment off)

- Domestic Hot Water (DHW): water or hot water that is used in any type of building for domestic purposes such as drinking, food preparation, sanitation, and personal hygiene

- Seasons: for the purposes of this paper the summer, fall, winter, spring seasons will be defined as follows 


\begin{tabular}{|l|l|l|}
\cline { 2 - 3 } \multicolumn{1}{l|}{} & \multicolumn{1}{c}{ Start } & \multicolumn{1}{c|}{ End } \\
\hline Summer & 20-Jun & 22-Sep \\
\hline Fall & 22-Sep & 21-Dec \\
\hline Winter & 21-Dec & 19-Mar \\
\hline Spring & 19-Mar & 20-Jun \\
\hline
\end{tabular}

Figure 6: Definition of Seasons for this Paper

\subsection{Equations}

\subsubsection{Heat Index}

The heat index equation is used in this paper to help describe the apparent temperature of the indoor ambient temperature in the SRE house during the summer months. This equation was deployed to better understand the indoor heat perceived by the SRE residents since it is a function of the indoor temperature and relative humidity.

$$
H I=c_{1}+c_{2} T+c_{3} R+c_{4} T R+c_{5} T^{2}+c_{6} R^{2}+c_{7} T^{2} R+c_{8} T R^{2}+c_{9} T^{2} R^{2}
$$

\section{E 1: Heat Index Equation (NOAA/ National Weather Service)}

$$
\begin{aligned}
& H I=\text { heat index }(\text { accuracy } \pm 1.3 F) \\
& T=\text { temperature }(F) \\
& R=\text { relative humidity }(\%) \\
& c_{1}=-42.38 \\
& c_{2}=2.049 \\
& c_{3}=10.14 \\
& c_{4}=-0.2248 \\
& c_{5}=-0.006838 \\
& c_{6}=-0.05482 \\
& c_{7}=0.001228 \\
& c_{8}=0.0008528 \\
& c_{9}=-0.00000199
\end{aligned}
$$




\subsubsection{Thermal Stress}

The equation of the thermal stress is used in this paper to help understand the source of cracking in the bottom corner of the windowsills. During the winter months there is a very large thermal difference between the inside and outside of the glass at the corner of the windows and this difference in temperature is used to determine what stress concentration it may create in the rammed earth material.

$$
\sigma=\frac{F}{A}=-E \alpha d T
$$

\section{E 2: Equation of Thermal Stress}

$E=$ Young's Modulus

$\alpha=$ coefficient of linear thermal expansion

$d T=$ change in temperature

For purpose that this equation is being used for, $E$ will be approximated to be $7.25 \mathrm{ksi}$ ( 50 MPa), $\alpha$ of the rammed earth will be approximated to be $1 * 10^{-6}$ in/in F (Mileto et al 2012), and $\alpha$ of the steel will be taken to be $6.4 * 10^{-6}$.

\subsection{Theory}

This project depends of the use of two separate theories that describe the transfer of heat. The first is that the rammed earth walls in the SRE house act as a geothermal mass. This implies that the geothermal mass has a thermal inertia which means the mass stores thermal energy from the sun during the day and then slowly releases that heat energy into the living space during the night even though the outside temperature has mostly likely dropped with the sun. The second principal is that the rammed earth walls have an intrinsic insulative property. In industry, most 
people quantify this as the materials $R$-value which indicates a material's ability to resist thermal change or the insulative effectiveness of that material.

The experiences of the residents in both structures' correlates strongly with their overall all living comfort in the home. National standards such as The American Society of Heating, Refrigeration, and Air-Conditioning Engineers (ASHRAE) Standard 55, International Organization for Standards (ISO) 7730, and European Standard (EN) 15251 all address the topic of living comfort in commercial and residential buildings. ASHRAE 55 is established with the assumption that the parameters laid out by that standard will result in $80 \%$ of the occupants finding the environment thermally comfortable. The living comfort in a residential dwelling is broken up into winter and summer months and is a result of the direct comparison of the indoor temperature and relative humidity. Humans are not able to perceive a change in relative humidity between $25 \%$ and $60 \%$ and for that reason it is often taken as a baseline for desired humidity levels. When relative humidity surpasses $65 \%$ for long periods of time, the risk of growing mold becomes more server and is therefore not recommended. With those parameters the following chart depicts the desired ranges for temperature and relative humidity to provide an ideal living comfort (Boduch et al 2009). 


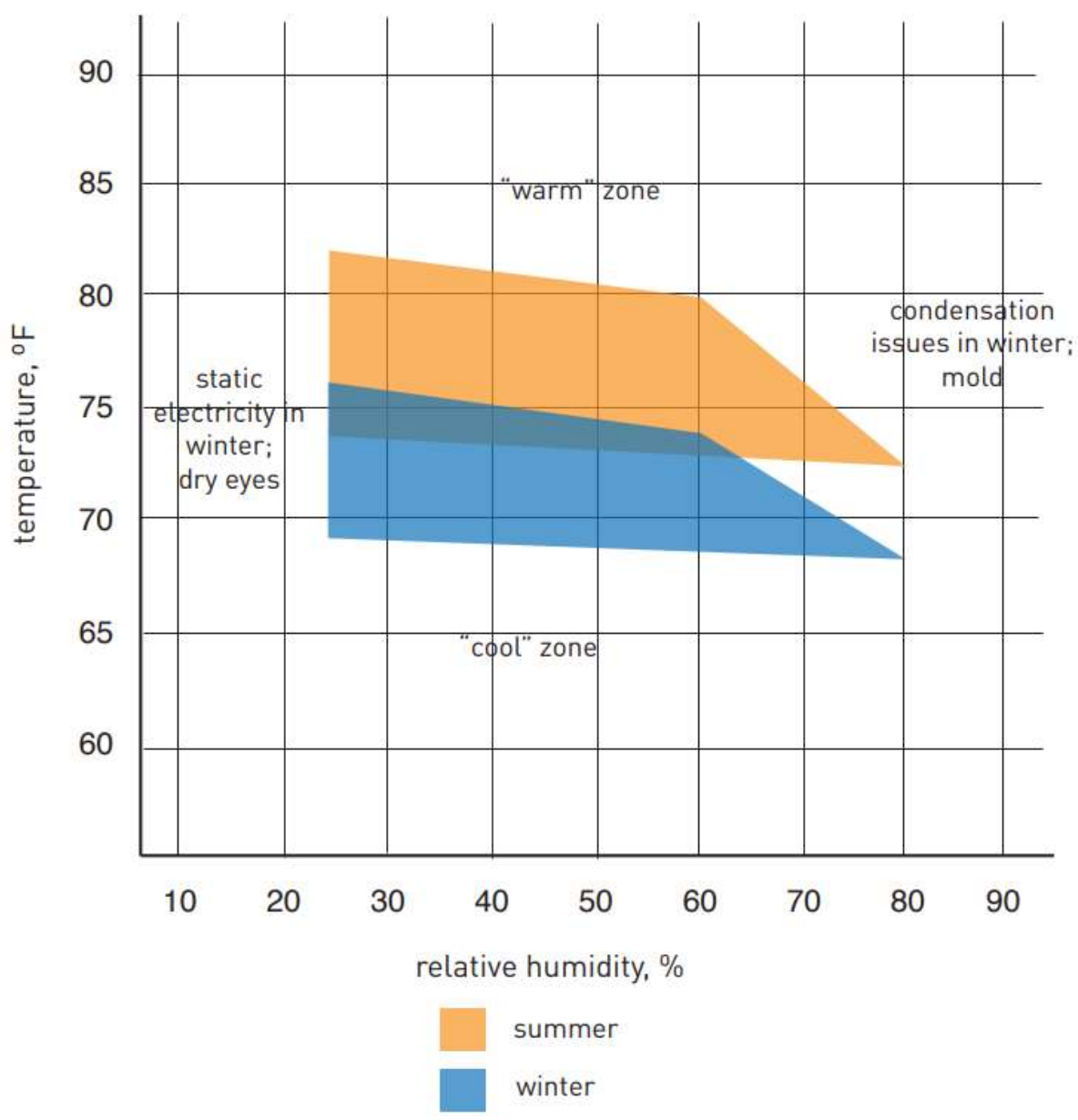

Figure 7: Summer and Winter Comfort Zones (Boduch et al 2009)

\subsection{Software Modeling}

The software modeling for this project was completed directly by the writer of this report at WVU using eQUEST. The AK Warm modeling and report was completed and published by The Alaskan Housing Authority.

First, eQUEST, the quick energy simulation tool - A free professional software tool produced and updated as a part of the Energy Design Resources program which is funded by California utility customers and administered by Pacific Gas and Electric Company, San Diego, and 
Southern California Edison, under auspices of the California Public Utilities Commission. Each building was modeled in eQUEST by building an accurate floor plan in AutoCAD and then uploading that drawing to eQUEST. eQUEST then requires the material properties and physical dimensions of the walls, floors, ceiling, roofs, and windows so that it can understand the buildings ability to retain heat inside of the building. The software also requires inputs to describe the utility usage of the building for heaters, appliances, lighting, and other common uses. The space heaters and water heaters are described in great detail for the software and then after the model has been completed the researcher is able to run energy simulation reports to gather current performance date or run energy efficiency reports which allows the researcher to adjust specific parameters of the building to derive a more energy efficient design.

The second software that was not directly run by researchers for this project was AK Warm. Several years before this report was written, the Housing Department of Alaska set out with a project to reduce the overall energy use of every building located within the state. AK Warm was developed as a quick and easy to use tool that builders, homeowners, and designers could use to understand the energy rating of their home. An AK Warm model was developed by the state for both buildings in this project and that information has been provided by the researchers at WVU. Along with other information, the report includes the predicted energy usages and cost annually for the different functions of the home. These reports were also reviewed to determine whether they agree with the eQUEST modeling and field data that has been collected for this project.

\subsection{Variables}

The most critical variables in this project are the differences between the two buildings that are being observed. The desired variable is the construction material of the of the walls of each 
home. The SRE home is built with rammed earth walls that are 24" thick walls that are 8" rammed earth, 8" stiff board insulation, and 8" of rammed earth in that order. The stud frame house is constructed using 2 " $\mathrm{x} 4$ " studs, 16" O.C. and filled with R 12 batt insulation between the studs. Another major variable between the two homes is the relative size of each. The SRE house is $1,788 \mathrm{ft}^{2}$ while the STUD house is $2,774 \mathrm{ft}^{2}$. The SRE house is heated using an in-floor heating system that heats water to the desired temperature and then pumps that through the uncovered, concrete slab that makes up the flooring in the SRE house. The STUD house is heated by a forced air furnace that uses hot water coils to heat the air that is pushed through the building. The garage in the STUD house is not connected to the furnace but instead heated to a cooler temperature using a Hot Dawg space heater that also runs on natural gas. The SRE house has no basement or crawl space and the concrete slab is the lowest level of the building while the STUD house has an accessible crawl space that is only insulated around the perimeter by R 30 batt insulation.

Another major difference between the two homes is the level of occupation of both buildings. The SRE house is being occupied by a family where the father works from home and the mother works in and out of the house. The thermostat in the SRE house is always set to the desired temperature since someone remains inside the building at all times. The residents of the STUD house work outside of the home and they set the temperature in the home down several degrees when they leave the house in order to save energy. The residents of the STUD housework typical 8-10hr days and the building goes unoccupied and thermally unaltered during this time since no one is home to set it to the desired living temperature. Also, the residents in the two buildings have different desired living temperatures. The residents of the SRE house set the thermostat to 
$71^{\circ} \mathrm{F}$ when home and the residents of the STUD house set the thermostat to $65^{\circ} \mathrm{F}$ when they stay at home and then $60{ }^{\circ} \mathrm{F}$ when they are away from home.

Table 3 is provided to give a summary of technical parameters that describes the variables for the two homes.

\begin{tabular}{|c|c|c|}
\hline & SRE & STUD \\
\hline Set Temperature & $71 \mathrm{~F}$ & $65 \mathrm{~F}$ night, $60 \mathrm{~F}$ day \\
\hline Living Space $\left(\mathrm{ft}^{2}\right)$ & 1,788 & 2,774 \\
\hline Heat Source & In-floor radient heating & Forced hot air furnace \\
\hline Floor R-Value & 47.8 & 14.9 \\
\hline Floor Description & Concrete slab on grade & Timber joist w/ insul. crawl space \\
\hline Wall R-Value & 36.5 & 12 \\
\hline Wall Description & Insulated Rammed Earth & 2"x4" STUD@16" OC w/ R 12 Batt \\
\hline Ceiling R-Value & 68.0 & 36.9 \\
\hline Window U-Value & 0.18 & 0.45 \\
\hline Window to Wall Ratio & $21.9 \%$ & $10.8 \%$ \\
\hline South Facing Window Area & 179 & 95 \\
\hline Air Leakage & $1.1,0.05$ & $3.8,0.30$ \\
\hline Square Footage & 1,788 & 2,774 \\
\hline
\end{tabular}

The HOBOlink temperature, RH, and DP (THD) sensors were placed in various locations for the two structures. Since the floorplans of the two homes were not identical, it was impossible to place the sensors at the same place for both homes. Instead, the writer of this report attempted to place the sensors in the STUD house in various locations in order to capture a wide variety of data that would reflect the data that is obtained by the SRE sensors. The following diagrams are provided to allow the reader to understand the approximate location of each of the THD sensors in both homes. 


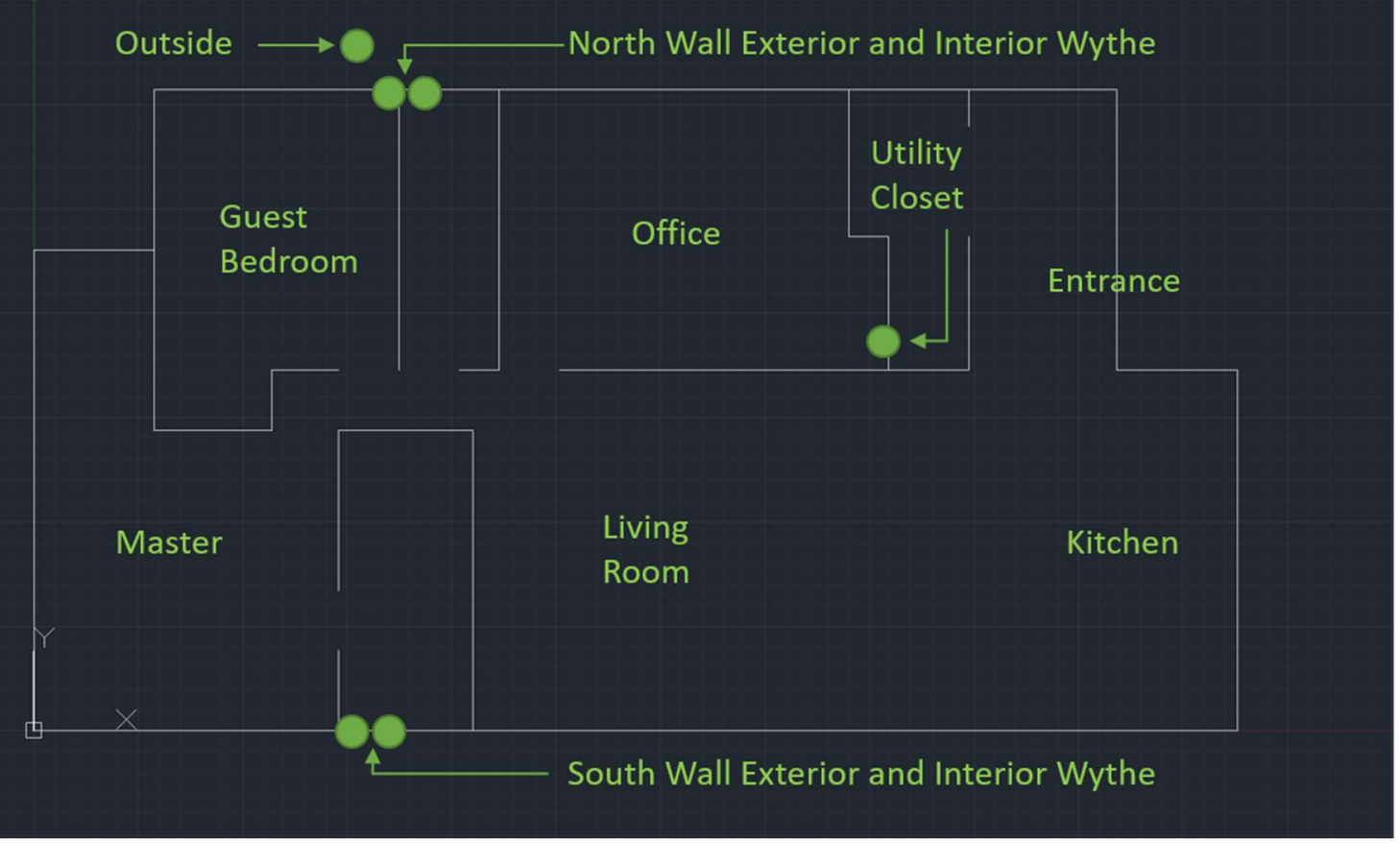

Figure 8: SRE Floorplan with Location of Sensors

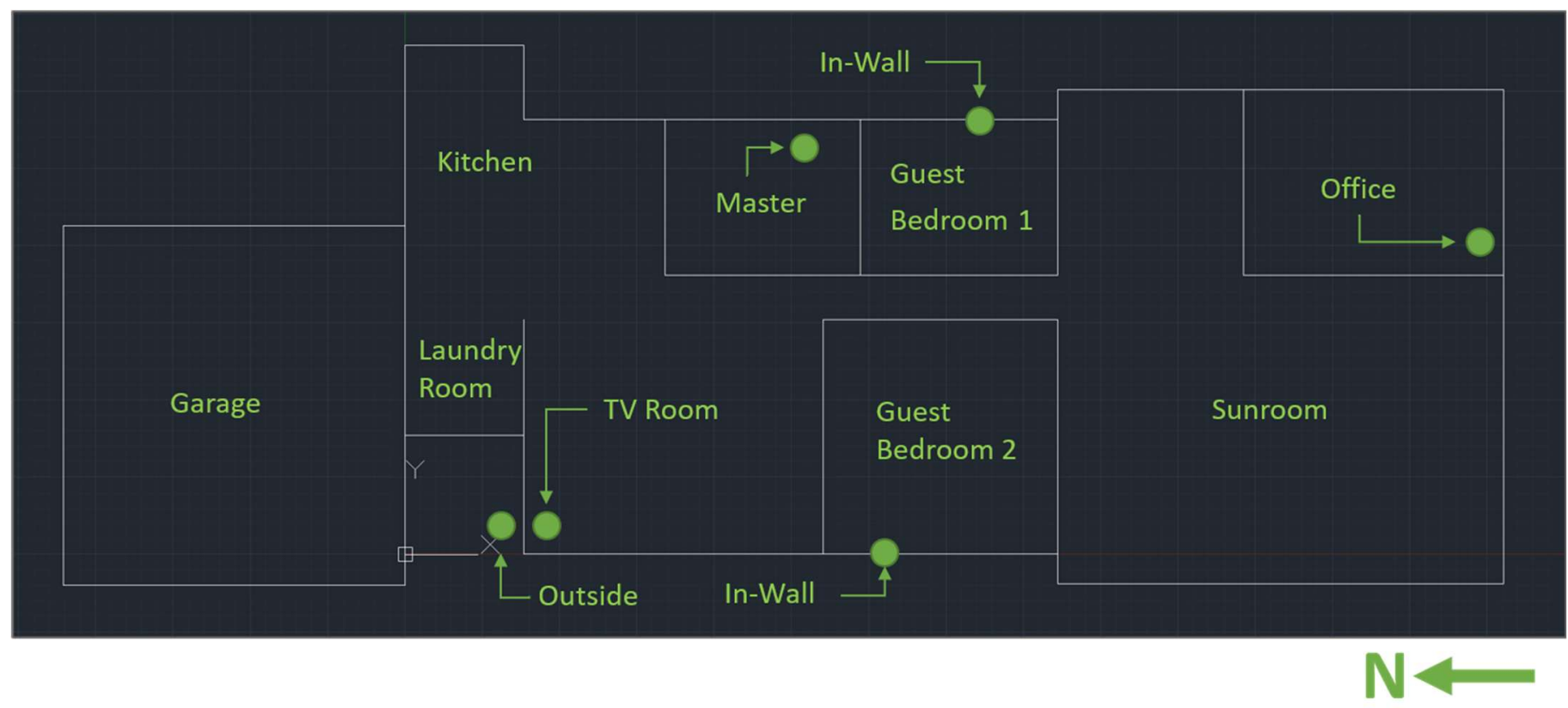

Figure 9: STUD Floorplan with Location of Sensors 


\subsection{Controls}

Both buildings are presently occupied by three people. Both buildings are in the same geographic region, within a half mile of one another on the same road and experience the same weather conditions. Both buildings are being monitored from within using the same HOBOlink sensors and data logger so that the output data from both homes is in an identical format and from a reliable product. Both homes are heated solely by natural gas applications. All the appliances in both homes are also operated by natural gas. Only the lighting and electrical needs such as computers, TVs, fans, and mobile devices use electricity in these homes.

\subsection{Sources of Error of Bias}

There does exist the chance for random errors to occur due to human involvement with extensive spreadsheets and virtual models that are dictated by inputs controlled by the user. The research does not predict systematic errors due to bias, however, there does exist several assumptions and limitations that are addressed in the next section.

\subsection{Assumptions and Limitations}

When creating a virtual model of any building to model the energy usage there will be certain limitations or assumptions that need to be made. While modeling the SRE building it was discovered that eQUEST does not have an "in-floor" heating mode available yet. In order to work around this problem, many people that use eQUEST for industry recommend using baseboard heating with zero forced ventilation as a reasonable way to model the in-floor heating. This simplification was made for the SRE building in this project. In general there are other

parameters and specifications for the heaters and appliances that are not known or have changed 
since they were installed - in particular in the case of the STUD house because much of the equipment being used there was installed when the house was built back in 1996. Although the residents of both homes have reported their general trends for usage and living comfort, irregular activities that have not been incorporated such as vacationing, power outages, and sick days all influence the amount of energy is used within the building.

When attempting to compare the utility data between the SRE and STUD home several assumptions were made so that a direct cost comparison can be made. The natural gas used in both homes is measured in centum cubic feet (ccf), or one hundred cubic feet of gas. The monthly usage of gas was divided by the number of square feet in each home to find the amount of gas required to heat each square foot of living space. The residents in the different homes set their thermostats to different temperatures, so in order to have a direct comparison of the energy being used, it was assumed that as the temperature in either home is increased, the amount of natural gas used also increases linearly. The difference in temperature was taken as a percent increase - the SRE house being kept at a warmer temperature - and that percent increase was applied to the STUD house to assume that both homes were always kept at $71^{\circ} \mathrm{F}$. With this adjustment being made, the researchers had the ability to directly compare the energy used in each home at the same temperature per square foot. 


\section{PROJECT EXECUTION AND RESULTS}

\subsection{Interview with SRE Tenants}

Two interviews were conducted with the residents of the SRE house. The first took place in May of 2019 and the second took place in February of 2020. The first interview was conducted with Peter and the second was conducted with Peter and his wife, Ava. Both interviews were conducted in person at the SRE home.

\subsubsection{Interview Conducted on May $7^{\text {th }}, 2019$}

Peter shared that his wife and son live in the home and they moved in during January of 2018. Peter and Ava both have work schedules that allow them to work from home or stay home so most days of the week the building is occupied through the entire day. The tenant did remind the researchers that this is still the only rammed earth building in Alaska.

The interview revealed that there are some serious pros and cons that were not known beforehand. The heat in the building is manipulated by controlling a water heater that pumps hot water through the concrete slab of the house. The heat then radiates up into the living space by warming the air. There is no air conditioner in the house since it is not typical for the region, but one of the biggest complaints of the resident is that it is near impossible to effectively cool the building down. During the summer months the building absorbs a lot of heat from the sun. During the nights and warm days, the high thermal mass in the walls continues to radiate heat into the building. For this reason, the building often feels like a fishbowl because they are a victim to the ambient temperature of the house during the hot days. A common solution to this

problem would be to simply open the windows, but none of the windows have screens or locks in an open position so they usually stay shut for security reasons. Replacing the windows with ones 
that can lock while open or installing secure screens would help to get some air flow and cool the building.

Peter pointed out that it is very easy to keep the building warm during the winter months with the in-floor heating and excellent thermal properties of the building. The major downfall of the building during the winter months is that large amounts of moisture will condense on the window and puddle on the windowsills. The water accumulates so rapidly that towels must be used on almost an hourly schedule to remove the puddle of condensation that forms at the base of the window. This flaw could be avoided by simply pulling the windows into the building a little more - currently they are set +8 " into the wall. In addition, the heat recovery ventilator kicks on every 10 to 15 minutes during the cold months just to keep its own pipes from freezing. The unit also collects a lot of condensation that drips down the wall and floor and has caused small amounts of water damage in the utility closet. Perhaps this is a low-quality system that needs to be replaced with a more robust one - a clear solution for this problem is not as obvious.

Peter reports that there have been no noticeable effects due to weathering on the outside of the building. All the noticeable cracks on the building are reported to have been there since construction and exist between the different lifts of soil. During November of 2018, the residents experienced a 7.2 earthquake and hundreds of aftershocks from this quake but felt very safe in the SRE house. No cracks formed on the inside of the house and only unmounted objects fell over during the quake. Overall, the residents are very pleased with the aesthetic quality of the home but would not choose to live in another SRE due to the challenge of cooling off during the summer months. 


\subsubsection{Interview Conducted on February $11^{\text {th }}, 2020$}

During the February meeting, the WVU researcher asked many of the same questions that had been asked during the previous visit to better understand any of the benefits or drawbacks of the SRE house. The questions and responses are listed below.

Q1: How much time do you stay away from the house?

R1: Peter works from the house and spends almost all his time in the home. Between all the occupants, the home is occupied nearly $100 \%$ of the time, easily $90 \%$ of the time.

Q2: How would you describe your living comfort in the home?

$\mathrm{R} 2$ : When the weather is $-10 \mathrm{~F}$ there is considerable condensation on all the windows and window frames. If $-20 \mathrm{~F}$ or lower they have to wipe up the moisture more than 4 or 5 times a day to prevent water damage to the windowsills. This is a really big issue by the front door because there will be so much condensation on the front and back door that during the very cold days the doors will freeze shut, locking the Peter and Ava out in the cold several times now. They believe that it does not appear that the window frames are insulated which is concerning to them and possibly causing some of the condensation problem. They hoped that by changing the blinds in the bedroom they could reduce the moisture in the deep windows, but it did not help. It will also get so cold that ceiling fans will freeze solid for weeks a time.

During the $-20 \mathrm{~F}$ weather for extended periods of time, Peter is not able to keep the house at a comfortable temperature with just the in-floor heating. The warmest they can get the building is $68 \mathrm{~F}$ when they usually have it set around $74 \mathrm{~F}$. They use a small, temporary space-heater to get the house up to the desired temperature. 
Q3: Can you share any additional good or bad experiences living here?

R3: They admit that they would never live in a rammed earth house again. The biggest drawback of the house is that they are not able to cool off the building during the summer months. This could easily be fixed by leaving the windows open to ventilate the hot air out of the building but none of the windows have screens or locks making it very easy for unwanted bugs, animals, or even people to get in the house with ease.

There also appears to be a problem with the septic system because there is a persistent smell from the system indicating that something may be backed up. Normal operations of the septic system should not leave a noticeable scent.

Q4: Does the home appear to be weathering well after the earthquakes and winters?

R4: Since the large earthquake before the previous visit (back in November of 2018) there have only been earthquakes with a level 6 - nothing serious that has disrupted normal living in the house. They always feel very safe in the house and there is never any damage compared to light cracks and damage that the neighboring homes sustain. There appears to be no crack growth inside or outside to indicate that ice is causing the rammed earth to come apart.

\subsubsection{Comments from Researcher}

From the perspective of the researcher, many of most concerning issues that the residents had with the SRE house are all items that the designer could easily avoid in the future. For instance, one of the biggest issues was the inability to cool the building during the summer months. This could be easily dealt with by installing locks on the windows so that they can be locked in the open position. Safety screens could also be added to improve security. With proper ventilation 
through the windows it would be much easier to prevent the residents from feeling like they were in a "fishbowl."

During the coldest months of the year, when the outside temperature is below $-20 \mathrm{~F}$ for sustained periods of time an additional space heater must be used in order to keep the air above 68F. A simple solution to this problem would be to use heater system that heated water for the in-floor heat as well as forced air furnaced that pushed hot air through the building. One would not need both systems year-round, but it would be used as "emergency heat" during the coldest months out of the year in Alaska. The in-floor heating would be adequate for any other location that does not see prolonged periods of time at $-20 \mathrm{~F}$.

During the colder months the residents repeated many times that they deal with large amounts of condensation on the windowsills and door frames. At the worst times, this caused the residents to be locked out of their home due to the moisture on the door frame freezing the door shut. This problem is most likely so prominent in the house because the designers did not anticipate for the high moisture levels. The designers most likely selected an air exchanger based on specifications for traditional stick frame homes. Since the SRE house retains much more moisture than that of a typical home, the current system is not able to withdraw enough moisture from the air. By adding a separate dehumidifier or selecting an air exchange system with higher dehumidification abilities, the residents would most likely no longer deal with excessive condensation build up or doors freezing shut. 


\subsection{NDT}

\subsubsection{Infrared Images}

Infrared photos were taken of both homes during the May 2019 and Feb 2020 visits. During the May 2019 visit the weather was 50F, clear skies, and direct sunlight on the buildings which made it very challenging to see where hot or cold air was leaking through the building. However, the photos from the Feb visit were taken while it was 0F outside and overcast so that there were no shadows on the ground. The infrared photos from the Feb 2020 visit were much more successful since the sunlight was not heating the building. The major source of heat was the warm air from inside of the building.

In order to correctly read the infrared photos, it must be understood that each photo has a different color gradient scale and it is listed on that photo. The infrared camera uses an automatic setting to best capture the difference in temperature within the viewing area. The darkest blue is associated with the coldest area within the view and the brightest red is associated with the hottest area within the view. When photos of windows are taken, the camera is not able to see through the glass material since it acts as an infrared barrier. For this reason, when people shown in the glass of a window are visible, it is a reflection of the people in the home, not outside of the home.

\subsubsection{Infrared Images of SRE House}

The infrared photos in this section come from the Feb 2020 visit to the SRE house. The following four infrared photos highlight several key features discovered by infrared camera (for additional infrared photos of the inside of the SRE structure see page 80 located in the Appendix). It appears that the metal frames for the doors and windows acts as a thermal bridge, 
allowing the heat energy to escape. The best way to halt this transfer of thermal energy would be to use a material that acts like a thermal barrier, such as a plastic or FRP material for the window and door frames. This would also prevent the condensation that is currently forming on the metal surfaces during the wintertime.

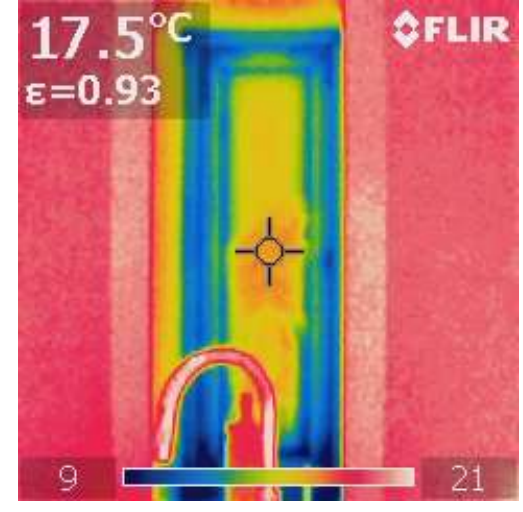

Figure 10: South Wall Window 1 - Kitchen Sink

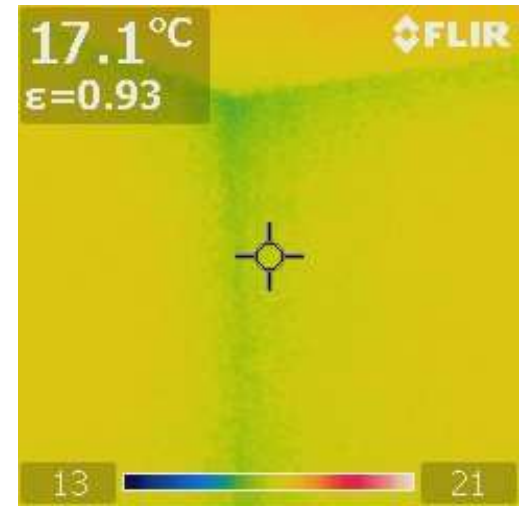

Figure 10: South-West Interior Ceiling Corner - Master Bedroom

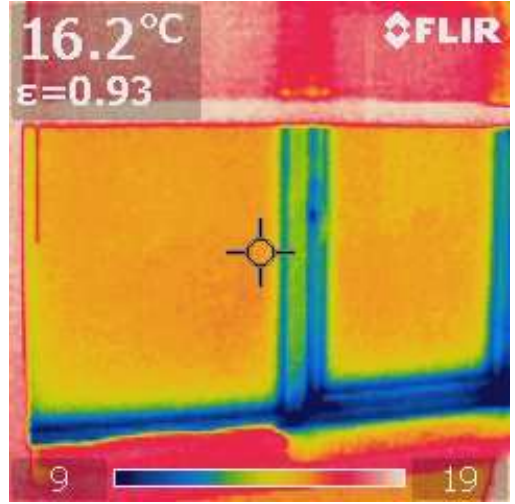

Figure 11: South Wall Sliding Glass Door 2 (Bottom)

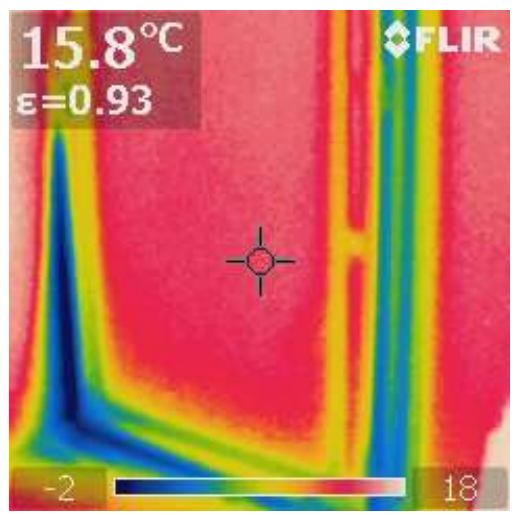

Figure 12: East Wall Front Door (Bottom)

\begin{tabular}{|l|c|}
\hline \multicolumn{1}{|c|}{ Area } & Common T (F) \\
\hline Window Glass & 59 \\
\hline Window Trim & 48 \\
\hline Door Trim & 28.4 \\
\hline Interior Wall Surface & 63 \\
\hline
\end{tabular}

Table 4: Summary of Common Interior Temperatures in SRE Building 
The infrared photos from within the SRE reveal that the window glass in the windowpanes is restricting heat transfer relatively well. However, the metal frames of the window appear to be a thermal bridge and a source of heat loss. This helps to explain why condensation always forms on the metal window and door frames. These frames could be replaced with a plastic or fiber reinforced plastic (FRP) to act as a thermal barrier. The photos of the ceiling corners do not have much temperature variance and indicate that cold air is not making its way into the home from those locations. The SRE walls in every photo appear to be relatively uniform in temperature which is to be expected since they are such a large thermal mass with uniform construction. Colder areas in the rammed earth walls would be concerning because those would be locations that cold air has found a path to travel through the wall and into the house, but that does not appear to be the case in any of the photos.

The following infrared photos were taken from the outside of the SRE house on the same Feb 2020 visit. Similarly (for additional photos taken from the outside of the SRE structure see page 82 located in the Appendix), objects that are visible in the glass reflect the photographer outside of the building.

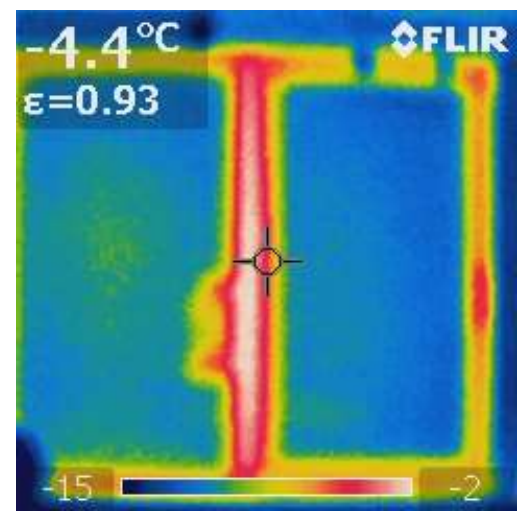

Figure 13: South Wall Sliding Glass Door 1

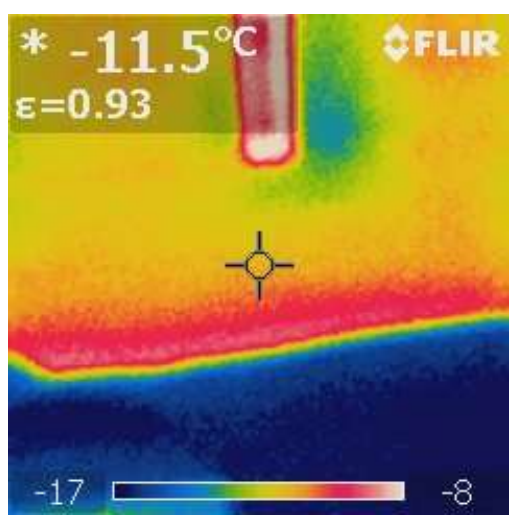

Figure 14: South Wall View of Wall-Slab Joint Outside 


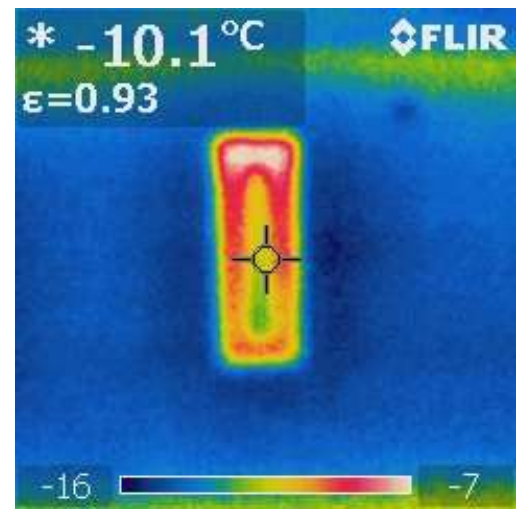

Figure 15: North Wall Window 2 - Guest Bathroom

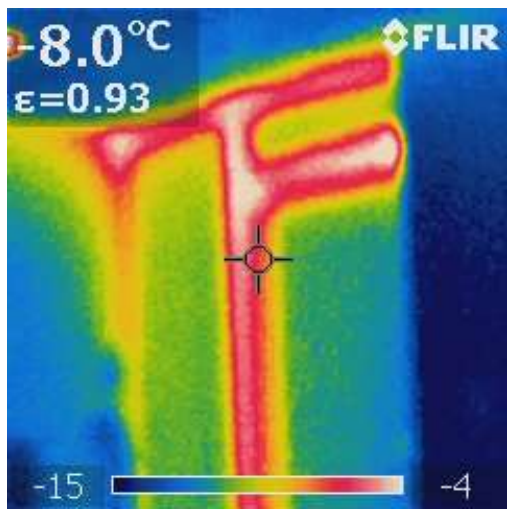

Figure 16: East Wall Front Door (Top)

\begin{tabular}{|l|c|}
\hline \multicolumn{1}{|c|}{ Area } & Common T (F) \\
\hline Window Glass & 8.6 \\
\hline Window Trim & 28 \\
\hline Door Trim & 26.6 \\
\hline Exterior South Wall Surface & 12 \\
\hline Exterior North Wall Surface & 3.2 \\
\hline South Wall at Slab & 16 \\
\hline
\end{tabular}

Table 5: Summary of Common Exterior Temperatures on SRE Building

The outside photos of the home continue to indicate that the window frames are the greatest source of heat loss for the conditioned air. The windowpanes themselves reflect the cold air that is on the outside, but the window frames appear to be transferring the heat from inside to the outside of the building. The views of the overhangs indicate that they are warmer than the surrounding areas. It is tempting to think that they are a source of large amounts of heat loss, but the temperature of the overhangs is considerably cooler than the windows and window frames and is not likely indicating any significant heat loss. 


\subsubsection{Infrared Images of STUD House}

Similar to the SRE house - the pictures taken during the Feb 2020 trip were much more successful and are shown below. However, during the February visit researchers only had access to the outside of the building so unfortunately there are no infrared photos from inside the house (for additional infrared photos of the outside of the STUD home see page 85 located in the Appendix).

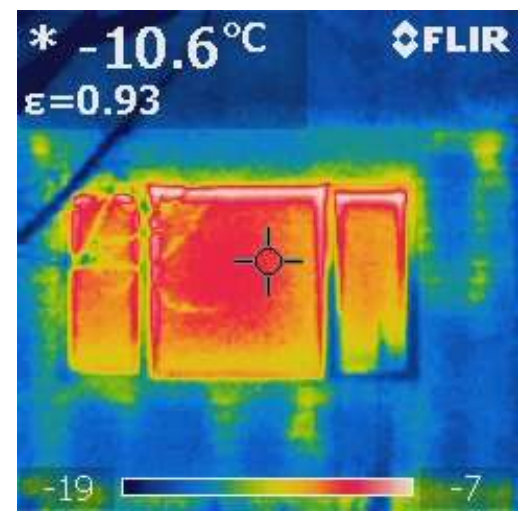

Figure 17: West Wall Window - Living Room

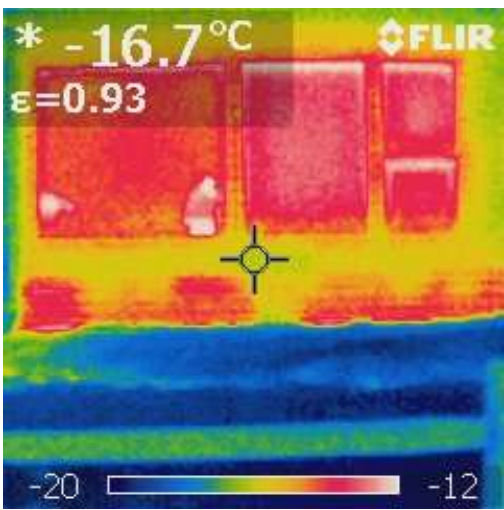

Figure 19: South Wall Window 1 - Sunroom

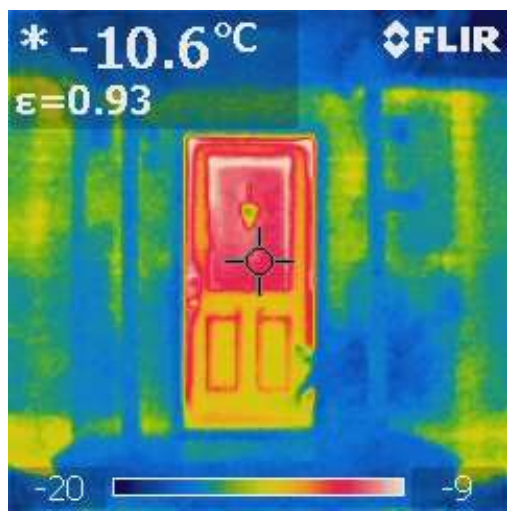

Figure 18: West Wall Front Door

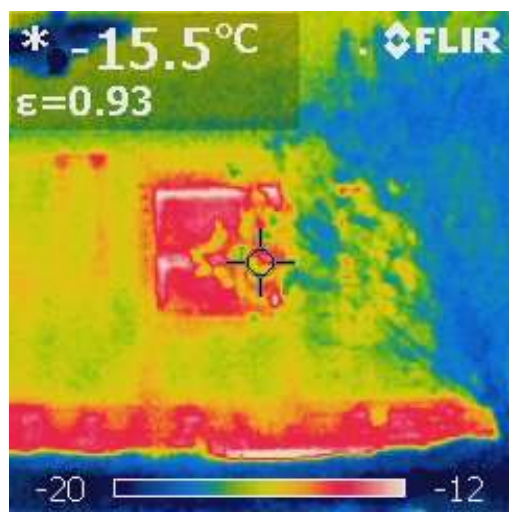

Figure 20: South Wall Window 2 - Office 


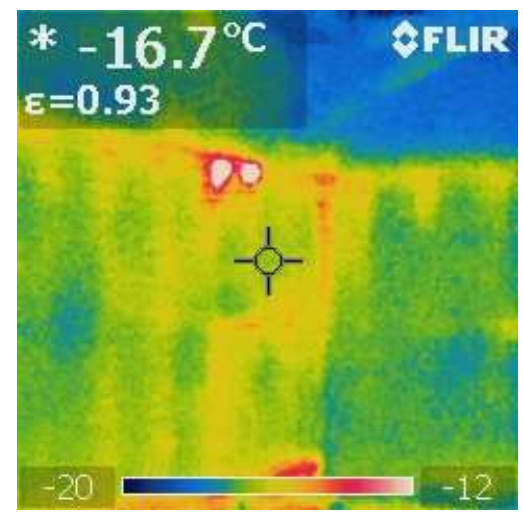

Figure 21: North Wall Leakage - Laundry Room

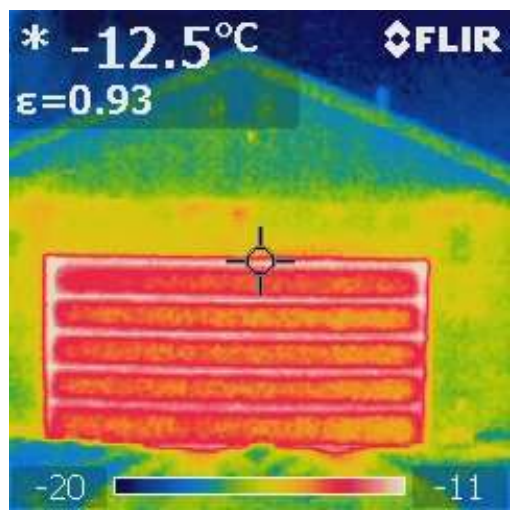

Figure 22: West Wall Overhead Garage Door

\begin{tabular}{|l|c|}
\hline \multicolumn{1}{|c|}{ Area } & Common T (F) \\
\hline Window Glass & 15.8 \\
\hline Window Trim & 16 \\
\hline Door & 5 \\
\hline Door Trim & 12 \\
\hline Exterior South Wall Surface & 3.2 \\
\hline Exterior North Wall Surface & 1 \\
\hline South Wall at Crawlspace & 8.6 \\
\hline
\end{tabular}

The photos of the STUD house show several things that contrast with that of the SRE house. The SRE house has triple paned, high-performance windows installed, but the STUD house only has tripled paned windows on the sunroom which is an addition that was built during the last several years. When looking at the walls on the STUD house one can see where the heat is traveling from the inside, through the 2" x 4" stud and to the outside surface. In the infrared photos, it appears as warm vertical lines underneath the siding. Another feature that is unique to the STUD house is the large, metal-overhead garage door. From the image it is clear to see that it is a very large surface that is not properly insulated and allowing heat to be transferred to the outside of the building. 


\subsubsection{Ultrasound Tap Meter Results}

An ultrasound tap meter called, the $\mathrm{RD}^{3}$ (Rapid Damage Detection Device), made by Wichitech Industries (see Figure 23 below) was used to perform on-site non-destructive testing. This device is a portable and inexpensive tool that is typically used to measure delaminations in composites but can also be used on hard surfaces to detect surface defects or cracks. This device was brought to the SRE house to help detect if the seams in the soil were indeed less stiff than the surrounding material and if they were located past the edges of the visible surface defects.

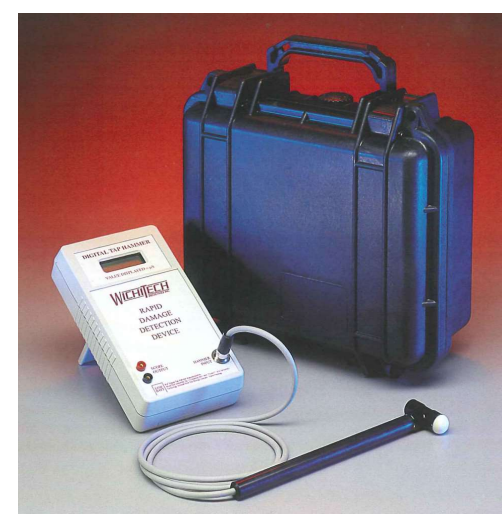

Figure 23: $\mathrm{RD}^{3}$ Digital Tap Meter by Wichitech Industries

When using the tap meter on the rammed earth soil that was defect free, the device returned a value of $1080-1120 \mu \mathrm{s}$ which indicates no surface damage or underlying damage to the material. While inside the SRE house, each crack was noted, photographed, and then tested with the tap meter. When tapping in the area immediately surrounding the cracks, the tap meter read a value between 1080 and $1120 \mu$ s which indicated that the crack did not extend past where it was visible. When tapping directly onto the crack the tap meter would return values greater than 2000 $\mu$ s or less than $800 \mu$ s indicating that there is debonding in the surface of that material which is to be expected. At no point were the researchers able to find a location where the tap meter returned 
a poor value for an area that was not directly located on a crack/seam. When investigating, the residents were asked about each crack that was found and they pointed out that the crack had been there since they moved in and that it has not changed since then. When touching or aggravating the material though, you can knock free some loose pieces of sand and stone but that typically does not happen. The researcher concluded that the tap meter did not identify any areas of concern but rather pointed out the cracks that were intrinsic to the structure since the day that it was built. Below are several photos of field-testing displaying results for delaminations absent and present.

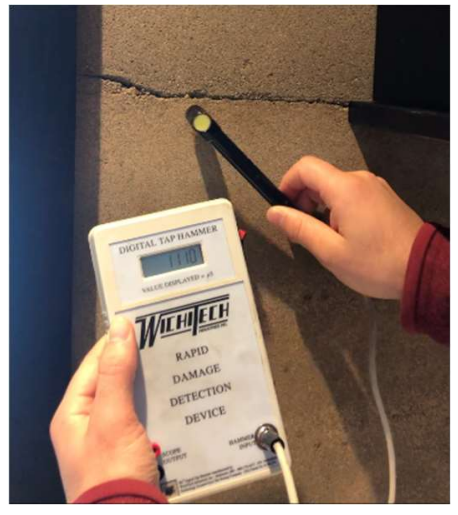

Figure 24: Tap Meter Results - $1110 \mu \mathrm{s}$

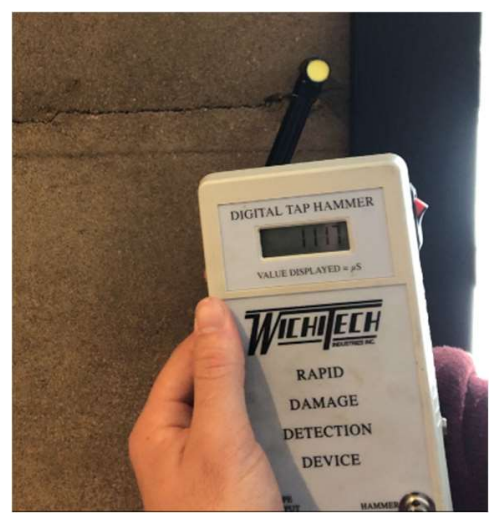

Figure 26: Tap Meter Results - $1117 \mu \mathrm{s}$

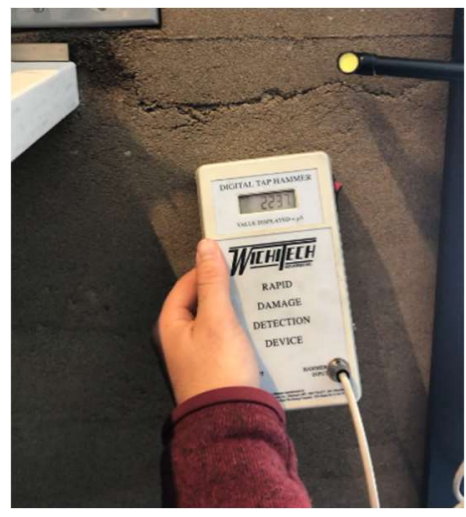

Figure 25: Tap Meter Results - $2237 \mu \mathrm{s}$

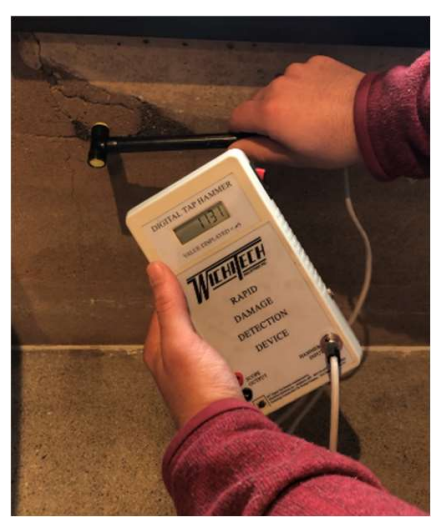

Figure 27: Tap Meter Results - $1131 \mu \mathrm{s}$ 


\subsubsection{Visual Inspection of SRE Structure}

Visual inspection of the property revealed that there are very few blemishes within the rammed earth walls. The only cracks that could be found on the inside of the building were seams between the lifts of the soil that were present when the walls were constructed. The only major defects that could be found on the interior surfaces were where the builders had a hard time consolidating the soil around the bottom edges of windowsills. There is only one case of this occurring within the structure, but it appears that the builder overcame this problem by adding an epoxy to the material that was falling out and then compacting it into place. This can be seen in the photos below.

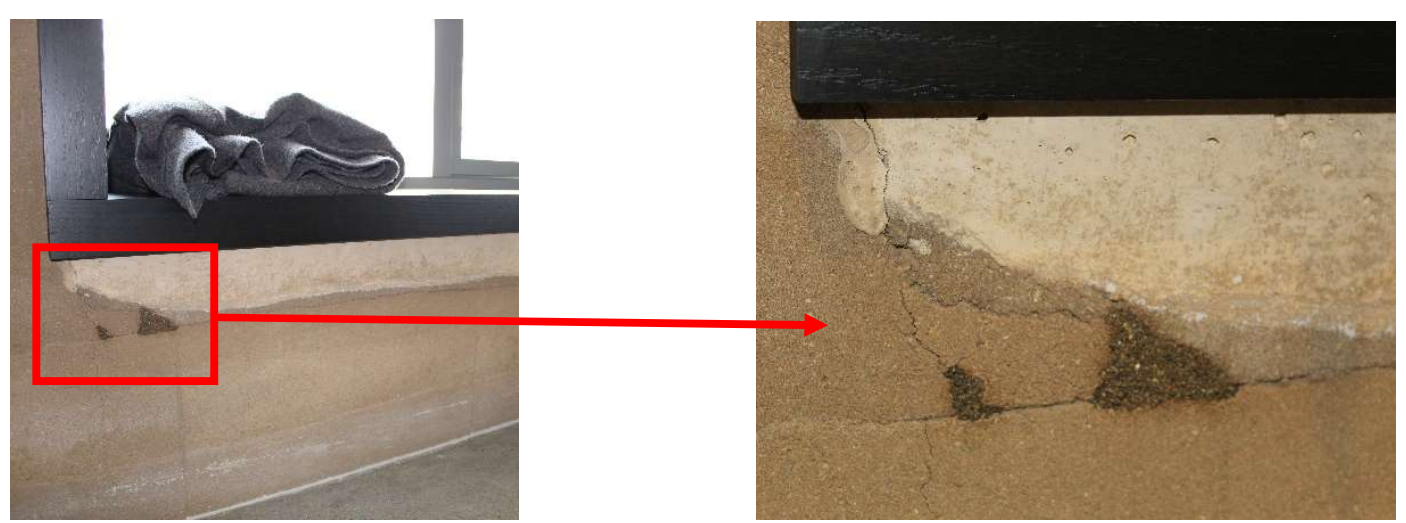

Figure 28: South Window 3 - Interior Delamination Master Bedroom
Figure 29: Close up of South Window 3 - Interior Delaminations - Master Bedroom

The surface seams that were previously mentioned can be seen in the following pictures. 


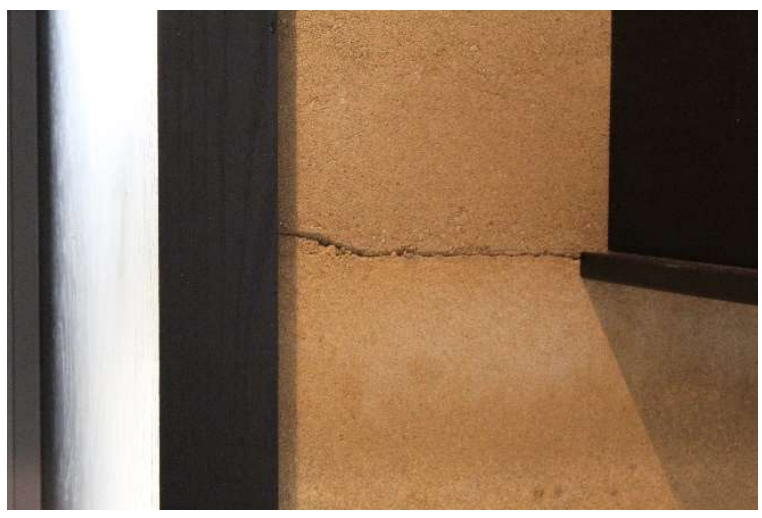

Figure 30: Kitchen Seam 1

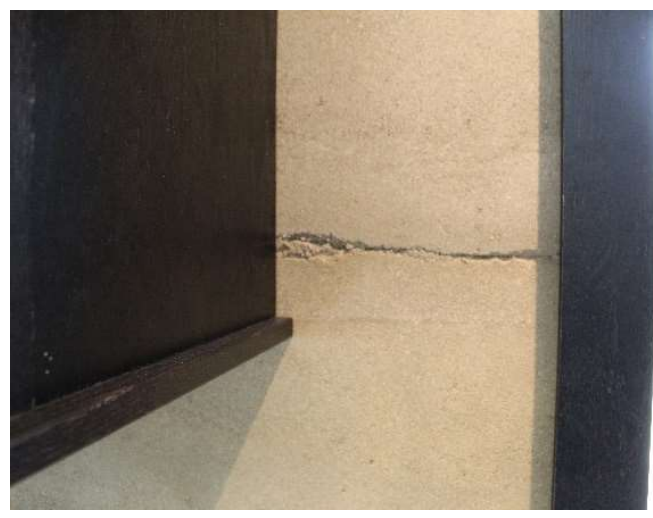

Figure 31: Kitchen Seam 2

While inspecting the exterior surfaces of the SRE building, several very thin, vertical cracks were discovered that passed through 3-4ft of the material. These cracks were not present on the inside of the building. They typically originated in the corner of a windowsill and traveled down to the slab of the material. Given that there are no visible cracks in the foundation of the structure - it is not likely that these cracks are due to settling. Given the nature of the cracks being recorded, it is possible that they are due to shear concentrations during a seismic event or a result of thermal stress due to a large thermal gradient across the thickness of the wall during the coldest months of the year. Since the cracks do not exist in every windowsill or on the inside of the windows as well, it is not very likely that these are in fact due to a seismic event.

Using the equation of thermal stress described in this paper (E 2), we can determine the stress in the rammed earth due to thermal change. During the winter months there is no force of expansion due to thermal stress so it will not be considered to be the mechanism of tension cracking. However, during the summer months there is a difference in the ambient temperature and temperature of the surface of the wall that causes the rammed earth and metal window frames to expand at different rates. The stress due to this uneven expansion can be described 
using the following three step solution. When using E 2 we find that increase in outside wall surface contact temperature (not ambient atmospheric temperature in the summer) over the inside temperature at the time of construction $(\sim 60 \mathrm{~F})$ is around $60 \mathrm{~F}$, which causes the following stress:

$$
\sigma=\left(1 * 10^{6}\right) *\left((6.4-1) * 10^{-6}\right) *(60 F)=324 p s i
$$

The above equation takes into consideration the linear effect of thermal expansion from steel minus that of the rammed earth at an ambient temperature of $60 \mathrm{~F}$ to create an internal pressure of $324 \mathrm{psi}$ in the rammed earth. This pressure is increased when we look at the surface of the rammed earth wall also expanding since it is in direct sunlight and approximately $120 \mathrm{~F}$, creating a $d T$ of $60 \mathrm{~F}$. This stress effect can be written as follows:

$$
\sigma=\left(1 * 10^{6}\right) *\left(1 * 10^{-6}\right) *(60 F)=60 \text { psi }
$$

When these two stresses are combined and a stress concentration factor of 2.5 is applied since this is occurring at a sharp corner the stress is found to be:

$$
\sigma_{t}=(324+60) * 2.5=940 p s i
$$

This simplified approach delivers that the tension in the rammed earth at the corners of the windows due to thermal expansion can be taken to be 940 psi which is twice the stress to cause tension failure in concrete. This solution does neglect the 2-D effects of the depth of the wall, but it is still useful to understand that the difference in material between the window fame and rammed earth causes a concerning stress concentration due to thermal expansion. This can be addressed by simply using a plastic or FRP window frame, using plastic reinforcement on the corners of the rammed earth walls, or using curved corners in the window openings to reduce the stress concentration. 
Another likely culprit of these vertical cracks is shrinkage due to loss of moistures during the curing process since the rammed earth walls contain about $8 \%$ cement. In general concrete or lime construction projects will very typically see this type of cracking occur if proper precautions are not taken. One common solution to shrinkage cracking that can be applied to construction projects like the SRE house would include cutting very shallow lines or reliefs from the corner of the windowsill down to the foundation so that the shrinkage crack has a dedicated path to follow and does not alarm the user of the building. This practice is very common for large concrete walls or slabs that generate a lot of heat when curing and henceforth, cause a lot of moisture loss that results in unsightly shrinkage cracking. By creating man-made reliefs in the material, the crack has a path to follow and is generally not noticed by people using the structure. See Figure 32 through Figure 35 to see the cracks described in this section. 


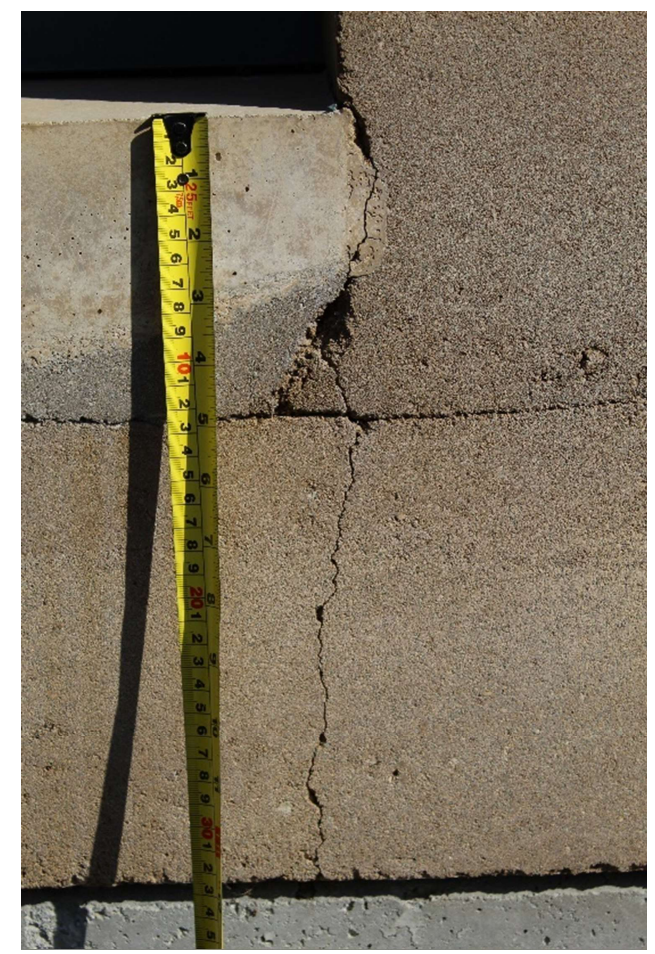

Figure 32: Crack 1 - South Wall Window 3

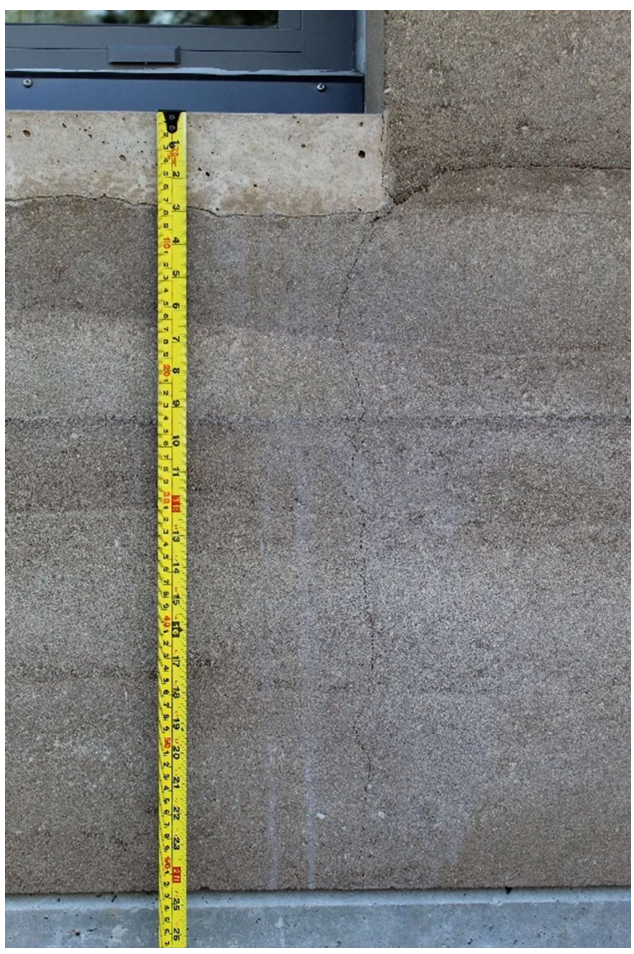

Figure 34: Crack 3 - North Wall Window 3

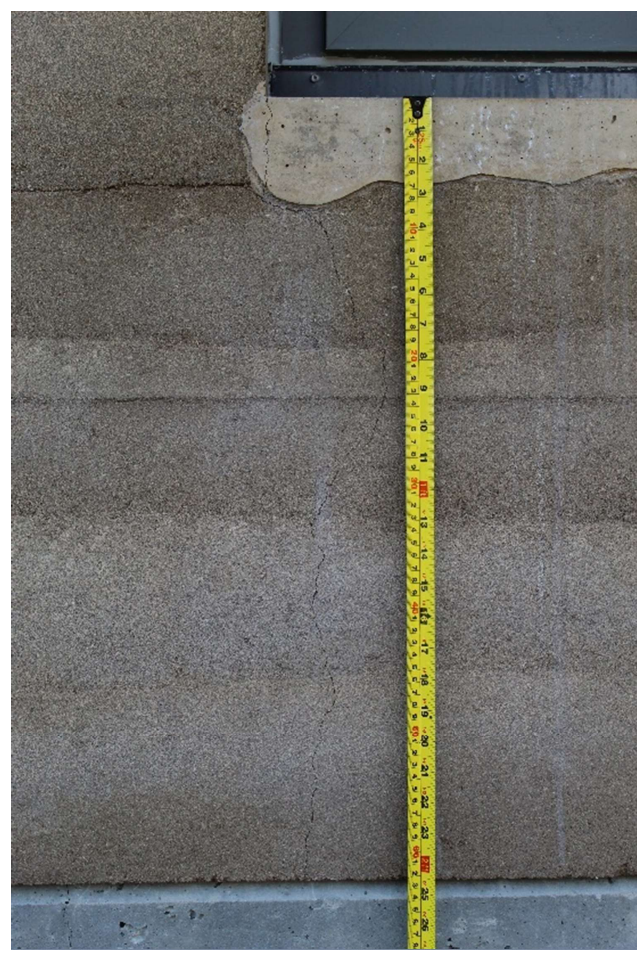

Figure 33: Crack 2 - North Wall Window 2

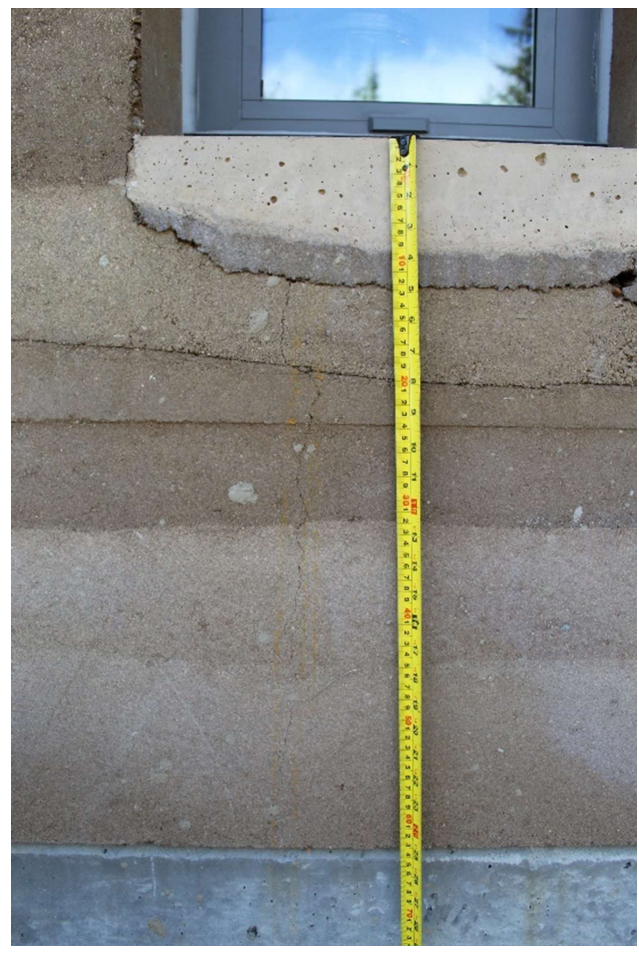

Figure 35: Crack 4 - North Wall Window 4 


\subsection{Data Processing}

The quantitative results for this project are derived from four sources. First, the data from the HOBOlink data logging system was retrieved and then processed so that an accurate comparison between the homes could be made. Second, the utility information from the natural gas company, ENSTAR, was gathered for both homes so that the researcher could compare the living comfort of each home with volume of energy that was used to heat each one. Checking this information was done two ways, (1) using the AK Warm project models that had already been conducted by the state and (2) by completing our own energy modeling by using eQUEST. The combination of all these data sources proved the validity of the results seeing that they all confirm one another. Specific details can be found in the sections below.

\subsubsection{HOBOlink Data Logs}

The HOBOlink data loggers were installed in both locations at different times. The data logger for the SRE house came online in Fall of 2017, but the data logger did not come online in the STUD house until the Spring of 2019. As a result of this discrepancy, there is only side-byside data for the two homes for eleven months now. Both data loggers will continue to operate autonomously unless shut down by the researchers. In order to view the full temperature, humidity, and dew point data for both of the structures turn to the Appendix to see Figure 79 through Figure 108.

Figure 4Table 7 below is included to show the average, max, and min temperatures in the SRE house, STUD house, and outdoors for each season that the data loggers have been active. They also include the average, max, and min RH for the SRE and STUD house so that they can be compared side-by-side. 
SRE House Values

\begin{tabular}{lccccccccccc} 
& FA 17 & WIN 18 & SP 18 & SU 18 & FA 18 & WIN 19 & SP 19 & SU 19 & FA 19 & WIN 20 \\
\hline $\mathrm{T}_{\text {avg }}\left({ }^{\circ} \mathrm{F}\right)$ & 62.77 & 63.90 & 67.00 & 70.10 & 64.78 & 62.97 & 67.27 & 71.14 & 64.48 & 61.27 \\
$\mathrm{~T}_{\max }\left({ }^{\circ} \mathrm{F}\right)$ & 69.64 & 71.88 & 73.39 & 76.25 & 69.51 & 67.97 & 72.52 & 78.12 & 67.71 & 66.47 \\
$\mathrm{~T}_{\min }\left({ }^{\circ} \mathrm{F}\right)$ & 57.94 & 56.38 & 58.54 & 65.53 & 58.97 & 56.73 & 63.00 & 62.53 & 55.26 & 46.93 \\
$\mathrm{RH}(\%)$ & 65.1 & 62.8 & 69.0 & 72.0 & 69.2 & 66.6 & 67.0 & 64.8 & 58.94 & 56.38 \\
$\mathrm{RH}_{\max }(\%)$ & 79.9 & 78.1 & 81.2 & 82.5 & 79.9 & 75.6 & 77.6 & 77.6 & 70.80 & 70.50 \\
$\mathrm{RH}_{\min }(\%)$ & 27.2 & 15.7 & 34.5 & 47.3 & 51.4 & 30.2 & 38.2 & 34.9 & 32.70 & 21.70
\end{tabular}

STUD House Values

\begin{tabular}{|c|c|c|c|c|c|c|c|c|c|c|}
\hline & FA 17 & WIN 18 & SP 18 & SU 18 & FA 18 & WIN 19 & SP 19 & SU 19 & FA 19 & WIN 20 \\
\hline $\mathrm{T}_{\text {avg }}\left({ }^{\circ} \mathrm{F}\right)$ & - & - & - & - & - & - & 61.34 & 64.77 & 58.68 & 57.42 \\
\hline $\mathrm{T}_{\max }\left({ }^{\circ} \mathrm{F}\right)$ & - & - & - & - & - & - & 75.38 & 86.94 & 64.89 & 64.16 \\
\hline $\mathrm{T}_{\min }\left({ }^{\circ} \mathrm{F}\right)$ & - & - & - & - & - & - & 35.64 & 35.88 & 6.72 & 6.72 \\
\hline RH (\%) & - & - & - & - & - & - & 56.64 & 63.04 & 72.35 & 35.92 \\
\hline $\mathrm{RH}_{\max }(\%)$ & - & - & - & - & - & - & 94.90 & 99.40 & 100.00 & 88.00 \\
\hline $\mathrm{RH}_{\min }(\%)$ & - & - & - & - & - & - & 29.00 & 18.30 & 38.80 & 25.10 \\
\hline
\end{tabular}

\begin{tabular}{cccccccccccc} 
& \multicolumn{1}{c}{ Ambient Values } \\
& FA 17 & WIN 18 & SP 18 & SU 18 & FA 18 & WIN 19 & SP 19 & SU 19 & FA 19 & WIN 20 \\
\hline $\mathrm{T}_{\text {avg }}\left({ }^{\circ} \mathrm{F}\right)$ & 24.34 & 16.46 & 44.34 & 56.78 & 32.71 & 18.73 & 47.19 & 60.55 & 33.47 & 7.29 \\
$\mathrm{~T}_{\max }\left({ }^{\circ} \mathrm{F}\right)$ & 47.78 & 45.71 & 72.91 & 81.33 & 59.14 & 46.84 & 74.08 & 88.26 & 56.21 & 45.90 \\
$\mathrm{~T}_{\min }\left({ }^{\circ} \mathrm{F}\right)$ & -9.66 & -16.55 & 7.14 & 0.00 & -0.62 & -19.83 & 21.18 & 35.98 & 1.48 & -25.86
\end{tabular}

Table 7: Summary of Seasonal HOBOlink Temperature, RH, and DP Data

Figure 36 through Figure 38 also represent the same temperature data for the SRE house, STUD house, and outside so that they can be compared visually. From the charts below and the tables above, it is clear to see that the average temperature in the SRE house is warmer than that of the average temperature in the STUD house. The plotted line on the chart reveals the difference between the cold and warm seasons and the average indoor temperature also follows the same trend, but only within the desired living temperatures. 


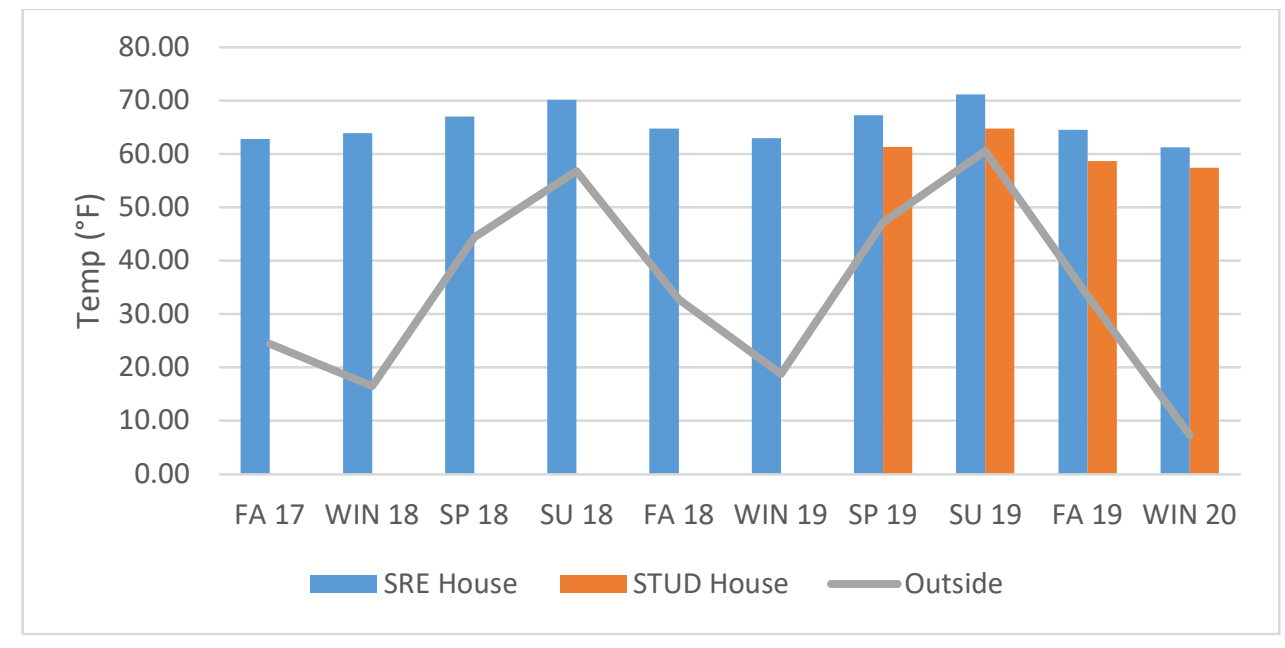

Figure 36: Average Seasonal Temperatures Measured in SRE house, Stud house, and Exterior

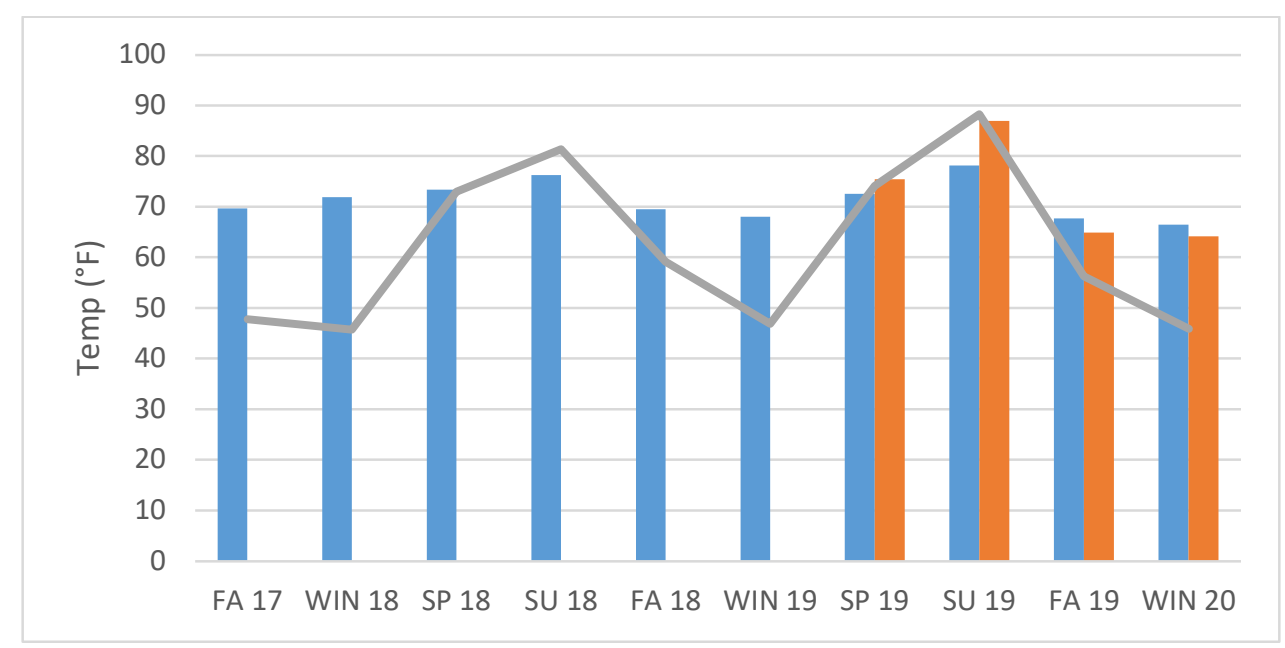

Figure 37: Max Temperatures Measured in SRE house, Stud house, and Exterior

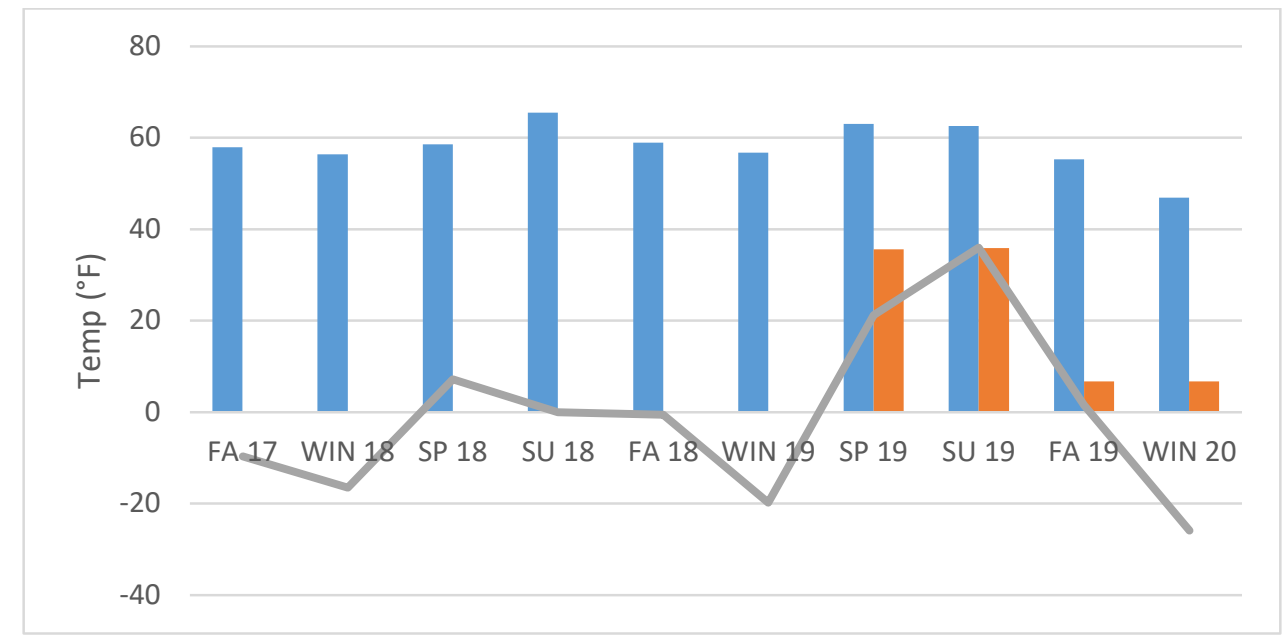

Figure 38: Min Temperatures Measured in SRE house, Stud house, and Exterior 
Using the raw data provided by the HOBOlink data loggers the researchers were able to find and compare the standard deviation of the temperatures, $\mathrm{RH}$, and DP in each of the three structures in order to compare which location was the most thermally stable. The results below indicate that the SRE house was better able to maintain steady temperatures, RH, and DP.

\begin{tabular}{|c|c|c|c|c|c|c|c|c|c|}
\hline Season & $\begin{array}{c}\text { Outside } \\
\text { T SD }\end{array}$ & $\begin{array}{c}\text { SRE T } \\
\text { SD }\end{array}$ & $\begin{array}{c}\text { STUD } \\
\text { T SD }\end{array}$ & $\begin{array}{c}\text { Outside } \\
\text { RH SD }\end{array}$ & $\begin{array}{c}\text { SRE RH } \\
\text { SD }\end{array}$ & $\begin{array}{l}\text { STUD } \\
\text { RH SD }\end{array}$ & $\begin{array}{l}\text { Outside } \\
\text { DP SD }\end{array}$ & $\begin{array}{l}\text { SRE DP } \\
\text { SD }\end{array}$ & $\begin{array}{l}\text { STUD } \\
\text { DP SD }\end{array}$ \\
\hline FA 17 & 15.73 & 2.72 & - & 9.77 & 2.01 & - & 14.75 & 3.58 & - \\
\hline WIN 18 & 14.48 & 3.36 & - & 9.26 & 6.88 & - & 14.10 & 3.55 & - \\
\hline SP 18 & 11.87 & 2.35 & - & 15.96 & 6.45 & - & 9.89 & 5.03 & - \\
\hline SU 18 & 7.85 & 1.71 & - & 15.84 & 2.21 & - & 4.47 & 1.63 & - \\
\hline FA 18 & 13.92 & 1.37 & - & 11.61 & 2.05 & - & 12.01 & 2.11 & - \\
\hline WIN 19 & 15.48 & 1.65 & - & 9.61 & 1.86 & - & 14.39 & 1.66 & - \\
\hline SP 19 & 10.59 & 1.82 & 2.11 & 17.18 & 2.37 & 5.33 & 8.11 & 2.44 & 2.98 \\
\hline SU 19 & 9.81 & 2.80 & 4.07 & 16.71 & 3.23 & 7.04 & 5.81 & 3.65 & 2.90 \\
\hline FA 19 & 10.75 & 1.07 & 1.98 & 11.79 & 1.49 & 7.47 & 9.07 & 1.38 & 4.38 \\
\hline WIN 20 & 17.85 & 2.08 & 3.40 & 6.92 & 3.18 & 7.75 & 17.97 & 2.34 & 5.42 \\
\hline Average & 12.83 & 2.09 & 2.89 & 12.46 & 3.17 & 6.90 & 11.06 & 2.74 & 3.92 \\
\hline $\begin{array}{c}\% \text { of } \\
\text { Outside }\end{array}$ & & $16.3 \%$ & $22.5 \%$ & & $25.5 \%$ & $55.3 \%$ & & $24.7 \%$ & $35.4 \%$ \\
\hline
\end{tabular}

Table 8: Standard Deviations for Seasons from Recorded Temperature, RH, and DP Data

During the winter months the SRE house is always kept at 71F and the STUD house is set to $65 \mathrm{~F}$ when residents are home and $60 \mathrm{~F}$ when the residents are away. This difference in temperature can be clearly seen in the data shown above. It is also clear to see that the temperature within the homes is considerably more stable in the SRE house than the STUD house. The standard deviation of the temperature of the SRE house is $16.3 \%$ of that outside while the STUD house is $22.5 \%$ of that outside. The data clearly concludes that the SRE house remains warmer during the winter months but further investigation into the utilities used needs to be shown in order to prove that the SRE house is more thermally efficient compared to the STUD house per square foot. 
As mentioned in the Theory portion of this paper, the relative living comfort of a home as described by ASHRAE can be found using the relationship between relative humidity and temperature during the winter and summer months. This living comfort data has been standardized so that there are ranges of 'ideal' living comfort for winter and summer months and those were shown in Figure 7. The summer and winter relative humidity and temperature data from both the SRE home and the STUD home has been superimposed on top of the ideal data ranges in the flowing charts to describe the thermal comfort in both homes.

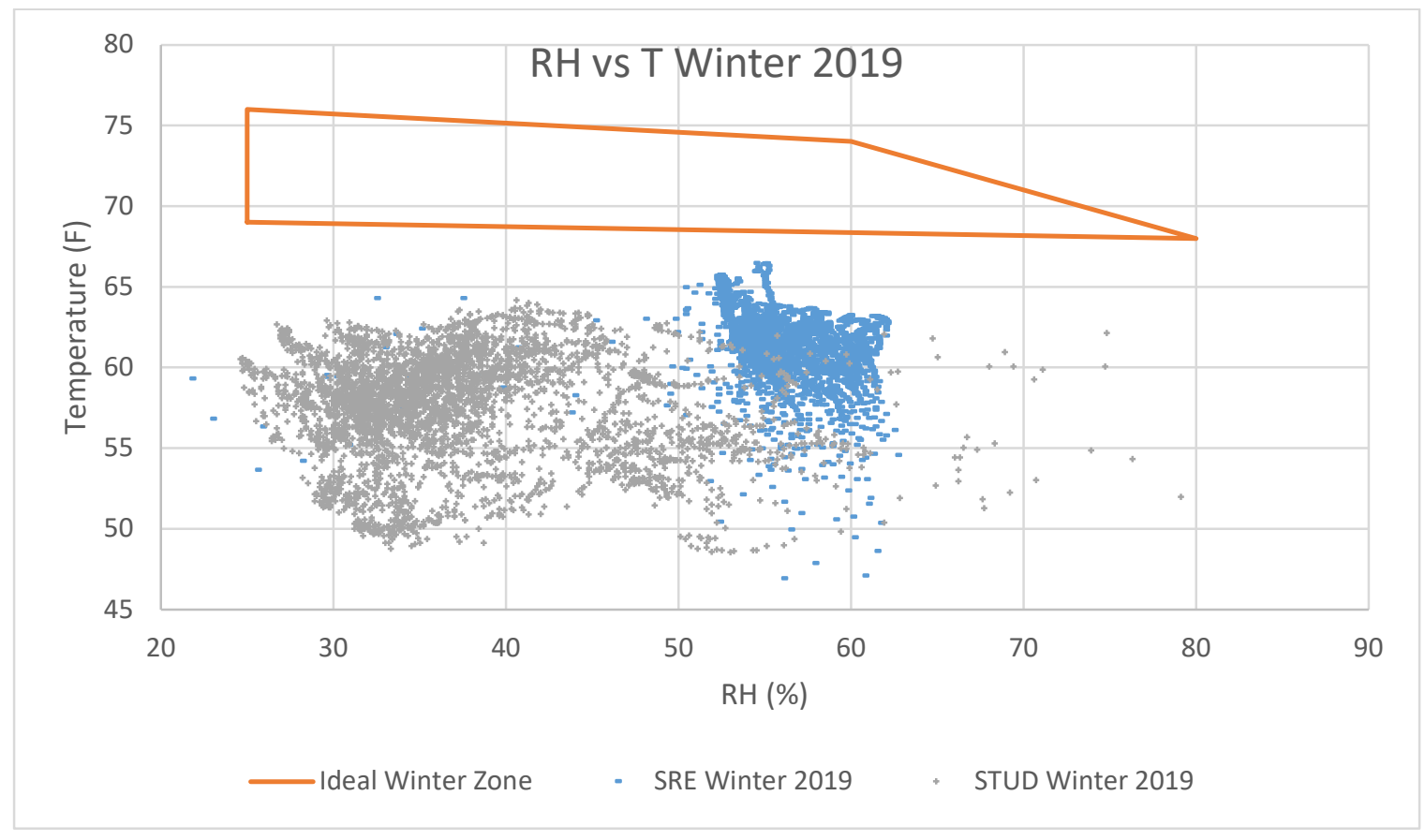

Figure 39: Winter of 2019 - Relative Humidity vs Temperature 


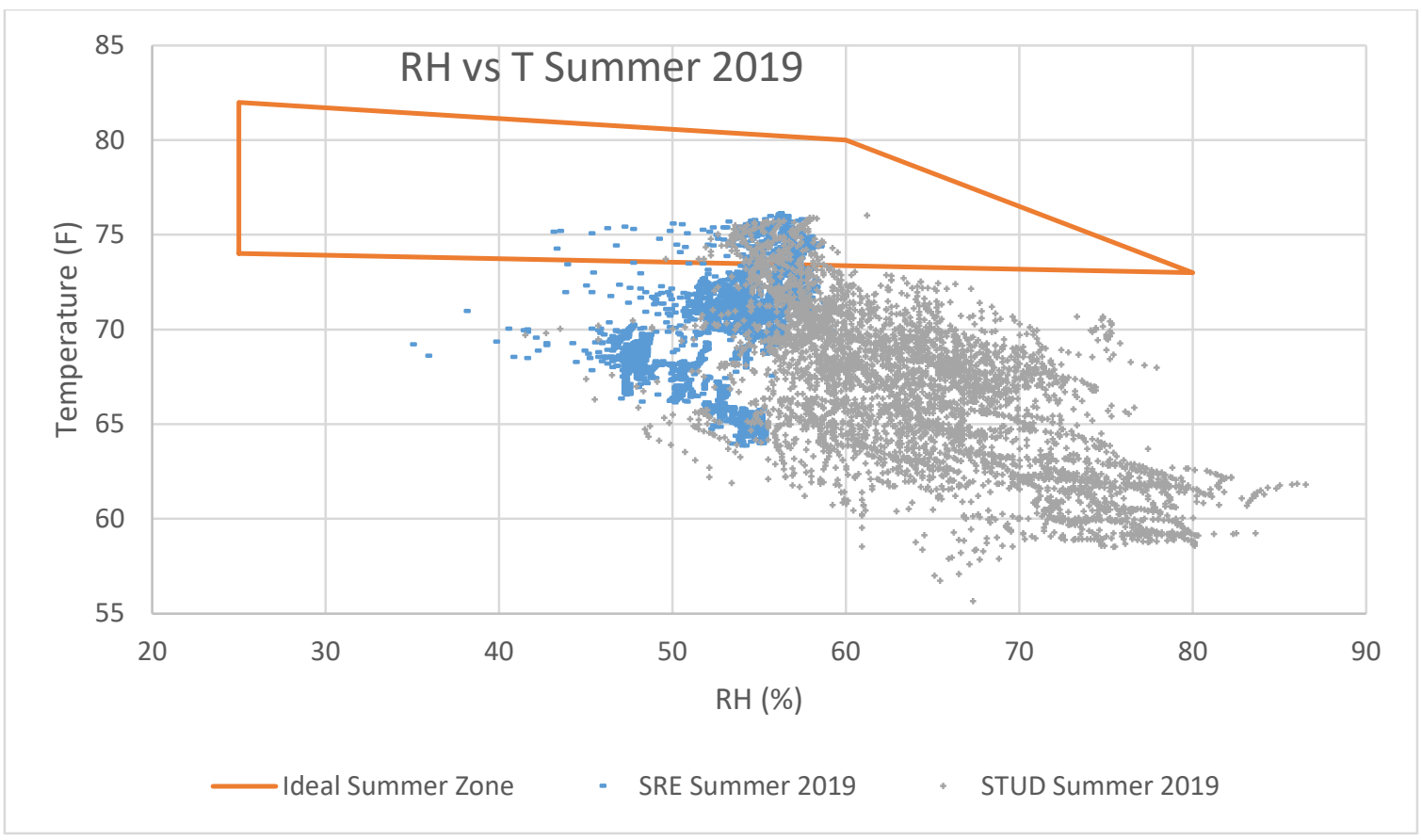

Figure 40: Summer of 2019 - Relative Humidity vs Temperature

In Figure 39 and Figure 40, it is clear to see that neither home spends much time in what is considered to be the standardized 'ideal' for living conditions. This is an interesting discovery and most likely due to the fact that the seasonal winter and summer temperatures in Alaska are considerably colder than other places in the country. It is to be expected that residents in a colder climate are more acclimated to the temperatures there and function better in cooler temperatures while overheating too easily in a what the rest of the country would consider to be a "cool summer." Further research in Alaska would have to be conducted to better understand what the desired living comfort across the state would be and how much that would differ from the rest of the country. However, there are several other things that can be learned from these figures. It appears that the SRE house has a very consistent relative humidity during each season and across the entirety of the year. The STUD house on the other hand has great variance in temperature and relative humidity for each season and then even greater spread when looking at the entirety of the 
year. Note: both homes have the same number of data points for each figure, meaning the spread indicates a wider range of data points, not a larger number of data points.

It is a good sign that the SRE home does not reach relative humidity levels above $65 \%$ since that is likely to result in the growth of mold in the living space. Since many of the complaints voiced by the residents of the SRE house were that the structure was too warm during the summer months, that would indicate temperatures above $75 \mathrm{~F}$ are not desirable. In order to help reduce the apparent temperature in the home, the residents could use a dehumidify to pull water out of the air and in turn, decreasing the heat impact on the body and overall improving the living comfort within the home without using any cooling equipment. Another major factor that would decrease the apparent temperature would be to increase the air flow so that the residents are able too cool off faster during the summer months. By using the heat index equation, the writer was able to find the apparent temperature in the SRE home during the summer months and can be described in the flowing table.

\begin{tabular}{|l|c|}
\hline \multicolumn{2}{|c|}{ SRE Summer Apparent Temps 2019} \\
\hline Average & 76.5 \\
\hline Max & 78.7 \\
\hline Min & 75.4 \\
\hline
\end{tabular}

Figure 41: Summary of SRE Apparent Temperatures during Summer Months of 2019

\subsubsection{Utility Data Comparison}

In both properties natural gas is used for space heating as well as domestic hot water (DHW). With this being said, both homes have three residents and an assumption was made that the hot water used per person in each home was the same so that the natural gas being used directly reveals the difference in required energy to heat the space in both homes. The natural gas used in each home is measure by ccf, centum cubic feet which translates to 100 cubic feet for $1 \mathrm{ccf}$. The 
STUD house is larger than the SRE house so the natural gas was normalized by square foot so that the energy input could be described as ccf of natural gas to heat one square foot. That number then had to be adjusted again since both homes are kept at different temperatures. The STUD house was adjusted by a percent factor so that it reflected the amount of natural gas needed to heat the home to $71 \mathrm{~F}$. This percent factor was derived from the difference between $60 \mathrm{~F}$ and $71 \mathrm{~F}$ as well as $65 \mathrm{~F}$ and $71 \mathrm{~F}$ for the unoccupied and occupied durations of the day respectively. Using a weighted average for the different temperatures for different portions of a 24-hour period, the natural gas required to heat one square foot of living space to $71 \mathrm{~F}$ in the STUD house was finally derived.

When comparing the two homes, the STUD house is $\sim 2.3$ times more expensive to heat per square foot to $71 F$. The SRE house cost $\$ 293.03$ to heat for the year. To compare, when normalized by temperature and square footage, the STUD house costs $\$ 1,034.86$ to heat for the year. When considering the difference in square footage, the residents of the SRE house were able to save $56 \%$ of the cost required to heat their home. Since measures were taken to normalize both homes per square footage and at the same temperature, this is a direct comparison. Figure 42 below shows a visual comparison of the volume of gas used in the SRE home, STUD home, and the adjusted value for the STUD home if normalized to directly compare with the SRE values. 


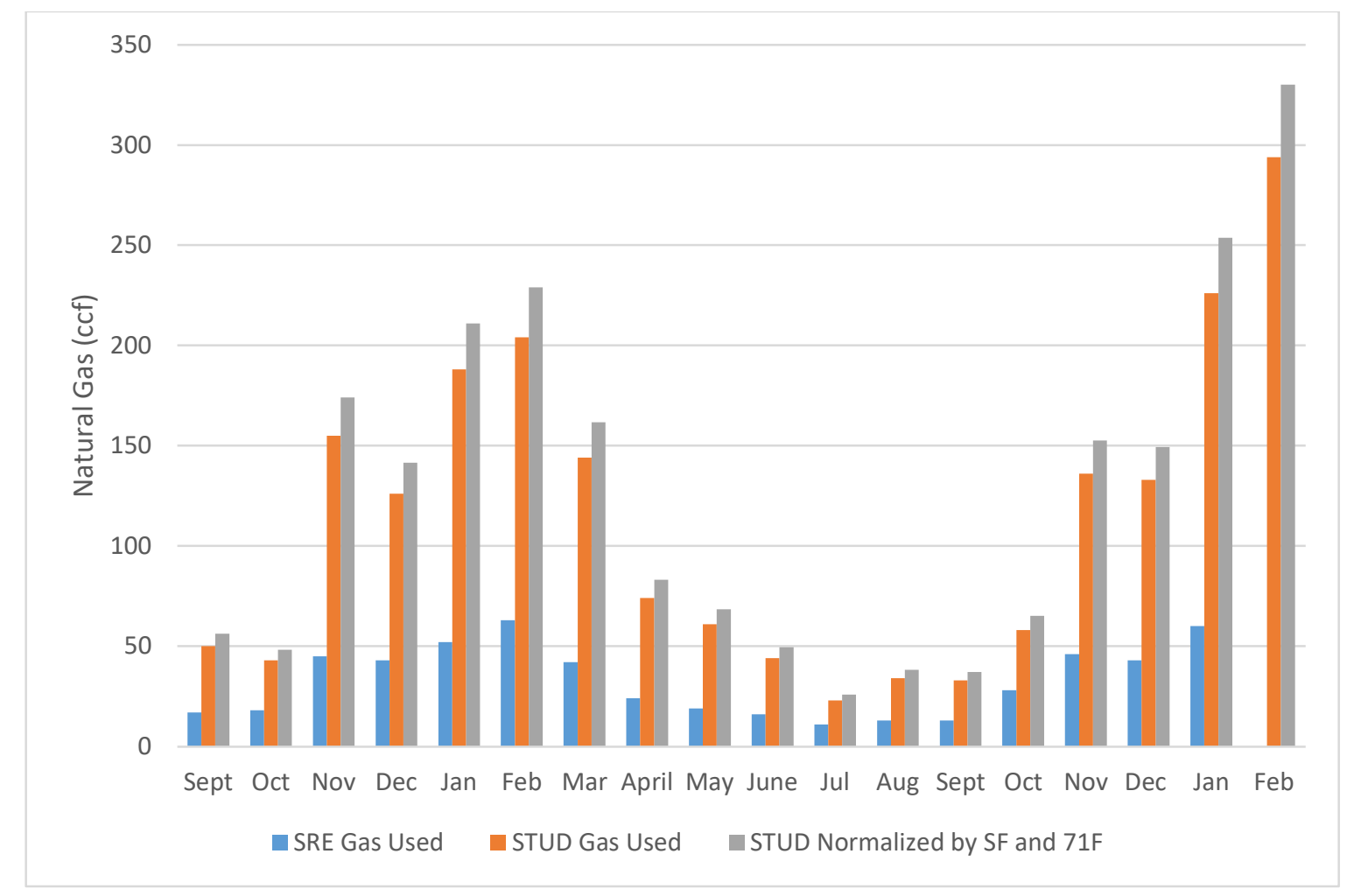

Figure 42: Vol. of Natural Gas Used in SRE house and Stud house and Predicted Vol. of Natural Gas Needed in STUD House Set to 71F

Using the natural gas data that was provided by the gas company a quick summary can be viewed in the following table to compare the cost per square foot and $\mathrm{CO}_{2}(\mathrm{lb})$ released per square foot for the year.

\begin{tabular}{|c|c|c|c|c|}
\hline Site & Cost of Natural Gas & $\$ / \mathrm{ft}_{2}$ & $\mathrm{CO}_{2}$ Produced & $\mathrm{CO}_{2} / \mathrm{ft}^{2}$ \\
\hline SRE & 293.03 & 0.16 & 52121 & 29.15 \\
\hline STUD & $1,034.86$ & 0.37 & 137212 & 49.46 \\
\hline & \$ Saving & 50-yr Savings per $\mathrm{ft}^{2}$ & $\mathrm{CO}_{2}$ Reduced & 50 -yr Savings per $\mathrm{ft}^{2}$ \\
\hline & $57 \%$ & 10.5 & $41 \%$ & 1015.657 \\
\hline
\end{tabular}


For a full break down of the month-to-month cost of natural gas utilities and calculations to determine the normalized values please turn to the Appendix to see Section 7.4 Natural Gas Utility Bills.

\subsubsection{AK Warm Modeling Comparison}

To reduce emissions and conserve energy, the state of Alaska created a program where homeowners are required to perform an energy rating on the home. The state of Alaska then provided funds to assist the homeowner to upgrade certain features of the home to improve the energy rating of the house. The rating system worked on a scale of $0-100$ points and was determined by the thermal efficiency of the structure - the more efficient, the higher the rating. The STUD house earned a score of 85.7 points while the SRE house earned a score of 98.3 points. Using the appliance information and building construction, the STUD house was estimated to produce $36,797 \mathrm{lbs}$ of $\mathrm{CO}_{2}$ a year while the SRE house was estimated to produce $10,277 \mathrm{lbs}$ of $\mathrm{CO}_{2}$ year. Which means that annually each square foot of the STUD home produces $13.25 \mathrm{lbs}$ of $\mathrm{CO}_{2}$ while each square foot in the SRE home produces $5.75 \mathrm{lbs}$ of $\mathrm{CO}_{2}-$ which is $56.6 \%$ less per square foot. Replacing the STUD house with an equivalent home constructed from rammed earth materials would mean an annual reduction of $\mathrm{CO}_{2}$ released into the atmosphere by $15,970 \mathrm{lbs}$. The AK Warm project estimates that the annual cost of the natural gas to provide space heating and hot water would cost about $\$ 2,487$ in the STUD house and $\$ 545$ in the SRE house. This appears to be a very conservative estimate compared to the utility data that was provided by the researcher. A summary of the data described in this paragraph and how it compares to the actual utility data recorded on-site is shown in the following table. 


\begin{tabular}{|c|c|c|c|c|c|c|c|c|c|c|}
\hline \multirow[b]{2}{*}{ Site } & \multirow[b]{2}{*}{$\mathrm{ft}^{2}$} & \multicolumn{6}{|c|}{ AK Warm Estimations } & \multicolumn{3}{|c|}{ Actual Utility Data } \\
\hline & & $\begin{array}{l}\text { Energy } \\
\text { Score }\end{array}$ & $\begin{array}{c}\mathrm{CO}_{2} \text { Produced } \\
\text { (lb) }\end{array}$ & $\mathrm{CO}_{2} / \mathrm{ft}^{2}$ & $\begin{array}{c}\text { Natural } \\
\text { Gas }\end{array}$ & $\$ / \mathrm{ft}^{2}$ & $\begin{array}{l}\text { Cost } \\
\text { Ratio }\end{array}$ & \begin{tabular}{|c|} 
Adj. \\
Natural Gas
\end{tabular} & $\$ / \mathrm{ft}^{2}$ & $\begin{array}{l}\text { Cost } \\
\text { Ratio }\end{array}$ \\
\hline$\overline{\text { SRE }}$ & 1788 & 98.3 & 10,277 & 5.75 & $\$ 545.00$ & $\$ 0.30$ & 1 & $\$ 293.03$ & $\$ 0.16$ & 1 \\
\hline STUD & 2774 & 85.7 & 36,797 & 13.25 & $\$ 2,487.00$ & $\$ 0.90$ & 2.941 & $\$ 1,034.86$ & $\$ 0.37$ & 2.276 \\
\hline
\end{tabular}

Table 10: Summary of AK Warm Data in Comparison with Measured Utilities

\subsection{4. eQuest Virtual Modeling and Comparison}

The use of eQUEST for this project was deemed necessary by taking advantage and imputing the field data into a virtual model to enhance the understanding of the building's thermal responses. The use of eQUEST came with several limitations because at this point of the software development it does not have in-floor heating (like in the SRE house) as an option that the user can select. Instead, the user is required to set up the model with baseboard heating with no ventilation. This reduces the accuracy to reflect the structure out in the field but still provided a good representative model.

eQUEST is divided into two main project types. Project where the user is modeling a simple structure that can be drawn as a single shell can be developed using the Building Creation Wizard. More complicated models that use multiple HVAC systems or multiple shells use the Design Development Wizard (DDW). The DDW was used for this project since it provides additional inputs that allow the researcher to better specify the building properties. For both the SRE and STUD building models, the user had to enter the DDW and provide numerous physical properties, thermal properties, and usage conditions. Some of these inputs include the following: general site information, season definitions, general building (shell) information, custom 
building footprint, roof components, exterior wall components, ground floor properties, building interior construction, various door types/materials and custom placement, exterior window types/materials and custom placement, shade and blind information, building operation schedule, activity area allocations, non-HVAC uses for modeling, interior lighting loads, cooking loads, refrigerator loads, miscellaneous loads, exterior lighting loads, and detailed heater specifications for domestic hot water and space heaters.

The critical utility that was investigated for this project was natural gas since it is used to heat both buildings and neither of them have any cooling equipment. Both models were created and then adjusted so that they best represented the natural gas consumption of the buildings in the field. When the models were first developed, the summer-time consumption of natural gas was identical to that of what the utilities recorded. The wintertime months in the model gave a very low volume of gas that was used compared to the field data recorded. After going back into the models and adjusting any erroneous data entries, an additional wizard was discovered to help adjust for extreme weather months.

During the winter months of 2018 and 2019, Butte, Alaska experienced several very cold and prolonged winters that eQUEST was not adequately modeling. It appeared that the eQUEST model was predicting that the SRE and STUD houses were using a considerably less volume of natural gas during the winter months than anticipated. After using all of the correct parameters, the researcher was able to accurately model the needs of both building in the summertime, late spring, and early fall. In order to further improve the accuracy of the model, a custom wizard in the software was used to increase the needed domestic hot water for certain months of the year. Typically, domestic hot water is only used for consumable purposes, but for the case of the SRE house and Stud house, the hot water heaters that acted as a source of heat for the building (in- 
floor heat in the SRE building, and hot water coils in the STUD house) also warmed the domestic hot water that is used in the home. eQUEST allows the user to loop the hot water systems in the domestic hot water systems. Since these systems are combined in both homes the natural gas used for "water heating" and "space heating" work in conjunction to heat the building. By using this wizard in eQUEST, the model was able to very accurately match the realworld natural gas usage. The accuracy of the model is very important since it can be used to manipulate individual characteristics of the model to understand the impact of the rammed earth walls, high performance windows, and a crawlspace individually.

Note: the "misc. equipment" listed in the reports below takes in account the natural gas needed for running the dryer and cooking loads.

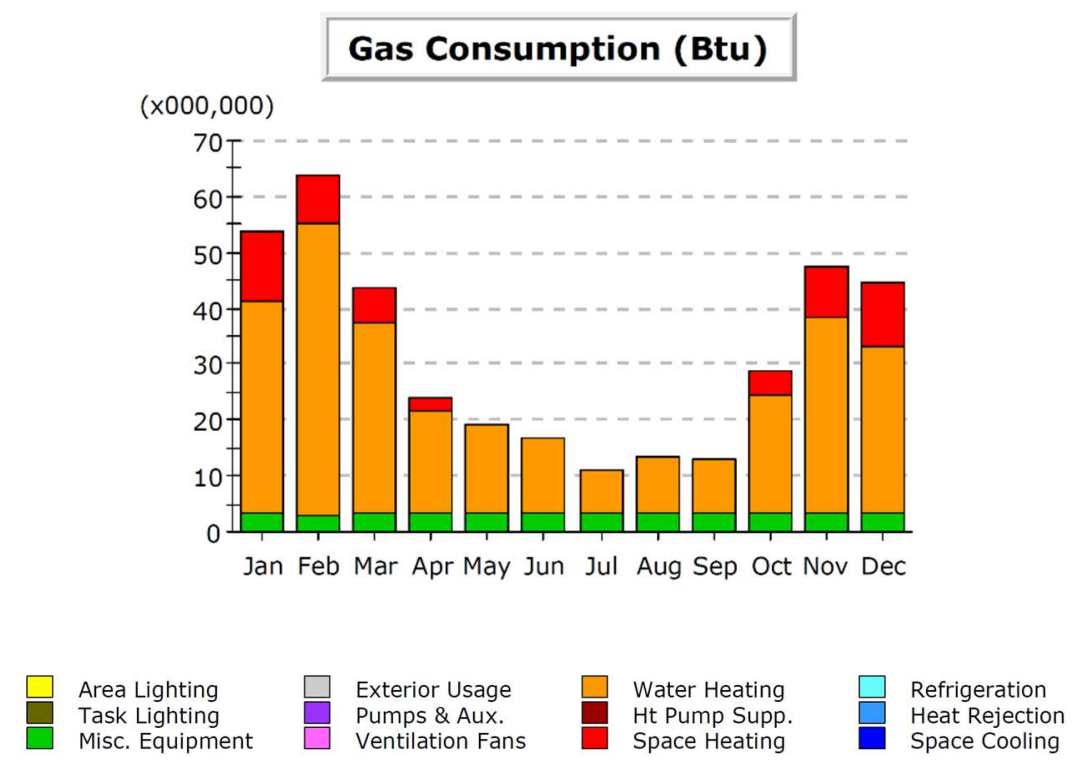

Figure 43: SRE Gas Consumption Chart from eQUEST

Gas Consumption (Btu x,000,000) 


\begin{tabular}{|c|c|c|c|c|c|c|c|c|c|c|c|c|c|}
\hline & Jan & Feb & Mar & Apr & May & Jun & Jul & Aug & Sep & Oct & Nov & Dec & Total \\
\hline Space Cool & - & - & - & - & - & - & - & - & - & - & - & - & 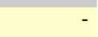 \\
\hline Heat Reject. & - & - & - & - & - & - & - & - & - & - & - & - & - \\
\hline Refrigeration & - & - & - & - & - & - & - & - & - & - & - & - & - \\
\hline Space Heat & 12.32 & 8.93 & 6.18 & 2.50 & 0.18 & - & - & - & 0.27 & 4.46 & 8.99 & 11.21 & 55.05 \\
\hline HP Supp. & - & - & - & - & - & - & - & - & - & - & - & - & - \\
\hline Hot Water & 37.97 & 51.96 & 33.94 & 18.29 & 15.87 & 13.33 & 7.78 & 9.84 & 9.54 & 21.16 & 35.13 & 29.85 & 284.68 \\
\hline Vent. Fans & - & - & - & - & - & - & - & - & - & - & - & - & - \\
\hline Pumps \& Aux. & - & - & - & - & - & - & - & - & - & - & - & - & - \\
\hline Ext. Usage & - & - & - & - & - & - & - & - & - & - & - & - & - \\
\hline Misc. Equip. & 3.35 & 3.02 & 3.35 & 3.27 & 3.35 & 3.25 & 3.36 & 3.35 & 3.25 & 3.36 & 3.20 & 3.36 & 39.46 \\
\hline Task Lights & - & - & - & - & - & - & - & - & - & - & - & - & - \\
\hline Area Lights & - & - & - & - & - & - & - & - & - & - & - & - & \\
\hline Total & 53.64 & 63.92 & 43.47 & 24.06 & 19.39 & 16.58 & 11.15 & 13.19 & 13.06 & 28.99 & 47.32 & 44.43 & 379.19 \\
\hline
\end{tabular}

Figure 44: SRE Gas Consumption Table from eQUEST

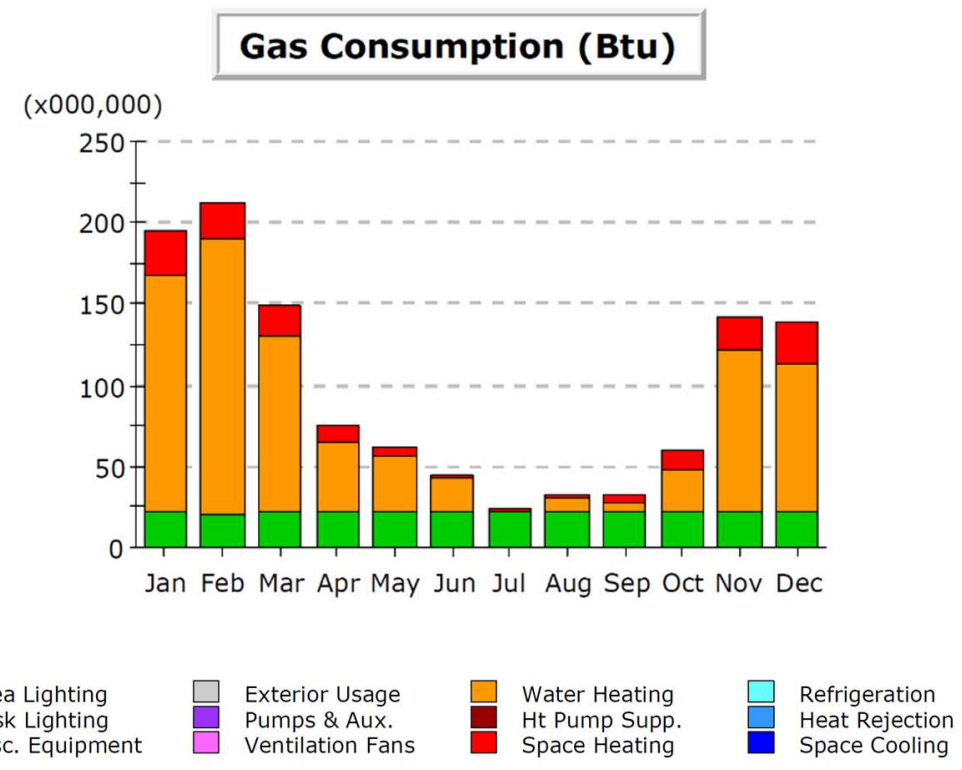

Figure 45: STUD Gas Consumption Chart from eQUEST

Gas Consumption (Btu x,000,000) 


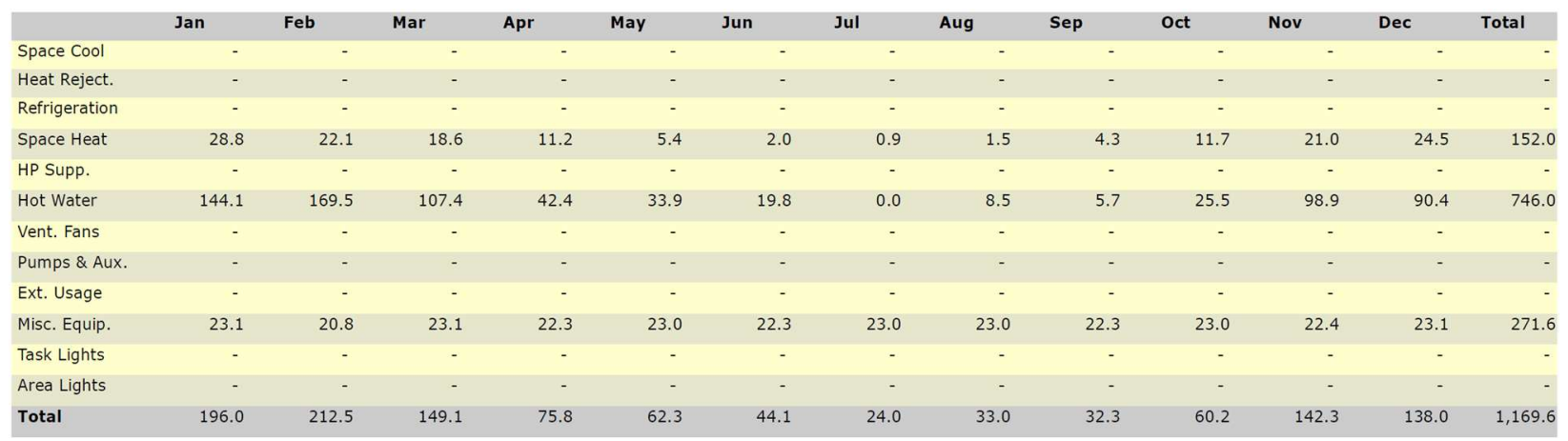

Figure 46: STUD Gas Consumption Table from eQUEST

\begin{tabular}{|c|c|c|c|c|c|c|c|c|c|c|c|c|}
\hline Month & Jan & Feb & Mar & Apr & May & Jun & Jul & Aug & Sep & Oct & Nov & Dec \\
\hline SRE Utility (MBtu) & 53.87 & 65.27 & 43.51 & 24.86 & 19.68 & 16.58 & 11.40 & 13.47 & 13.47 & 29.01 & 47.66 & 44.55 \\
\hline SRE eQUEST (MBtu) & 53.64 & 63.92 & 43.47 & 24.06 & 19.39 & 16.58 & 11.15 & 13.19 & 13.06 & 28.99 & 47.32 & 44.43 \\
\hline STUD Utility (MBtu) & 194.77 & 211.34 & 149.18 & 76.66 & 63.20 & 45.58 & 23.83 & 35.22 & 34.19 & 60.09 & 140.90 & 137.79 \\
\hline $\begin{array}{l}\text { STUD eQUEST } \\
\text { (MBtu) }\end{array}$ & 196.00 & 212.50 & 149.10 & 75.80 & 62.30 & 44.10 & 24.00 & 33.00 & 32.30 & 60.20 & 142.30 & 138.00 \\
\hline
\end{tabular}

Table 11: Gas Consumption Comparison to Prove eQUEST Model Accuracy

The information provided in Table 11 indicates that the models accurately reflect the natural gas usage of the SRE and STUD homes. Now that a reliable model has been established, one can manipulate individual building properties of the SRE house to understand how each element effects the demand on natural gas for space heating. Three variables that have a considerable impact on the energy efficiency of the building were explored: the influence of rammed earth walls, high performance windows, and the presence of a crawlspace. The SRE house model was simulated several more times by changing one of these parameters at a time so that after the first run the building had stud walls, after the second run the building had standard double paned windows, and after the third run the building had a crawlspace. The baseline report for each of these models were taken in order to determine the impact of each building feature. The results of this experiment are summarized in the following table. 


\begin{tabular}{|l|c|c|c|c|c|c|c|c|}
\hline $\begin{array}{l}\text { Increase of Energy Need } \\
\text { by using: }\end{array}$ & Jan & Feb & Mar & $\begin{array}{c}\text { April- } \\
\text { Sept }\end{array}$ & Oct & Nov & Dec & $\begin{array}{c}\text { Total for } \\
\text { Yr }\end{array}$ \\
\hline Stick Frame Walls & $28 \%$ & $32 \%$ & $50 \%$ & n/a & $56 \%$ & $33 \%$ & $29 \%$ & $42 \%$ \\
\hline Double Paned Windows & $19 \%$ & $18 \%$ & $21 \%$ & n/a & $28 \%$ & $20 \%$ & $19 \%$ & $22 \%$ \\
\hline A Crawlspace & $3 \%$ & $0 \%$ & $-1 \%$ & n/a & $15 \%$ & $10 \%$ & $5 \%$ & $8 \%$ \\
\hline North Orientation & $4 \%$ & $8 \%$ & $10 \%$ & n/a & $12 \%$ & $8 \%$ & $3 \%$ & $7 \%$ \\
\hline
\end{tabular}

Table 12: Influence of Specific Building Properties on the Energy Demand of the Model Structure

From the data provided in

\begin{tabular}{|l|c|c|c|c|c|c|c|c|}
\hline \begin{tabular}{|l|c|} 
Increase of Energy Need \\
by using:
\end{tabular} & Jan & Feb & Mar & $\begin{array}{c}\text { April- } \\
\text { Sept }\end{array}$ & Oct & Nov & Dec & \begin{tabular}{c} 
Total for \\
\hline Stick Frame Walls
\end{tabular} \\
\hline Double Paned Windows & $28 \%$ & $32 \%$ & $50 \%$ & n/a & $56 \%$ & $33 \%$ & $29 \%$ & $42 \%$ \\
\hline A Crawlspace & $19 \%$ & $18 \%$ & $21 \%$ & n/a & $28 \%$ & $20 \%$ & $19 \%$ & $22 \%$ \\
\hline North Orientation & $3 \%$ & $0 \%$ & $-1 \%$ & n/a & $15 \%$ & $10 \%$ & $5 \%$ & $8 \%$ \\
\hline
\end{tabular}

Table 12: Influence of Specific Building Properties on the Energy Demand of the Model Structure

it is very clear to see that the largest influence on energy need for space heating is wall material selection. By using stick frame walls, the coldest months of the year require $28-32 \%$ more energy to maintain the same temperature. During the coldest months of the year, the SRE building also benefits considerably from the use of triple paned windows considering the fact that if they were downgraded to double pane windows (like the ones used in the STUD house) the building would require about $19 \%$ more energy to maintain the same living temperature. Very interestingly, the crawlspace does not appear to be a major contributor to the thermal performance of the building since it has a very low impact during the coldest months of the year.

The above parameters that were adjusted in the SRE building model account for $79 \%$ of the improved energy performance that is seen in the SRE structure when comparing it to the STUD structure. The remining $21 \%$ improvements are most likely spread among several other factors 
such as: the age and efficiency of the hot water heater, air leakage of the building, and the loss of energy efficiency by altering the set temperature on a daily basis. 


\section{CONCLUSIONS AND FUTURE WORK}

The research presented in this report indicates that SRE construction proposes a viable and ready to use construction method that reduces the cost of construction and operation of a one-ortwo story building where land cost is not prohibitive, while also significantly reducing the volume of $\mathrm{CO}_{2}$ emissions that is released over the entire lifespan of the building. SRE buildings are made from locally sourced renewable materials that do not negatively impact the environment during use or termination.

The course of this research project presented several limitations for SRE structures. The accumulation of moisture on windowsills and door frames can be addressed by one of several ways. The air exchanger in the building needs to be reselected for a higher relative humidity since SRE structures are known to have more moisture in the air during the winter compared to stud homes. This could also be addressed by using plastic or fiber reinforced windowsills and door frames since the plastic would act as a thermal barrier, unlike the metal frames that act as a thermal bridge. Another limitation that need to be addressed is the accumulating heat in the building during the summer months. This can be resolved by installing locks on the windows that allow them to fix in the open position. Screens on the windows would also allow the residents to leave the windows open without the possibility of bugs coming into the home. The third important limitation is the inability to reach $71 \mathrm{~F}$ inside of the home when it is below $-20 \mathrm{~F}$ for several weeks in the winter. This can easily be addressed by using a dual hot air/hot water furnace system that heats the water for the in-floor heating system as well as provide backup hot air for "emergency cold" weather needs. This is a relatively common solution is readily available on the market as a way to supplement the heat of an in-floor heating system. 
Using the data gathered from the HOBOlink data loggers and the utility information collected, the following conclusions can be made:

- heating one square foot in a traditional stud construction home costs $\sim 2.3$ times as much compared to an SRE house,

- each square foot in a stud constructed house releases $\sim 2.3$ times the amount of $\mathrm{CO}_{2}$ emissions compared to an SRE home,

- the SRE home costs $56 \%$ less to heat,

- over a 50-yr lifespan an SRE structure will save $\$ 10.50$ per square foot on natural gas and prevent $1015.66 \mathrm{lbs}$. of $\mathrm{CO}_{2}$ per square foot from entering the atmosphere.

The AK Warm and eQUEST modeling data were also useful to this project to validate the field data that were recorded for the SRE and STUD structure. The SRE model in eQUEST was then altered considering one major building parameter at a time in order to better understand the energy savings of each feature. These findings show that over the course of the year:

- the rammed earth walls alone improve the energy efficiency by $42 \%$,

- high-performance, tripled-paned windows improve the energy efficiency by $22 \%$,

- absence of a crawlspace improved the energy efficiency by $8 \%$,

- and having the length of the building facing the south direction improved the energy efficiency by $7 \%$.

This project has a high emphasis on the building's ability to efficiently retain warm air inside of the building during very cold months. In order to determine if this construction style is truly advantageous, another research project similar-to this one must be conducted in an area that experiences all four seasons. Bringing this project to the lower forty-nine states would allow it to 
receive more attention from larger building contractors that are looking for cheaper building practices as well as homeowners that are looking for an aesthetically pleasing way to reduce their overall utility cost.

If this project were duplicated in another area with four seasons there would be a great potential to reduce the number of variables in a comparison study between two homes. The researcher could construct two identical homes, but, one with SRE walls, and the other with stud walls. This would mean that both buildings have the same square footage, floorplan, north orientation, window technology, window-to-wall ratio, air leakage, HVAC equipment, utility source, and foundation style. This would drastically increase the accuracy of the comparison between the two structures and much more effectively deliver an understanding of the relationship between wall material and thermal performance of the structure. 


\section{REFRENCES}

ASTM Standard E2392/E2392M, 2016, “Standard Guide for Design of Earthen Wall Building Systems," ASTM International, West Conshohocken, PA, 2016, DOI: 10.1520/E2392_E2392M-10R16.

Boduch, M., Fincher, W. (2009). "Standards of Human Comfort: Relative and Absolute." Center for Sustainable Development, UTSoA - Meadows Seminar

Bui, B., Hans, S., Morel, J. (2011). "First exploratory study on dynamic characteristics of rammed earth buildings.” Engineering Structures, 33, 3690-3695.

Hall, M., Allinson, D. (2009). “Assessing the effects of soil grading on the moisture contentdependent thermal conductivity of stabilized rammed earth materials." Applied Thermal Engineering, 29, 740-747.

Hall, M., Djerbib, Y. (2004). "Rammed earth sample production: context, recommendations and consistency." Construction and Building Materials, 18, 281-286.

Heathcote, K. (2011). "The thermal performance of earth buildings." Informes de la Construccion, 63, $117-126$.

IP, K., Miller, A. (2009). "Thermal behavior of and earth-sheltered autonomous building the Brighton Earthship.” Renewable Energy, 34, 2037-2043.

Jayasinghe, C., Kamaladasa, N., (2007). "Compressive strength characteristics of cement stabilized rammed earth walls." Construction and Building Materials, 21, 1971-1976.

Liang, R., GangaRao, H., Lei, Y., Li, Y., Stanislawski, D., Jiang, Y. (2013). "Nondestructive Evaluation of Historic Hakka Rammed Earth Structures.” Sustainability, 5 (1), 298315. 
Liang, R., GangaRao, H., Stanislawski, D., Lei, Y. (2011a). "Thermal and Mechanical Responses of Hakka Tulou Rammed Earth Structures: Lessons to Be Learned for a Sustainable Future, Research Paper.” Proceedings of 2011 NSF Engineering Research and Innovation Conference, Atlanta, Georgia.

Liang, R. (2013). "Historic Hakka Architecture Could be Key for Future Sustainable Buildings.” SangSaeng, 36 (1), 10-13.

Liang, R., Stanislawski, D., GangaRao, H. (2011b). "Structural Responses of Hakka Rammed Earth Buildings under Earthquake Loads.” Proceedings of International Symposium on Innovation \& Sustainability of Structures in Civil Engineering, Xiamen University, China.

Maniatidis, V., Walker, P. (2001). "A Review of Rammed Earth Construction for DTi Partners in Innovation Project 'Developing Rammed Earth for UK Housing.’”

Maniatidis, V., Walker, P. (2008). "Structural Capacity of Rammed Earth in Compression." Journal of Materials in Civil Engineering, 3, 230-238.

Mileto, C., Vegas, F., Cristini, V. (2012). "Rammed Earth Conservation.” CRC Press Technology and Engineering.

Morel, J., Mesbah, A., Oggero, M., Walker, P. (2001). "Building houses with local materials: means to drastically reduce the environmental impact of construction." Building and Environment, 36, 1119-1126.

NOAA/National Weather Service. (2014). “The Heat Index Equation.” National Weather Services - Weather Prediction Center.

Pacheco-Torgal, F., Jalali, S. (2012). "Earth construction: Lessons from the past for future eco-friendly construction." Construction and Building Materials, 29, 512-519. 
Serrano, S., Gracia, A., Cabeza, L. (2016). “Adaption of rammed earth to modernize construction systems: Comparative study of thermal behavior under summer conditions." Applied Energy, 175, 180 - 188.

Soebarto, V. (2007). "A study of the indoor thermal performance of rammed earth houses." $41^{s t}$ Annual Conference of the Architectural Science Association, 239 - 247.

Soebarto, V. (2009). "Analysis of indoor performance of houses using rammed earth walls." $11^{\text {th }}$ Annual International IBPSA Conference, $1530-1538$.

Stanislawski, D. (2011). "Structural Responses and Finite Element Modeling of Hakka Tulou Rammed Earth Structures.” West Virginia University Department of Civil and Environmental Engineering.

Taylor, P., Fuller, R., Luther, M. (2008). "Energy use and thermal comfort in a rammed earth office building." Energy and Buildings, 40, 793 - 800.

Treloar, G., Owen, C., Ray, R. (2001). "Environmental assessment of rammed earth construction systems." Structural Survey - MCB University Press, 19, 99-105.

Venkatarama Reddy, B., Kumar, P. (2010) “Embodied energy in cement stabilized rammed earth walls." Energy and Buildings 42, 380-385.

Yelland, R. (2013). "History, Made for Tomorrow: Hakka Tulous." Sustainability, 5(11), 4908-4919. 


\section{Appendix}

\subsection{Additional Project Documents}

The following list of references is provided to guide the reader to additional resources regarding this progression of this project sorted in chronological order:

Johnson, D., Liang, R., GangaRao, H. (2019-2020). “Stabilized Rammed Earth (SRE) Building, Quarterly Reports to HUD." WVU.

Liang, R. (2019). "Hakka Tulou Stories: From Yongding of China to Palmer of Alaska.” Department Seminar, Huaqiao University, Xiamen, China.

Liang, R., GangaRao, H. (2018). "Evolution of Hakka Tulou from Fujian Yongding to Alaska Anchorage." The $3^{\text {rd }}$ New York Hakka Conference, Manhattan Chinatown, New York.

Liang, R., GangaRao, H. (2018). "Initial Living Comfort Data from Embedded Sensors of the Stabilized Rammed Earth Building: Modernizing A Traditional Building Material for an Extreme Climate, Progress Report, Submitted to US Housing and Urban Development (HUD)."WVU.

Harper, J., Liang, R., GangaRao, H. (2016). “A Demonstration of Stabilized Rammed Earth: Modernizing A Traditional Building Material for An Extreme Climate.” Report to Aleutian Housing Authority (AHA), Anchorage, Alaska and US-HUD.

Harper, J., Liang, R., GangaRao, H. (2016). "Building a Model Home in the Arctic Based on Hakka Principles." 5th Toronto Hakka Conference, York University, Toronto, Canada.

Liang. R. (2015). “Hakka Earth Buildings as World Heritage.” First New York Hakka Conference, Cantor Film Center, NYU, New York, NY. 
Liang, R., GangaRao, H. (2012). "Engineering Values of Historic Hakka Rammed Earth Buildings.” Toronto Hakka Conference, York University, Keele Campus, Toronto, Canada.

Liang, R., GangaRao, H., Lei, Y., Stanislawski, D., Jiang, Y. (2011). "Nondestructive Evaluation of Historic Hakka Rammed Earth Structures.” Proceedings of International Symposium on Innovation \& Sustainability of Structures in Civil Engineering, Xiamen University, China.

Liang, R. (2011). "Material and Structural Response of Historic Hakka Rammed Earth Structures, Technical Highlight.” Proceedings of 2011 NSF Engineering Research and Innovation Conference, Atlanta, Georgia.

Liang, R. GangaRao, H. (2011). "SGER: Material and Structural Response of Historic Hakka Rammed Earth Structures.” NSF Award ID\# 0908199 Final Report, WVU, Submitted on 9/27/2011.

Liang, R., GangaRao, H., Stanislawski, D., Lei, Y., Li, Y., Jiang, Y. (2010). “Material and Structural Response of Historic Hakka Rammed Earth Structures." Proceedings of the 85th Annual Meeting of the West Virginia Academy of Science, p32, Morgantown, West Virginia.

Liang, R. GangaRao, H. (2010). "SGER: Material and Structural Response of Historic Hakka Rammed Earth Structures.” NSF Award ID\# 0908199 Annual Report, WVU, Submitted on $11 / 30 / 2010$.

Liang, R., Ostrowski, J., Ueda, M. (2010). "History, Made for Tomorrow - Hakka Tulous.” US History Channel/AETN Documentary Film, New York, NY. 
Liang, R. GangaRao, H. (2009). "SGER: Material and Structural Response of Historic Hakka Rammed Earth Structures.” NSF Award ID\# 0908199 Annual Report, WVU, Submitted on $12 / 30 / 09$.

Liang, R., GangaRao, H. (2009). "Hakka Tulou and Science: A NSF Project Prospectus." Forum on Hakka Tulous: Lessons to Be Learned, Past, Present and Future, Xiamen University, Xiamen, China.

Liang, R., Ostrowski, J. (2009). "Launching International Hakka Tulou Alliance (IHTA)." Forum on Hakka Tulous: Lessons to Be Learned, Past, Present and Future, Xiamen University, Xiamen, China.

Liang, R., GangaRao, H., Ostrowski, J., Lei, Y. (2009). “Applying Hakka Wisdom to Future Sustainable Structures: A Proposal.” Forum on Hakka Tulous: Lessons to Be Learned, Past, Present and Future, Xiamen University, Xiamen, China. 


\subsection{Additional Infrared Images}

\subsubsection{Infrared Photos Taken from inside of SRE house}

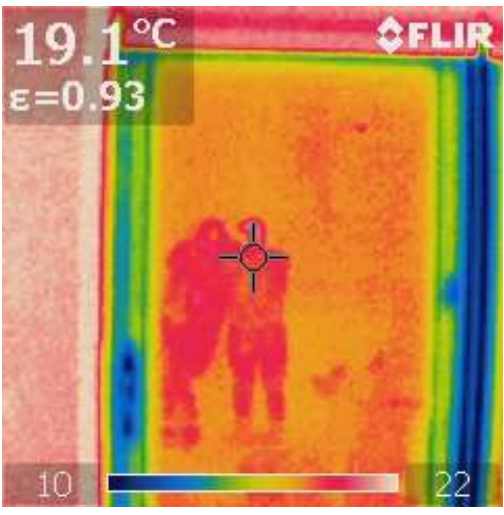

Figure 47: South Wall Sliding Glass Door 1

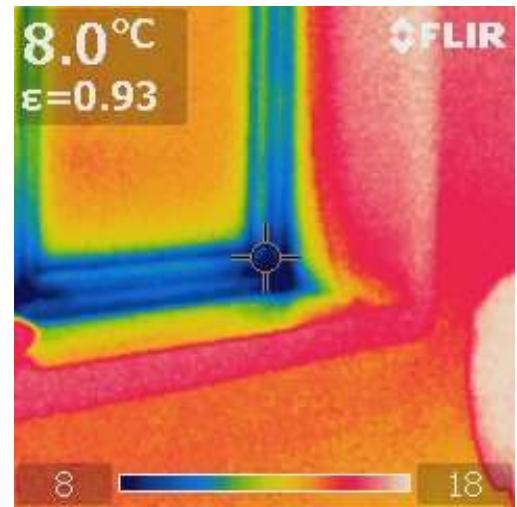

Figure 49: South Wall Sliding Glass Door 2 (Bottom Corner View)

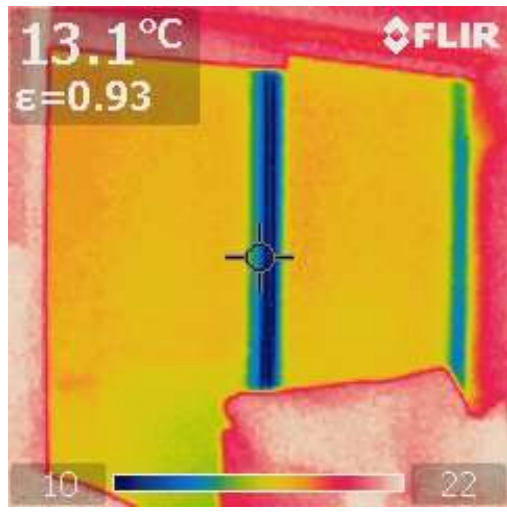

Figure 48: South Wall Sliding Glass Door 2

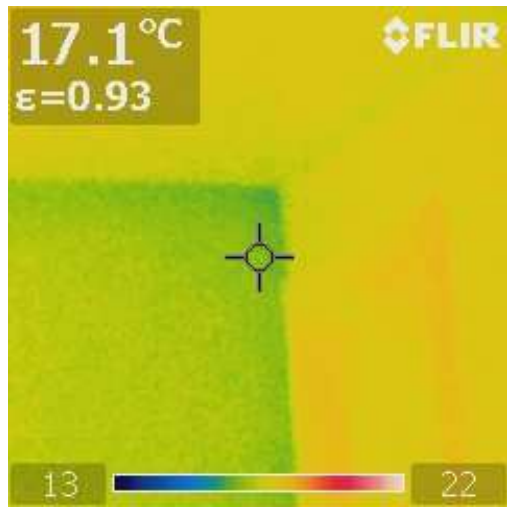

Figure 50: North-East Interior Ceiling Corner - Guest Bedroom 


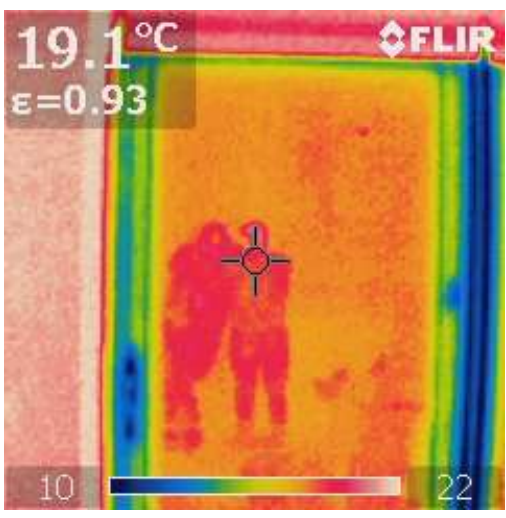

Figure 51: South Wall Sliding Glass Door 1

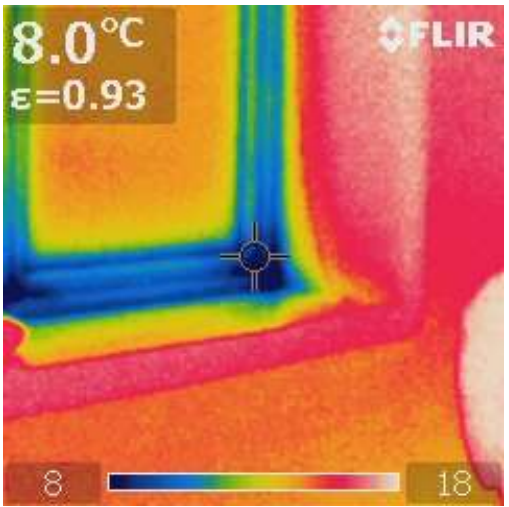

Figure 53: South Wall Sliding Glass Door 2 (Bottom Corner View)

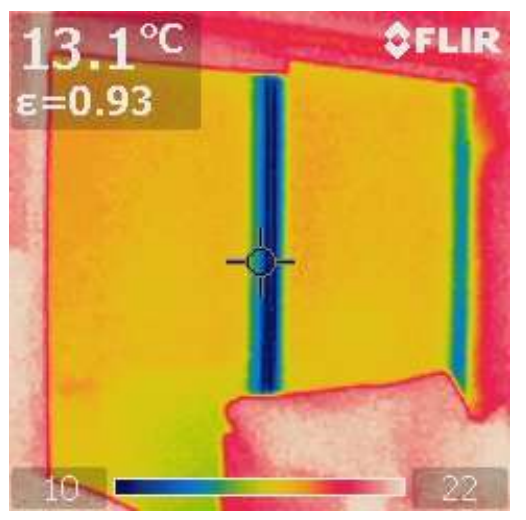

Figure 52: South Wall Sliding Glass Door 2

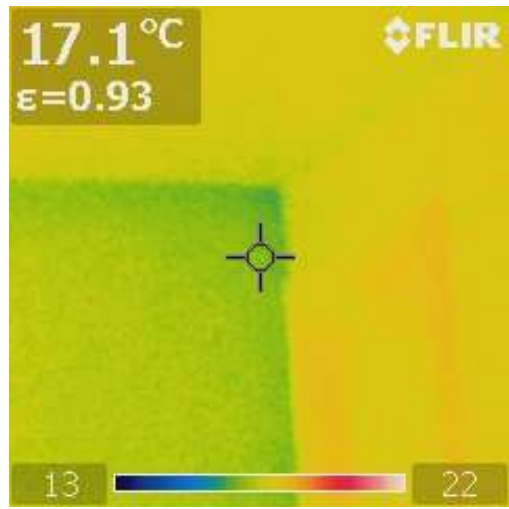

Figure 54: North-East Interior Ceiling Corner - Guest Bedroom 


\subsubsection{Infrared Photos Taken from Outside of the SRE House}

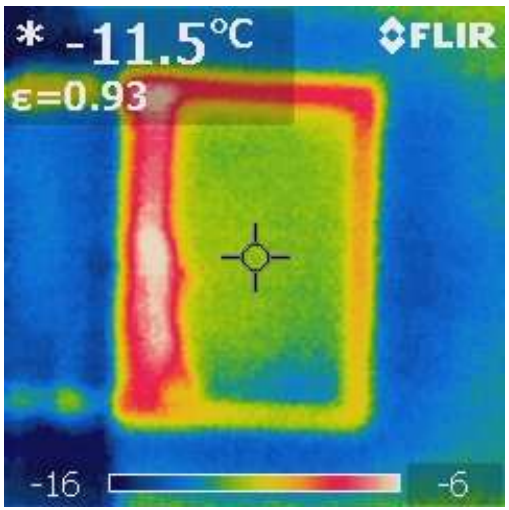

Figure 55: South Wall Window 3 - Master Bedroom Window

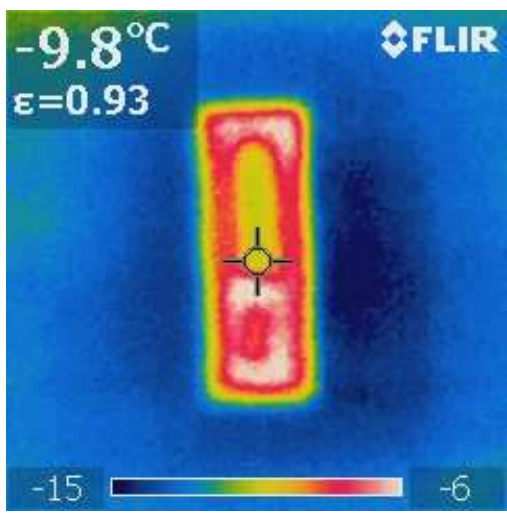

Figure 57: South Wall Window 2 - Master Bathroom Window

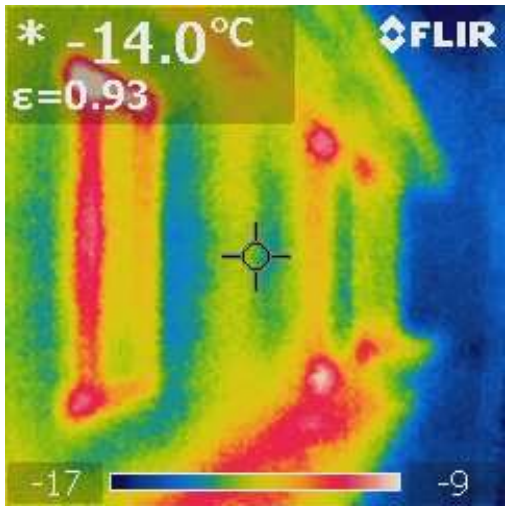

Figure 56: View of South Wall

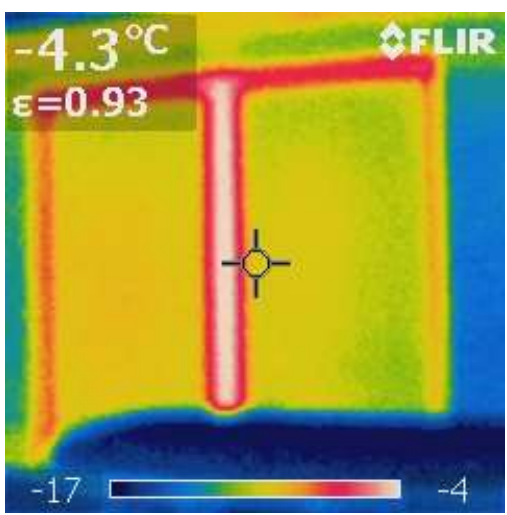

Figure 58: South Wall Sliding Glass Door 2 


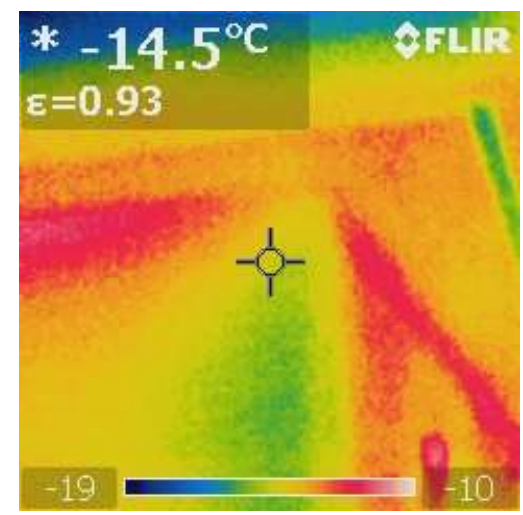

Figure 59: South-West Wall Corner

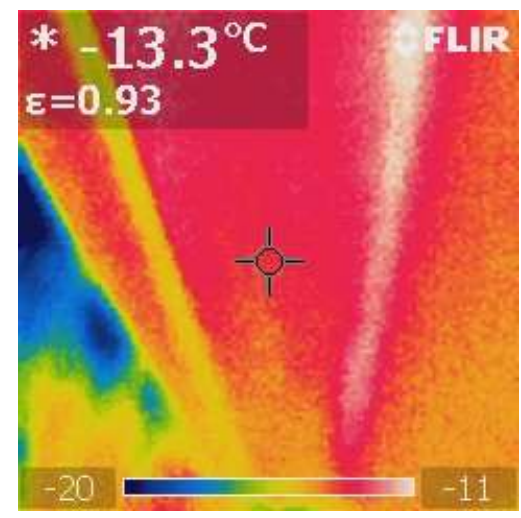

Figure 61: West Wall Roof Overhang

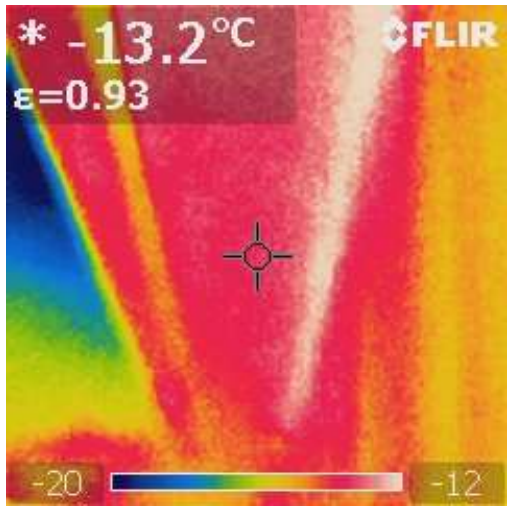

Figure 63: North Wall Roof Overhang

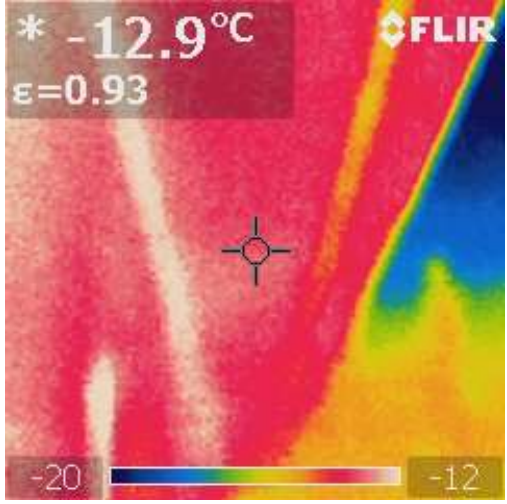

Figure 60: South Roof Wall Overhang

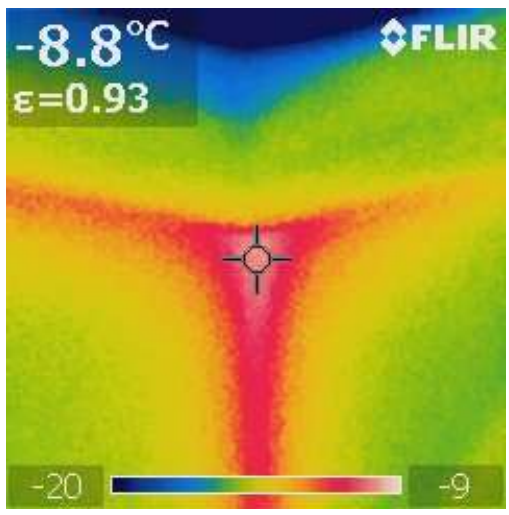

Figure 62: West Wall Convex Corner

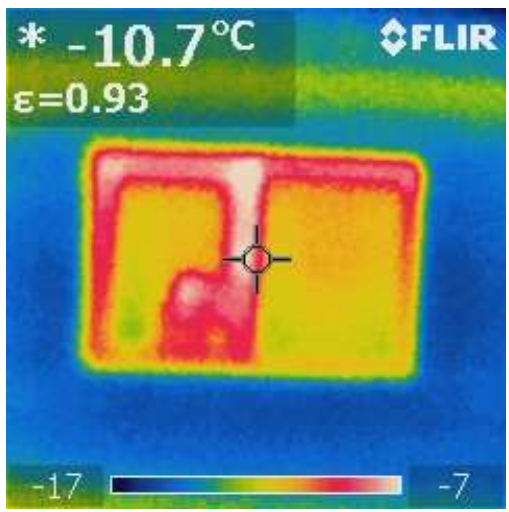

Figure 64: North Wall Window 1 - Guest Bedroom 


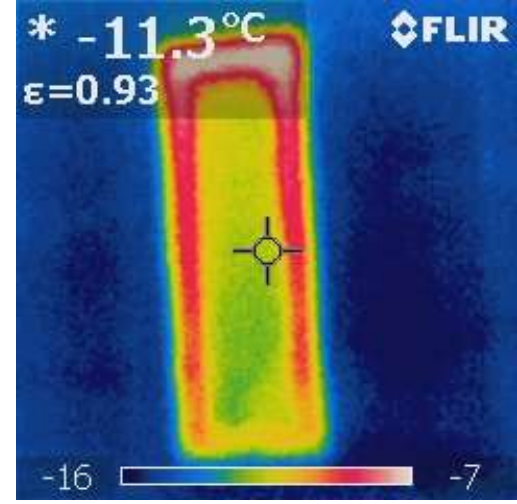

Figure 65: North Wall Window 4 - Entryway Window 1

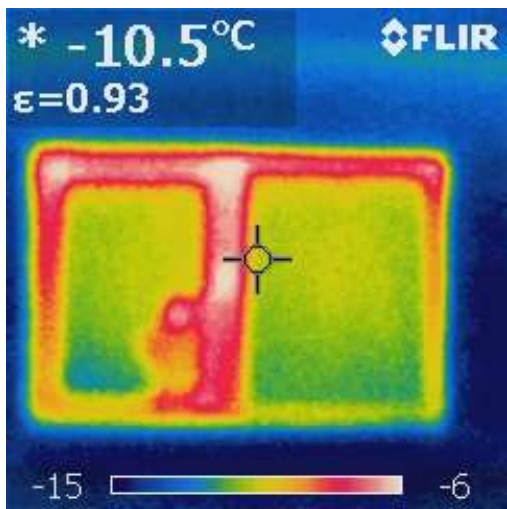

Figure 67: North Wall Window 3 - Office

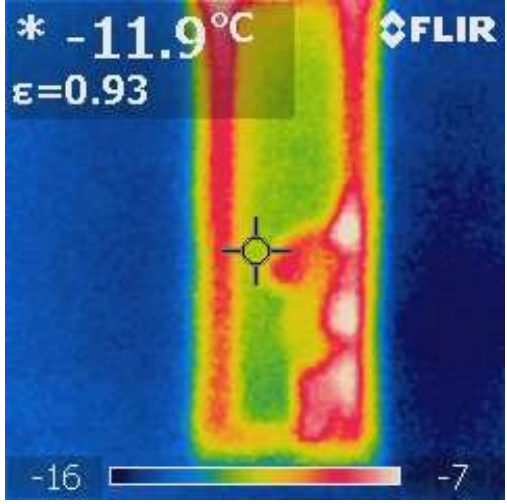

Figure 66: East Wall Window 1 - Entryway Window 2

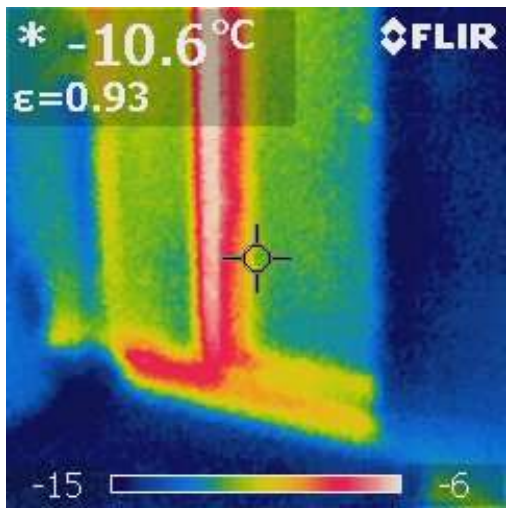

Figure 68: East Wall Front Door (Bottom) 


\subsubsection{Infrared Photos Taken from Outside of STUD House}

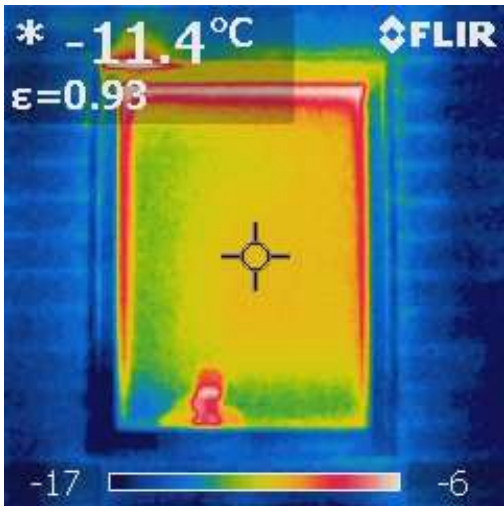

Figure 69: West Wall Window 1 -Laundry Room

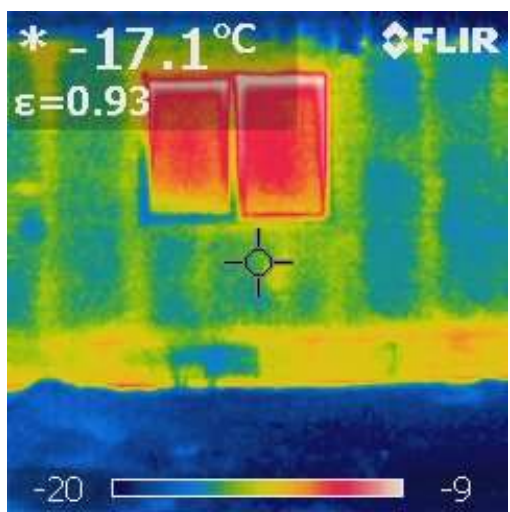

Figure 71: West Wall Window 3 - Guest Bedroom 1

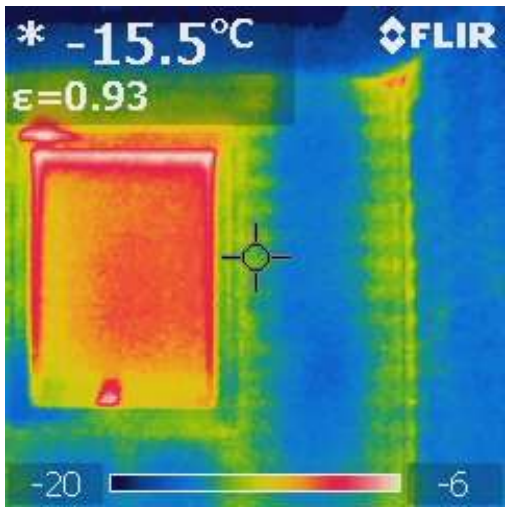

Figure 70: West Wall Window 2 - Living Room

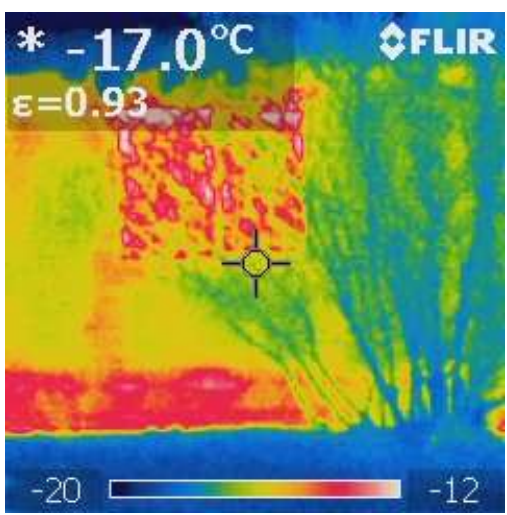

Figure 72: West Wall Window 4 - Guest Bedroom 2 


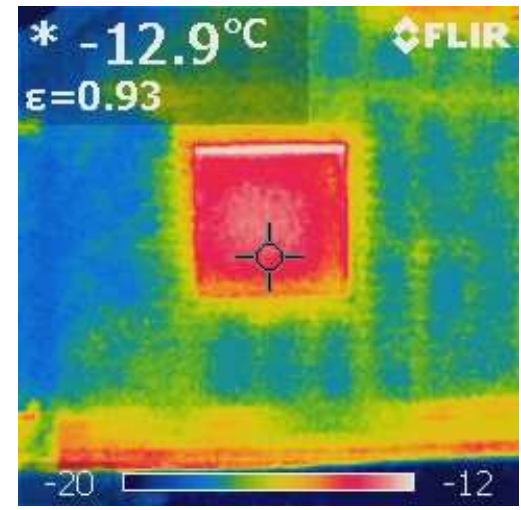

Figure 73: West Wall Window 5 - Sunroom

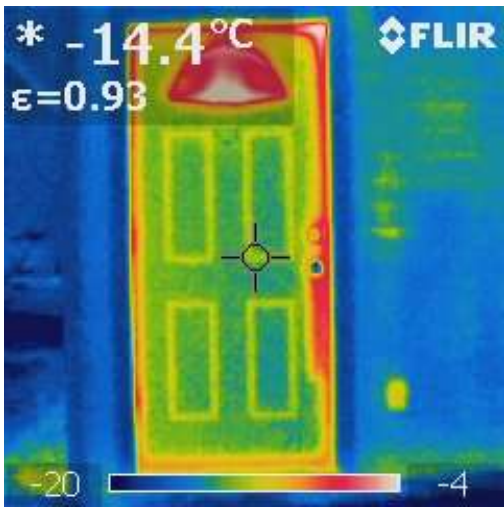

Figure 75: East Wall Door - Office

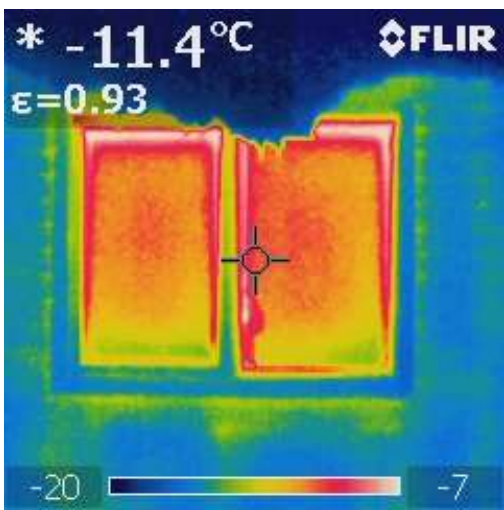

Figure 77: East Wall Window 2 - Master Bedroom

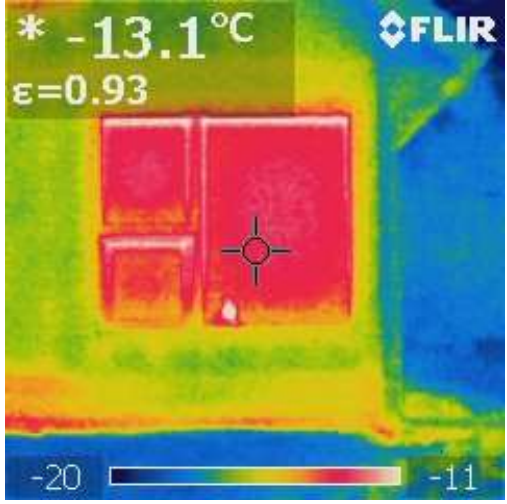

Figure 74: West Wall Window 6 - Sunroom

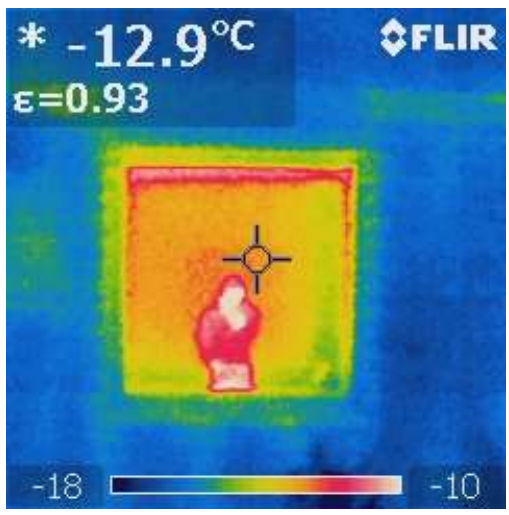

Figure 76: East Wall Window 1 - Office

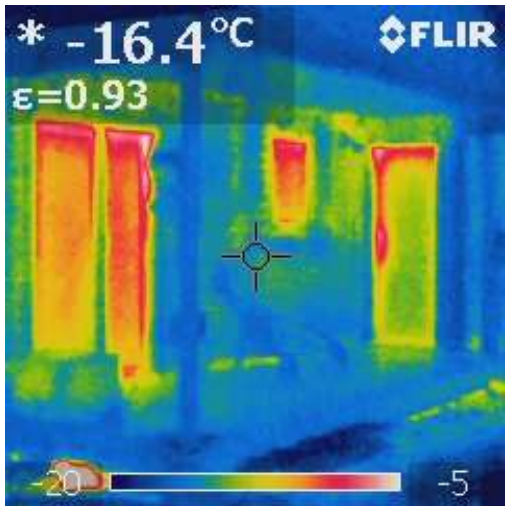

Figure 78: East Wall Back Patio - Sliding Glass Door, Kitchen Window, Kitchen Door 


\subsection{HOBOlink Data Results}

The following figures (Figure 79 though Figure 108) pertain to the information in Section 4.3.1 HOBOlink Data Logs. 


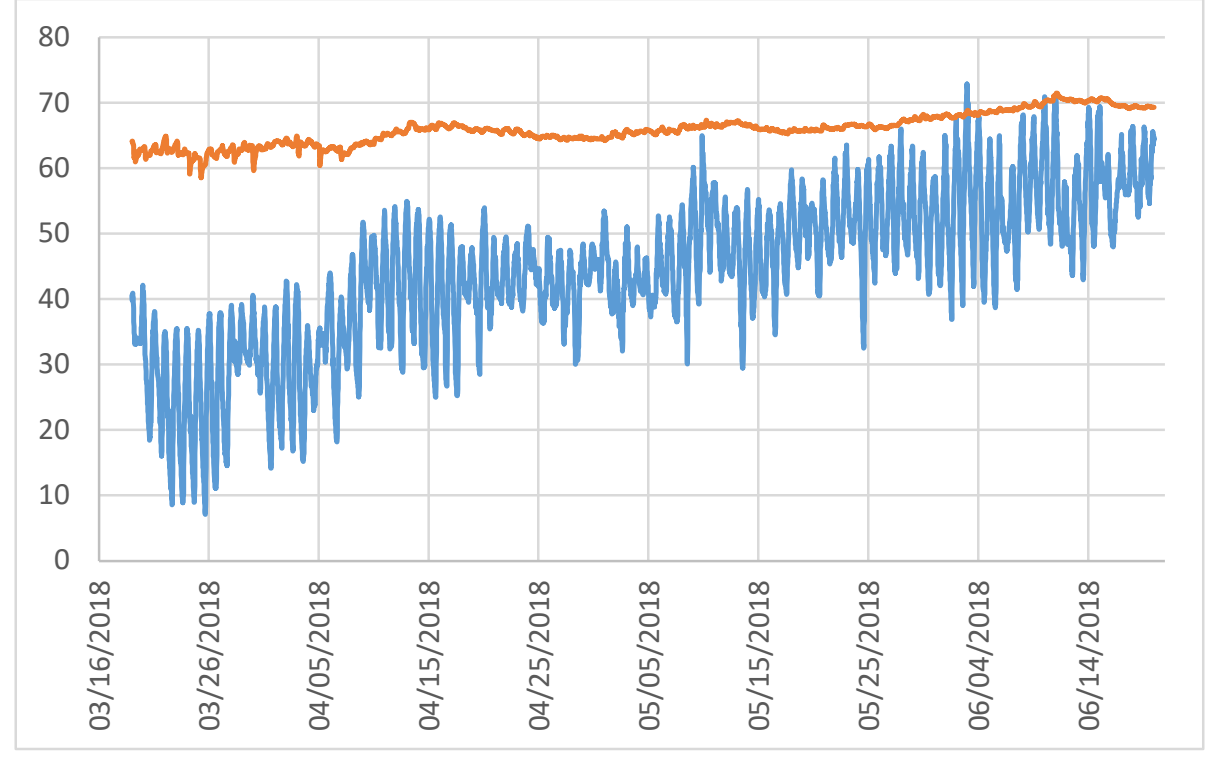

Figure 79: Spring 2018 Temps

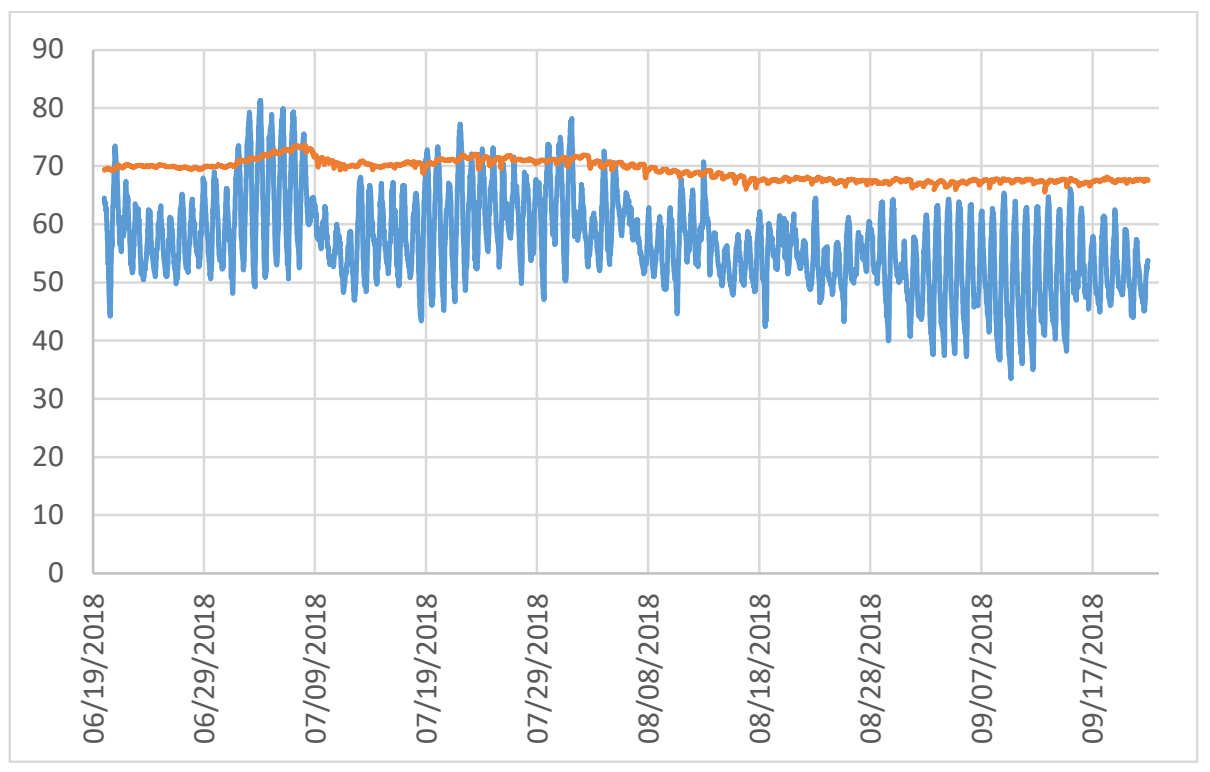

Figure 81: Summer 2018 Temps

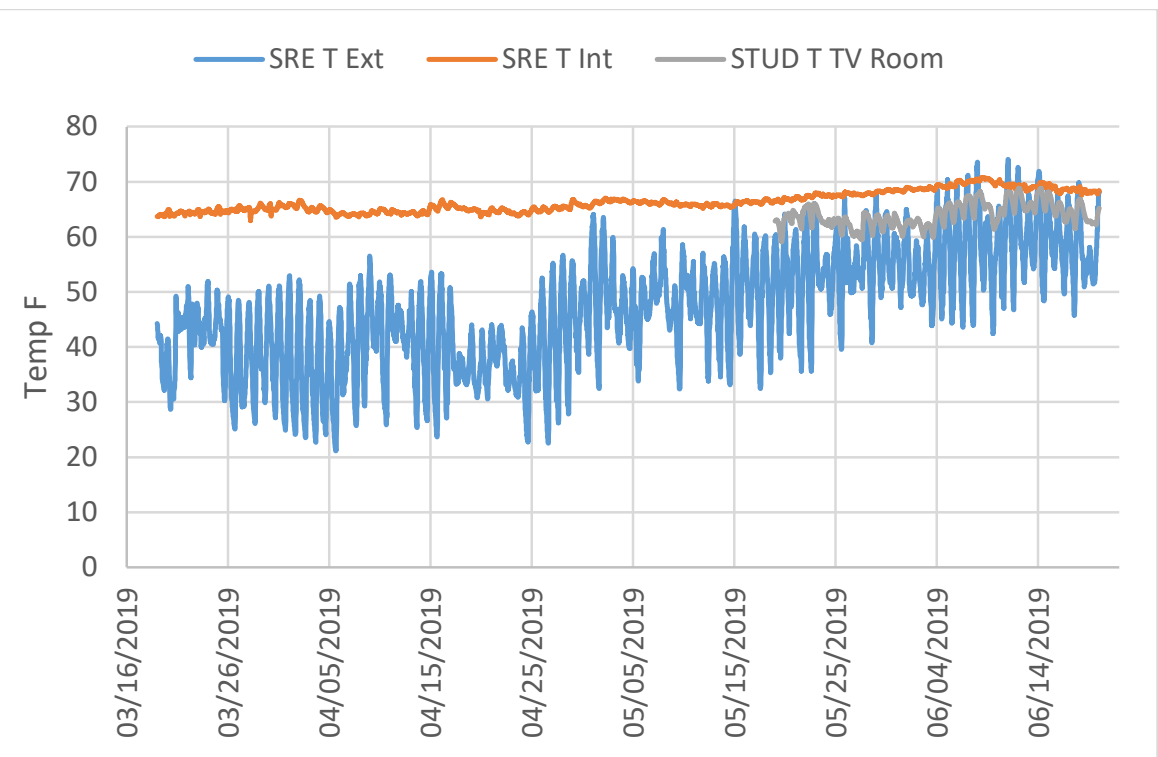

Figure 80: Spring 2019 Temps

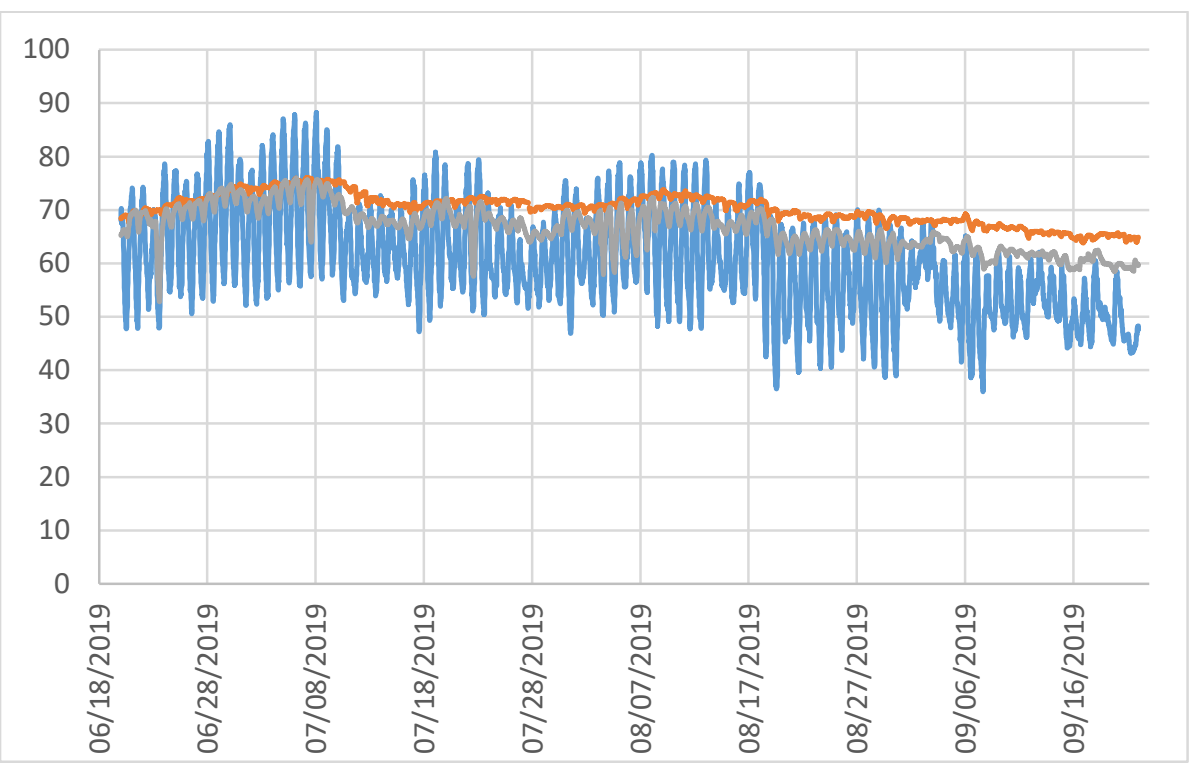

Figure 82: Summer 2019 Temps 


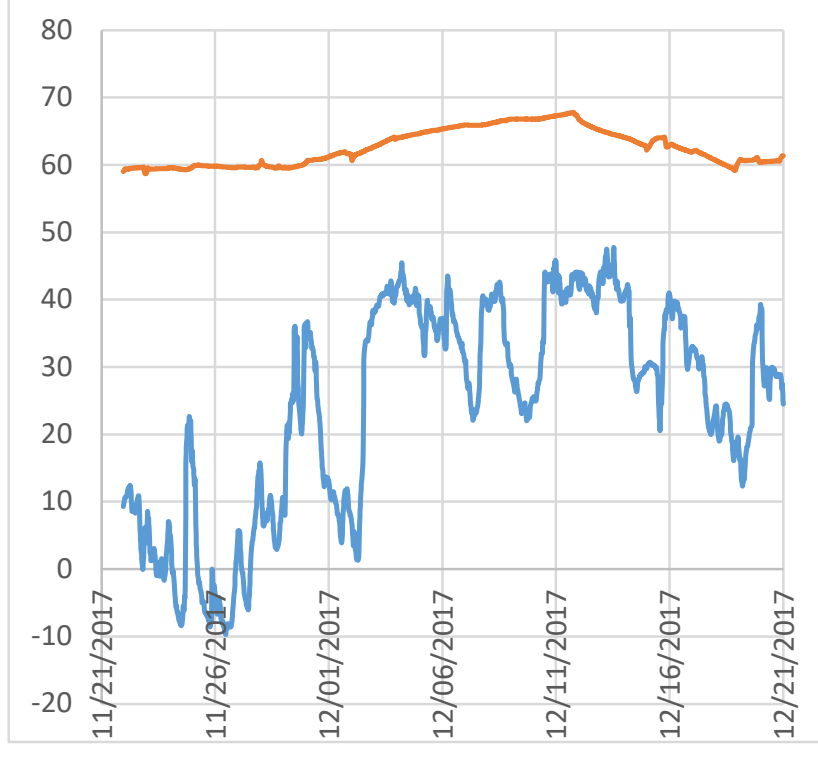

Figure 83: Fall 2017 Temps

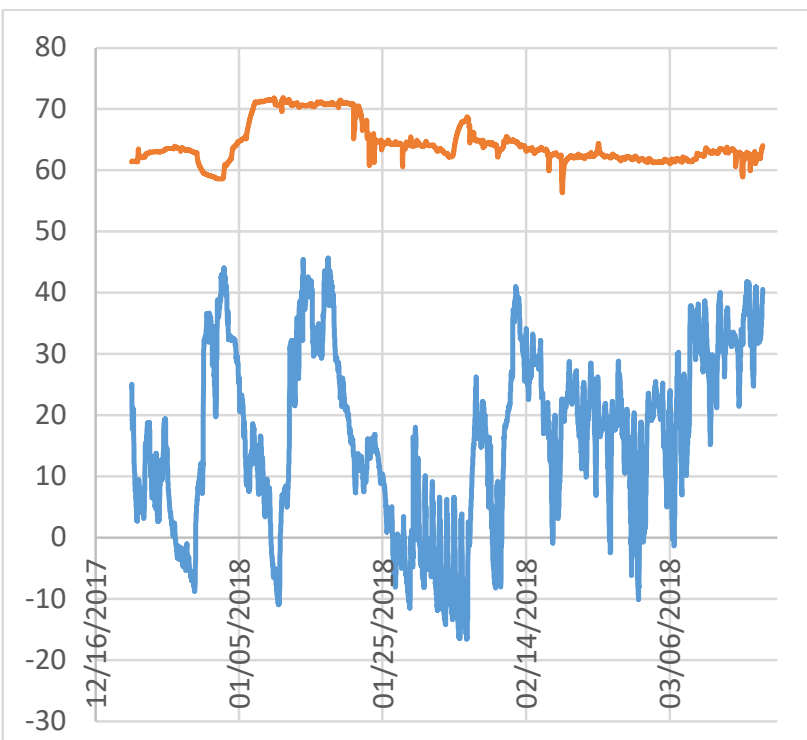

Figure 86: Winter 2017 Temps

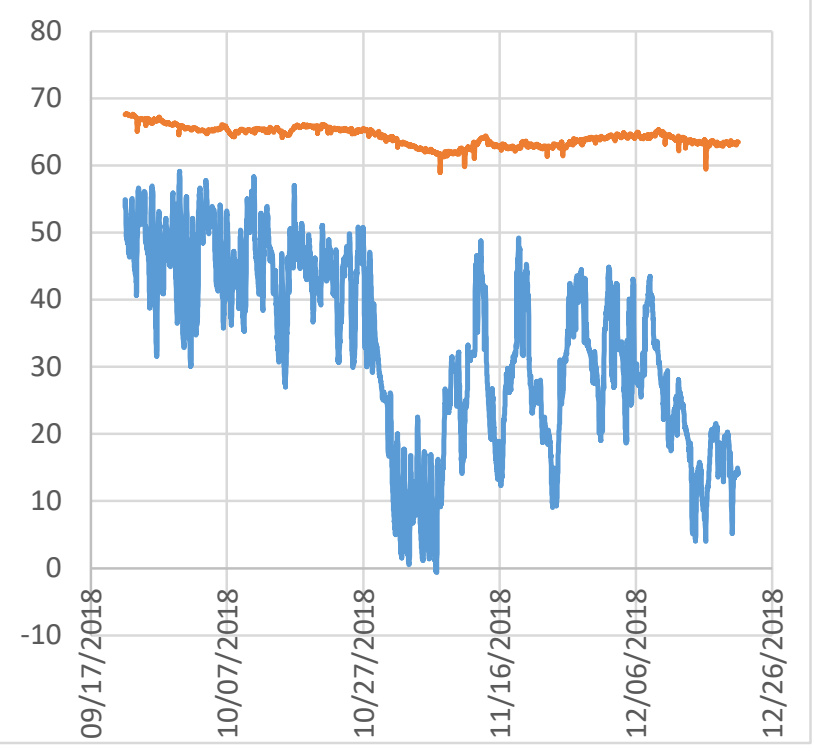

Figure 84: Fall 2018 Temps

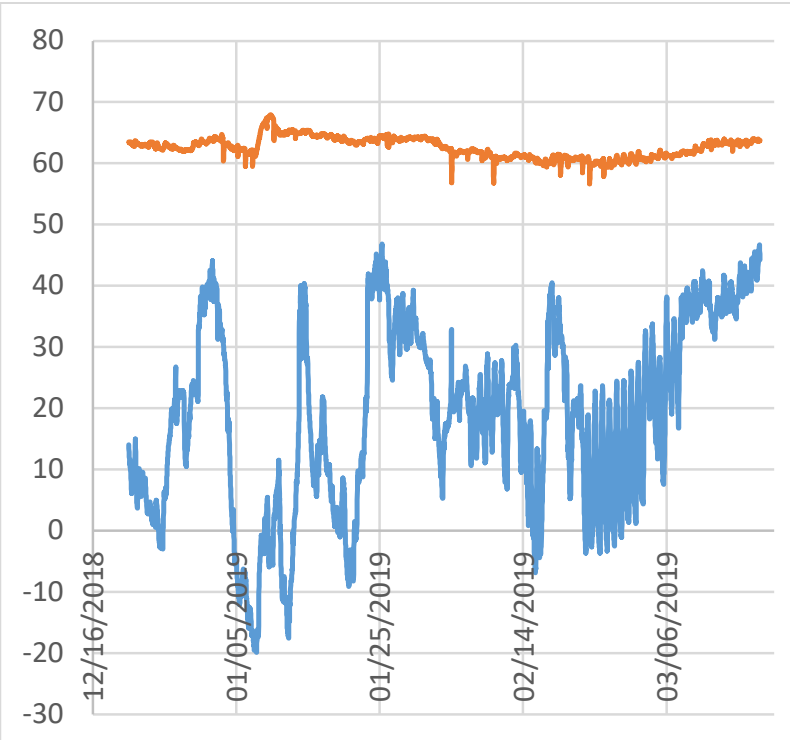

Figure 87: Winter 2018 Temps

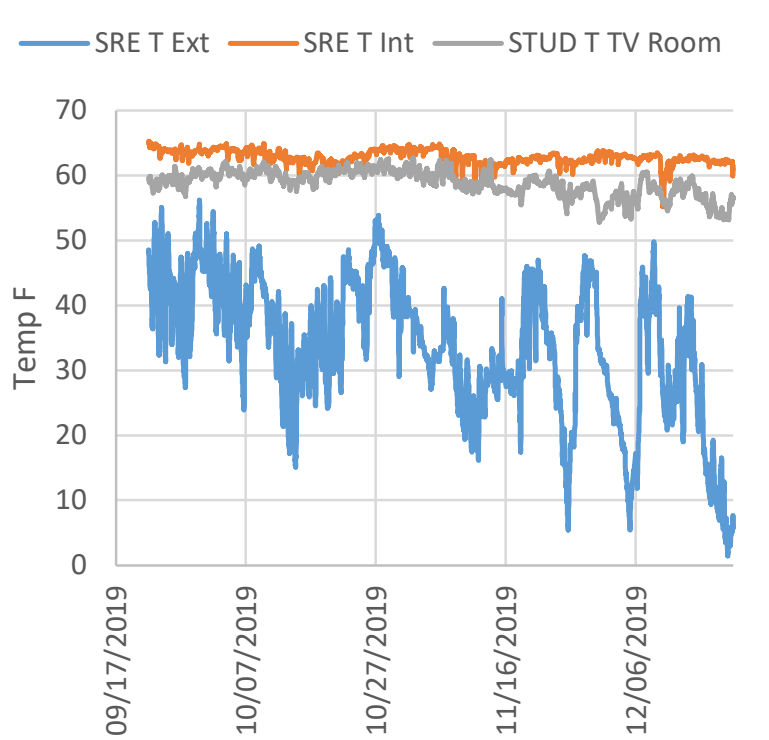

Figure 85: Fall 2019 Temps

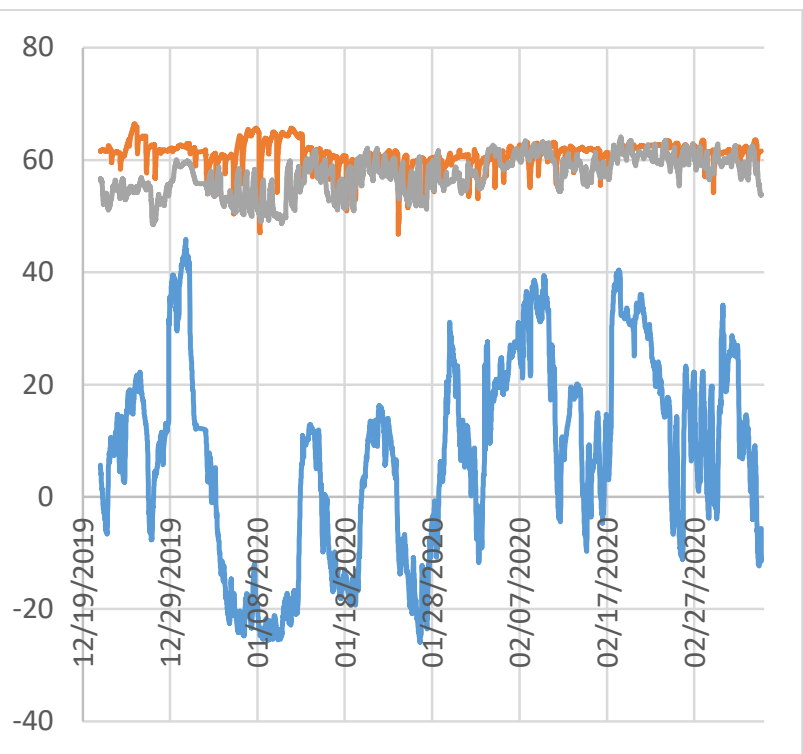

Figure 88: Winter 2019 Temps 


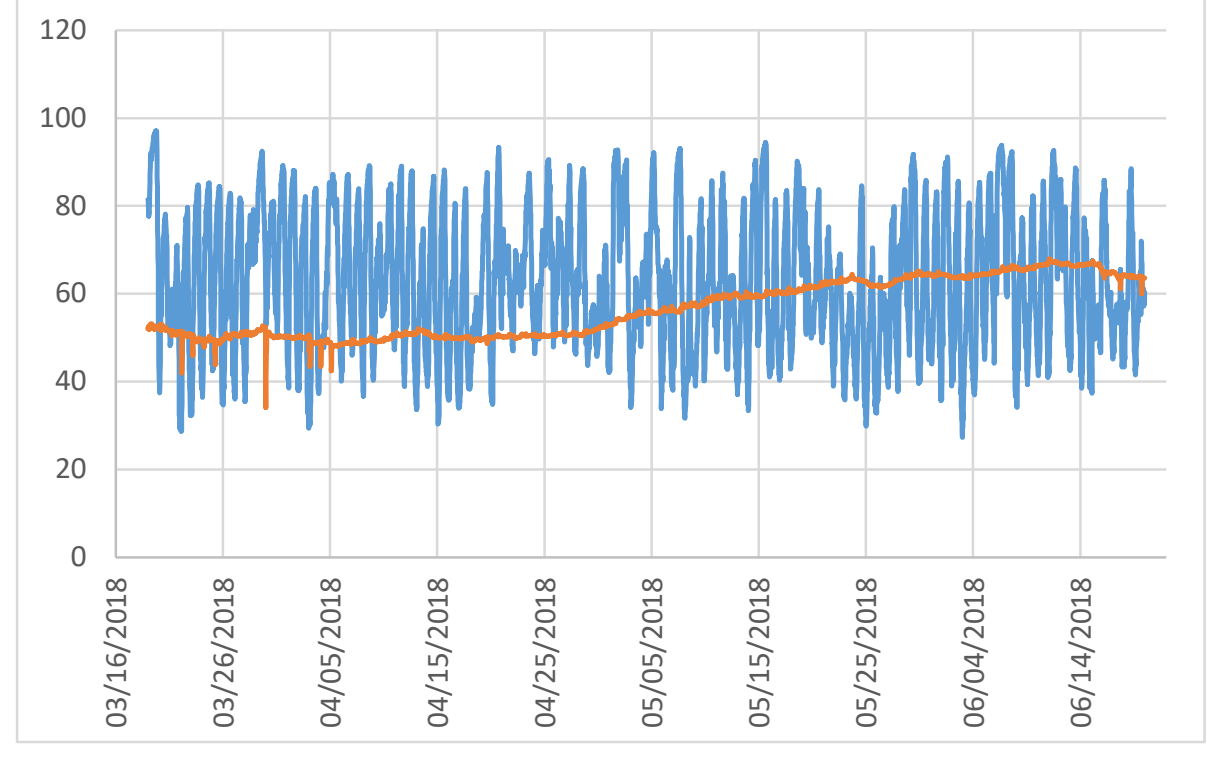

Figure 89: Spring 2018 RH

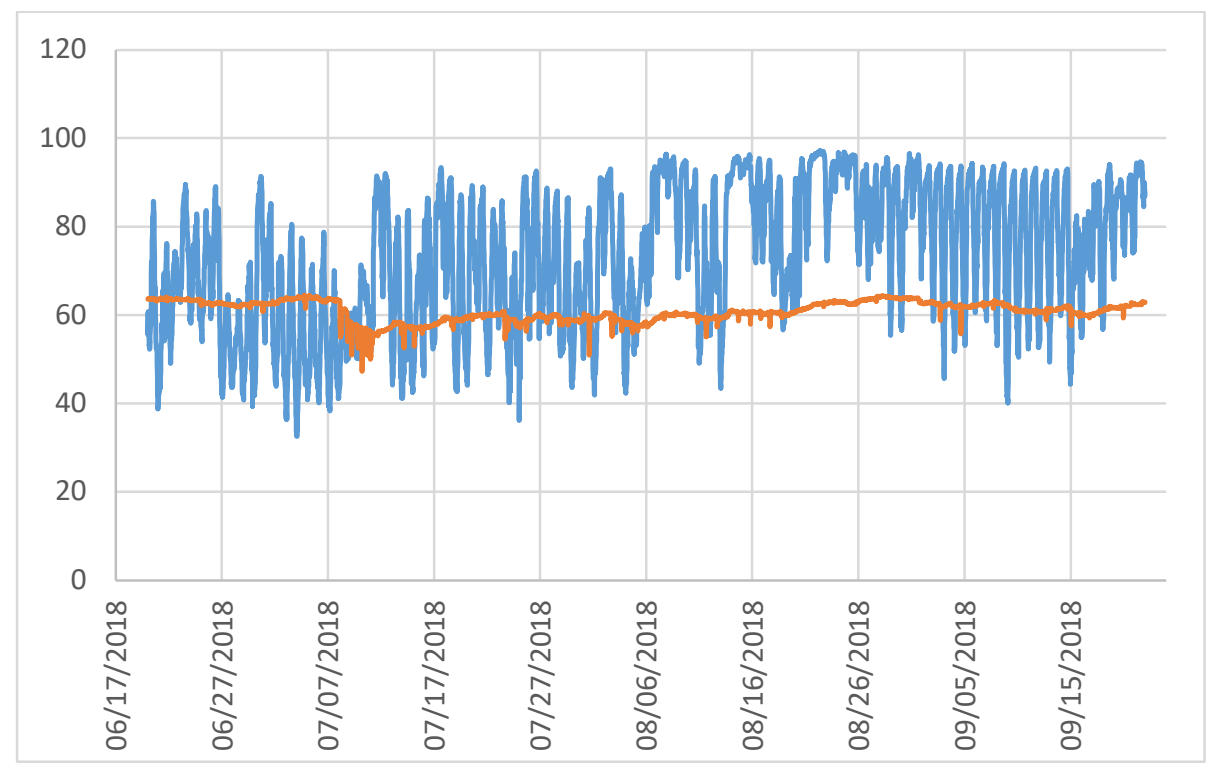

Figure 91: Summer 2018 RH

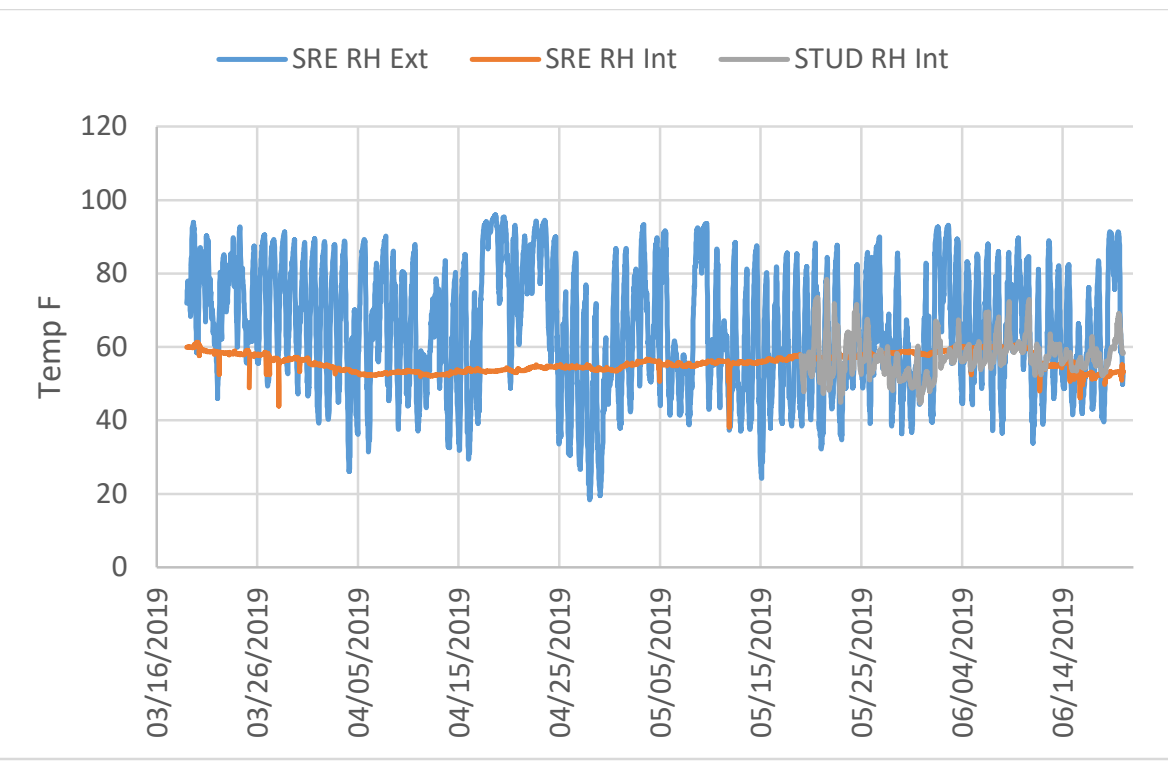

Figure 90: Spring 2019 RH

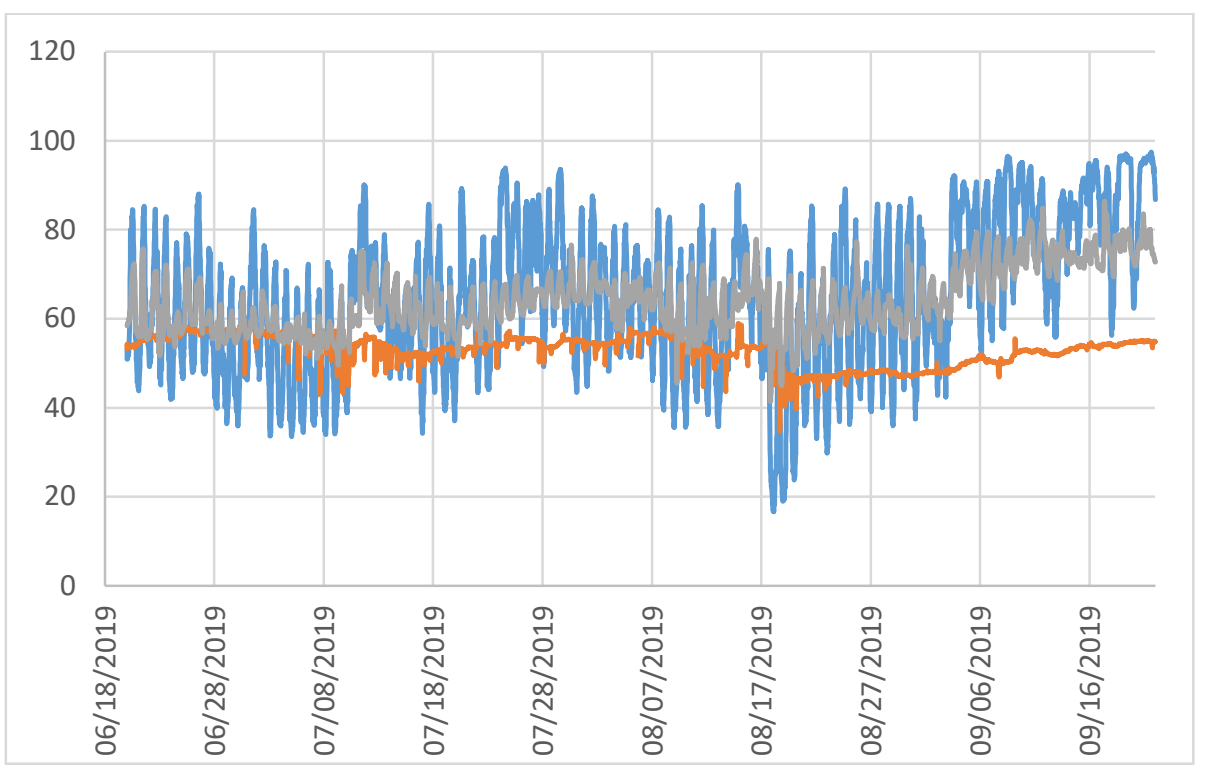

Figure 92: Summer 2019 RH 


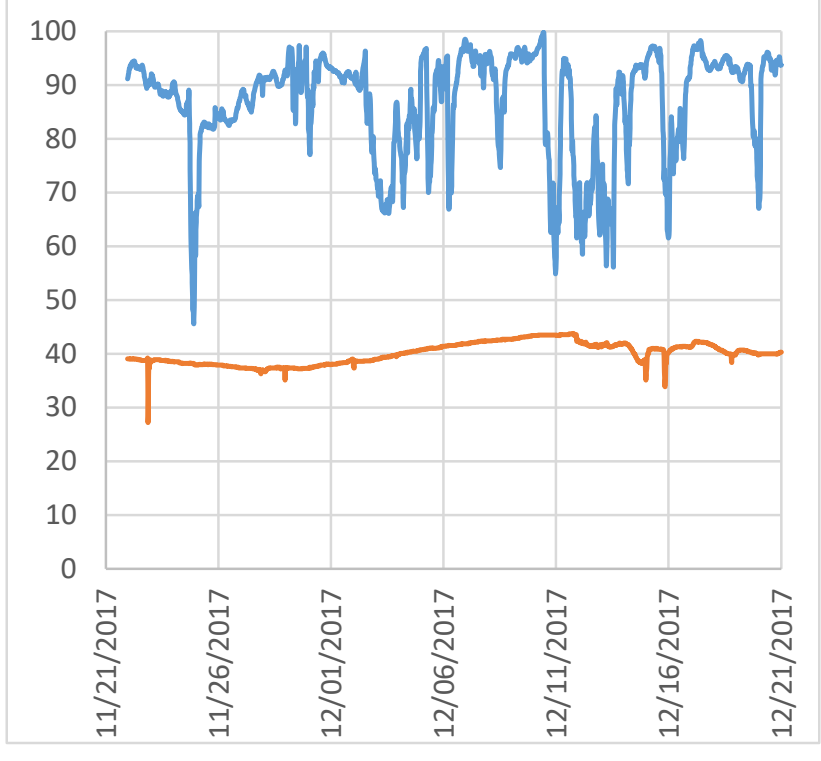

Figure 93: Fall 2017 RH

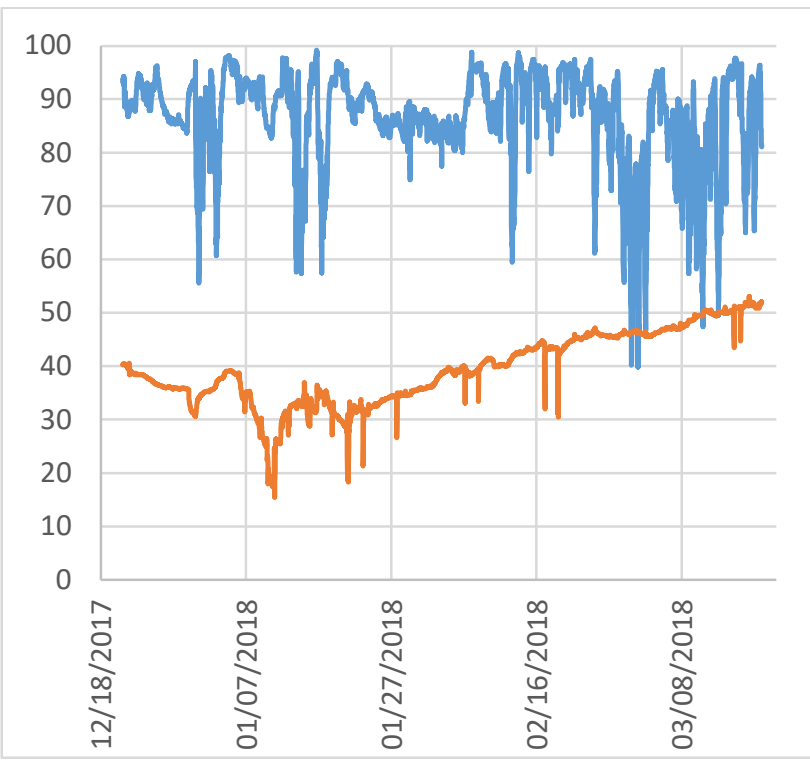

Figure 96: Winter 2017 RH

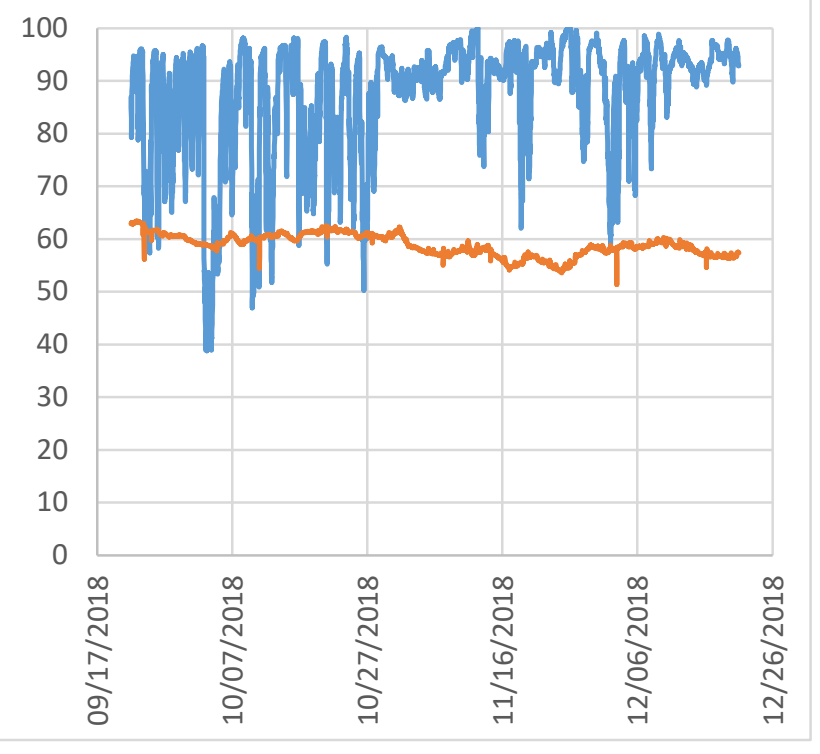

\section{Figure 94: Fall 2018 RH}

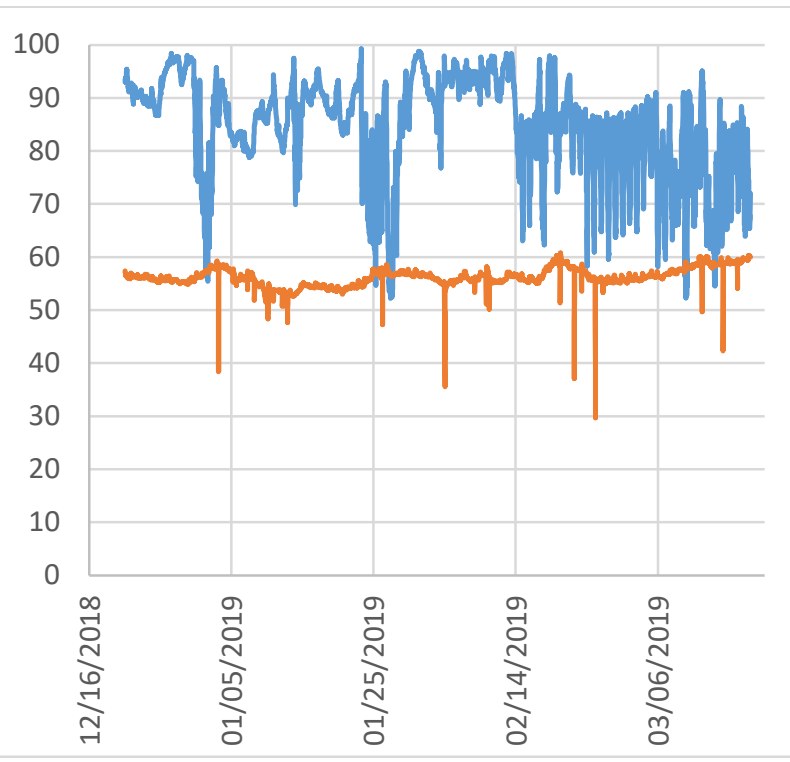

Figure 97: Winter 2018 RH

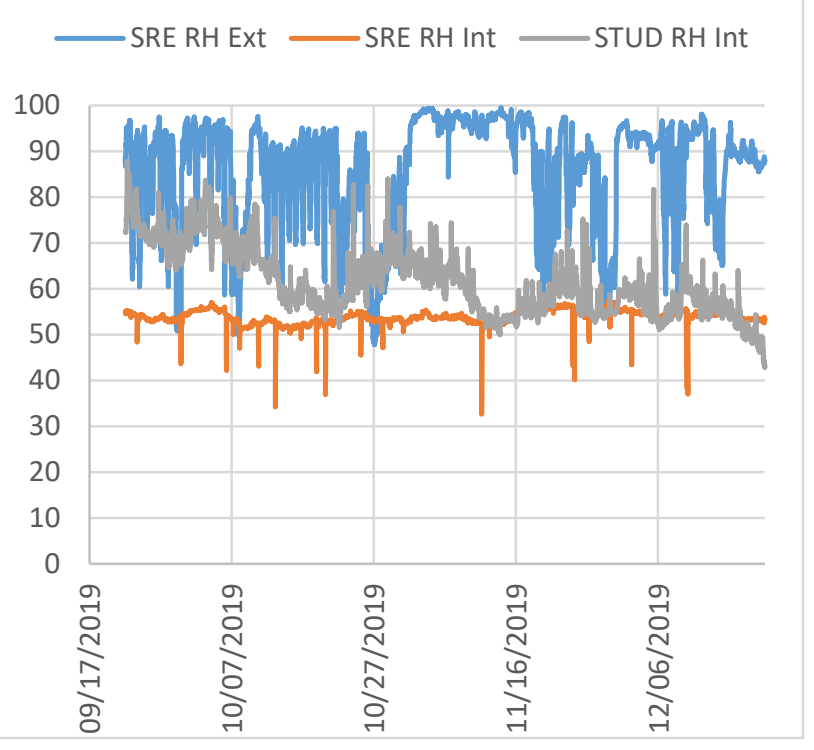

Figure 95: Fall 2019 RH

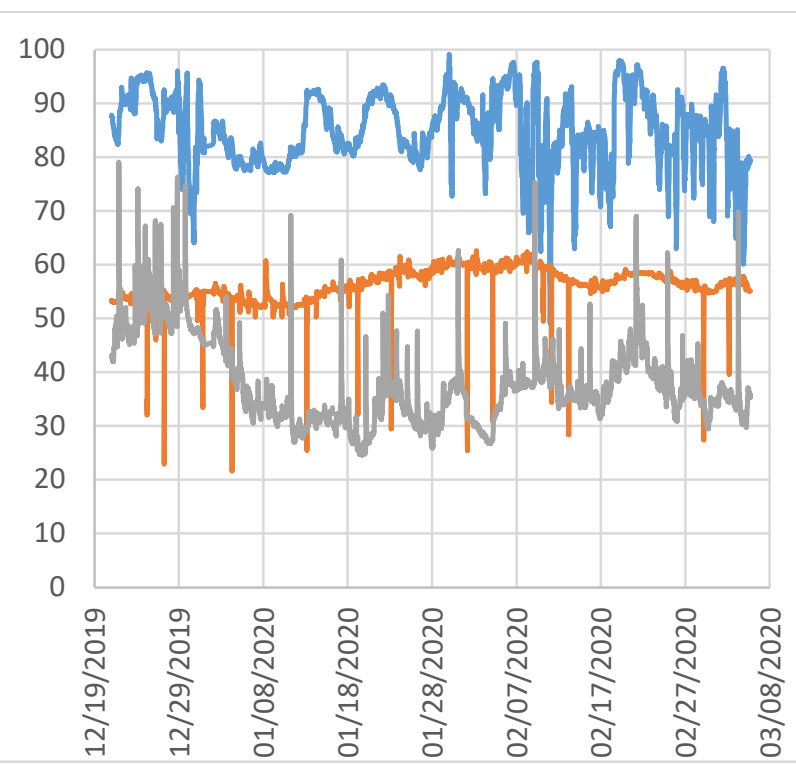

Figure 98: Winter 2019 RH 


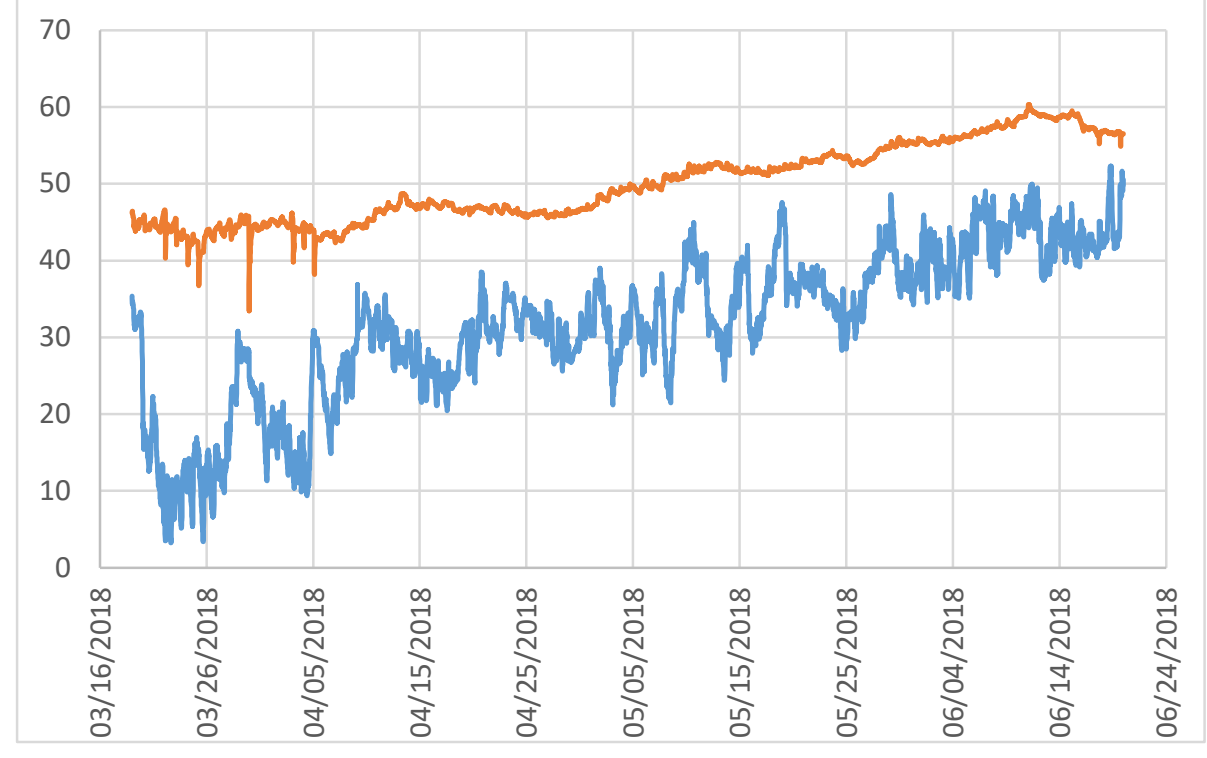

Figure 99: Spring 2018 DP

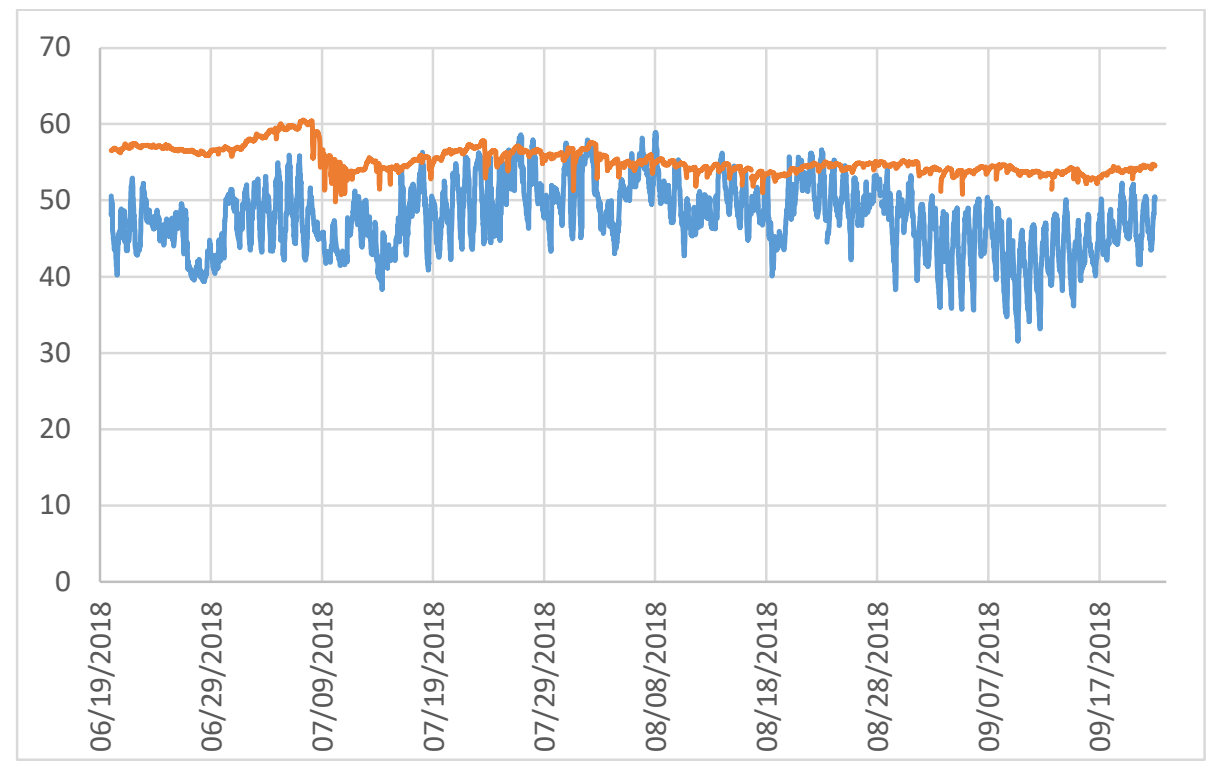

Figure 101: Summer 2018 DP

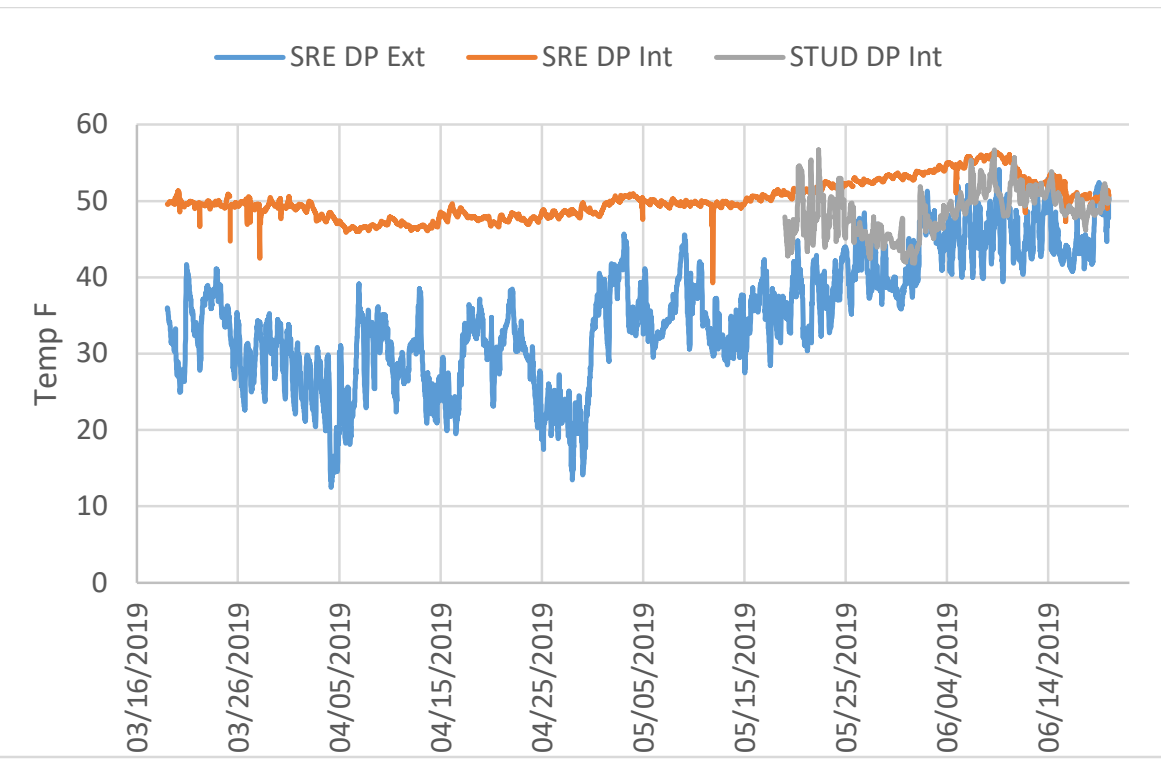

Figure 100: Spring 2019 DP

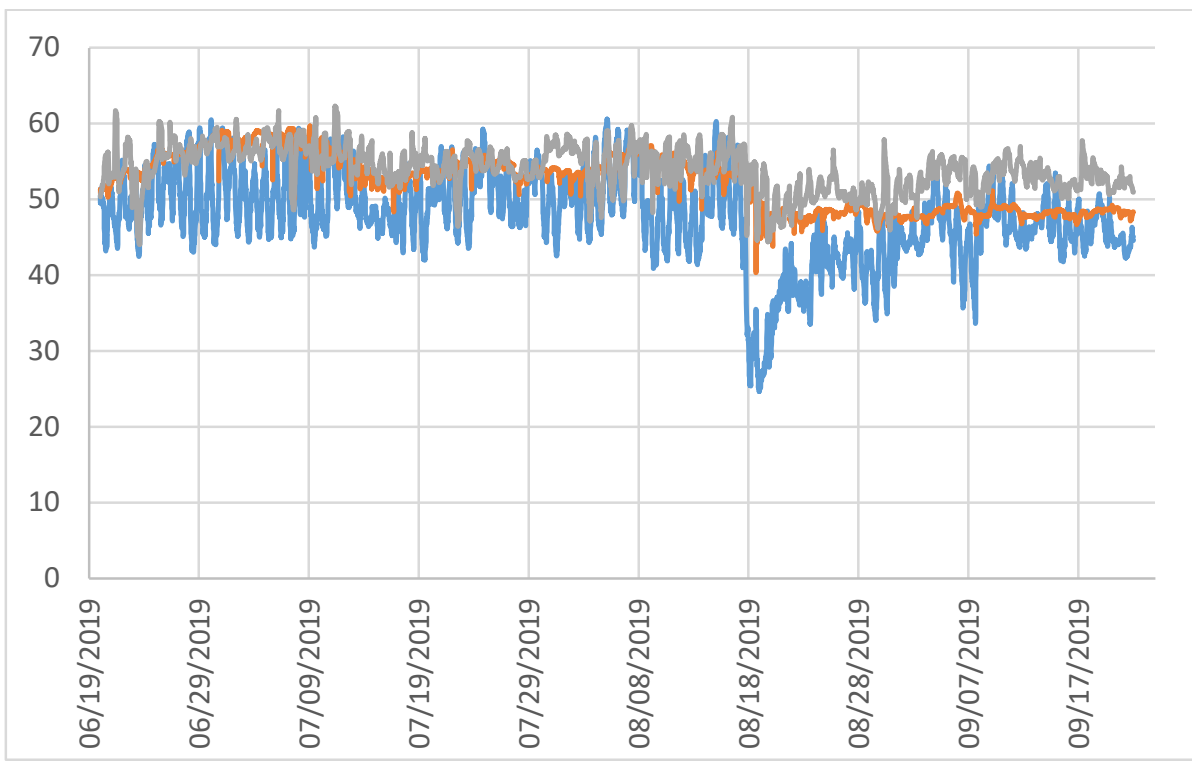

Figure 102: Summer 2019 DP 


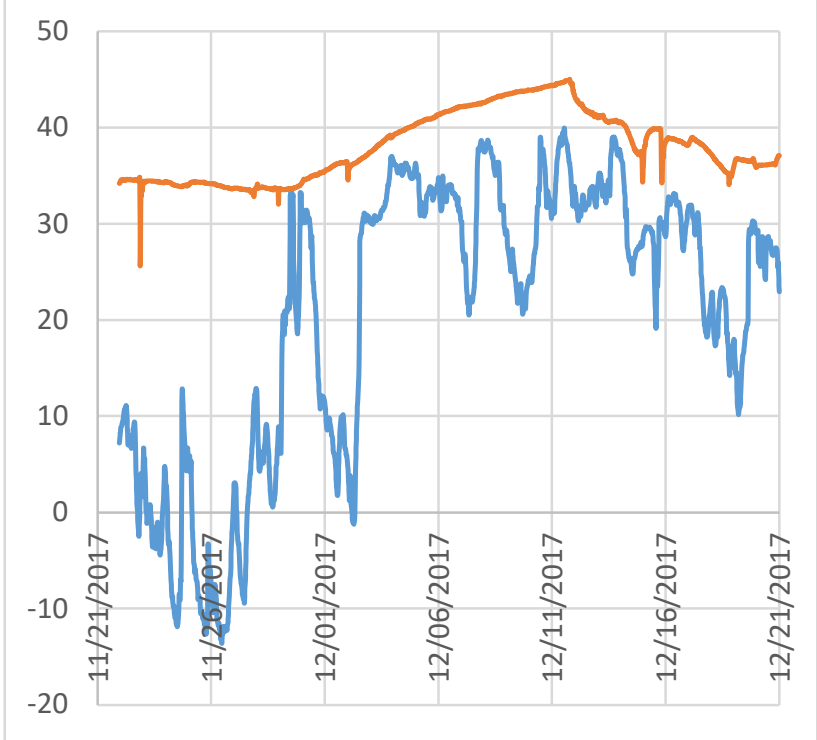

Figure 103: Fall 2017 DP

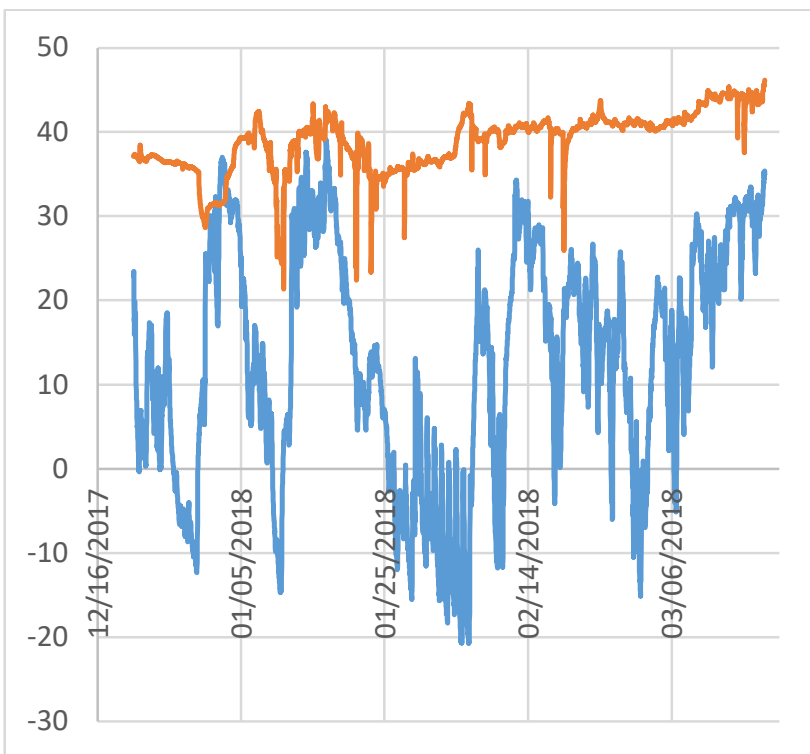

Figure 106: Winter 2017 DP

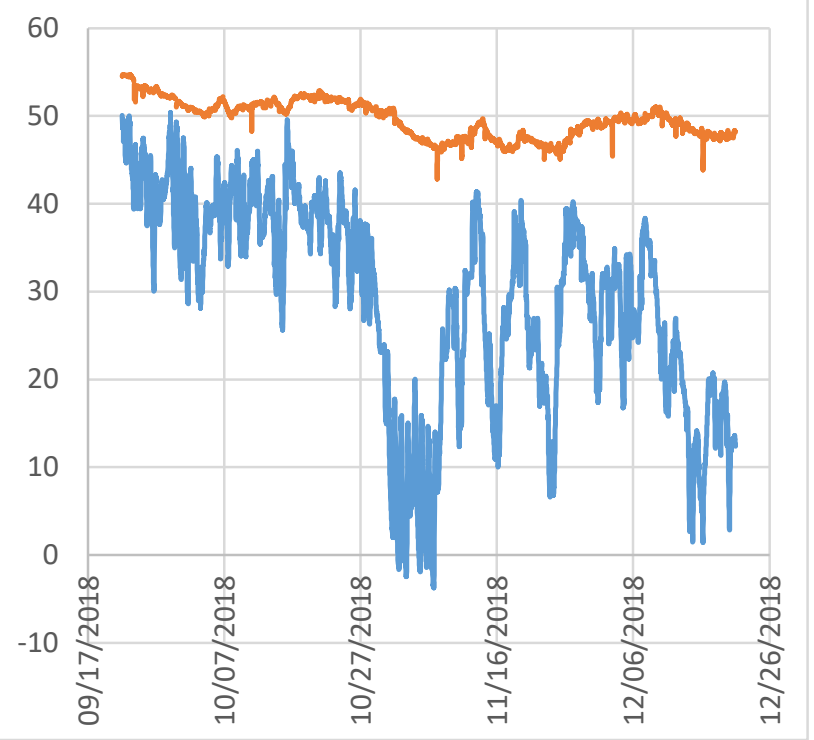

Figure 104: Fall 2018 DP

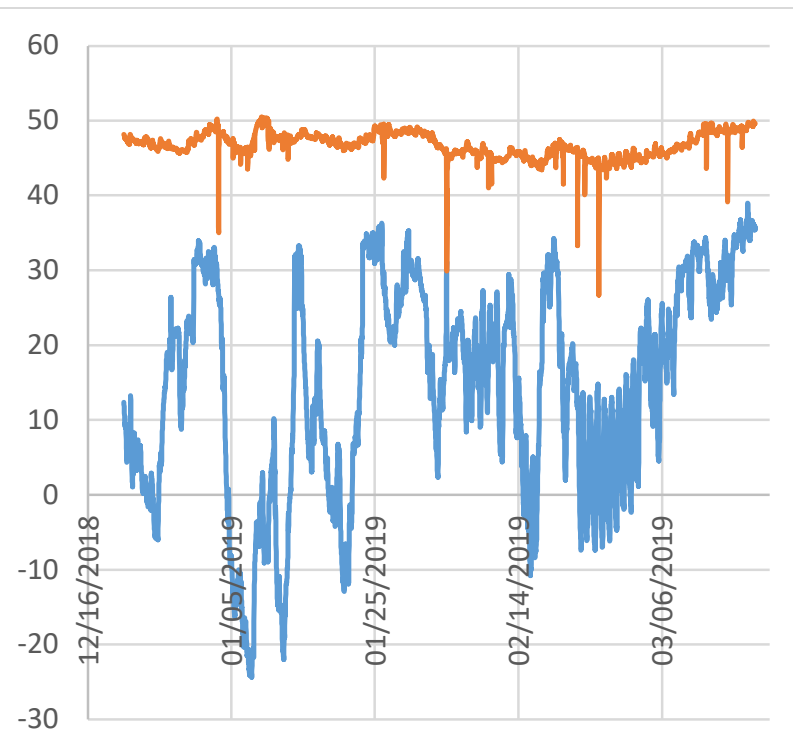

Figure 107: Winter 2018 DP

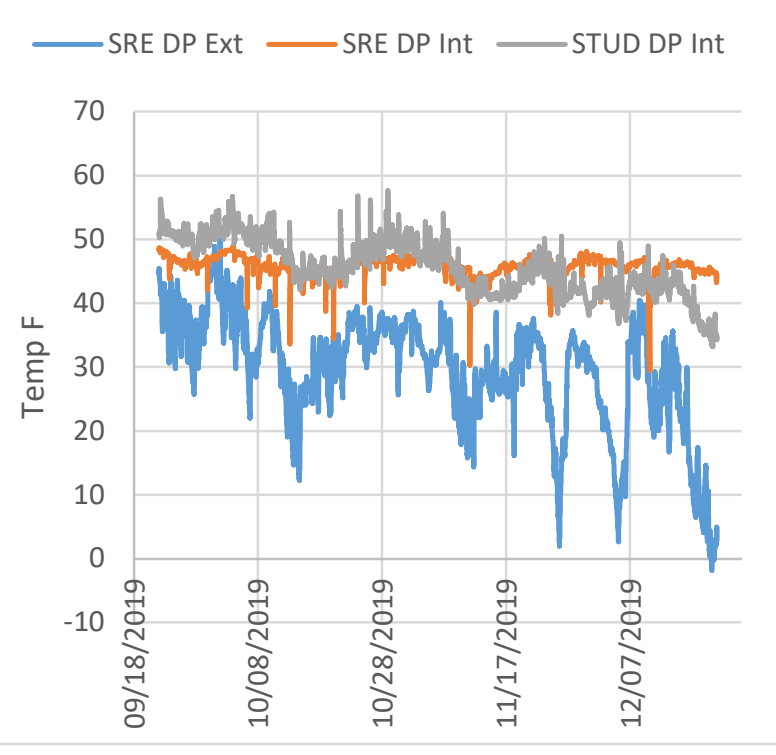

Figure 105: Fall 2019 DP

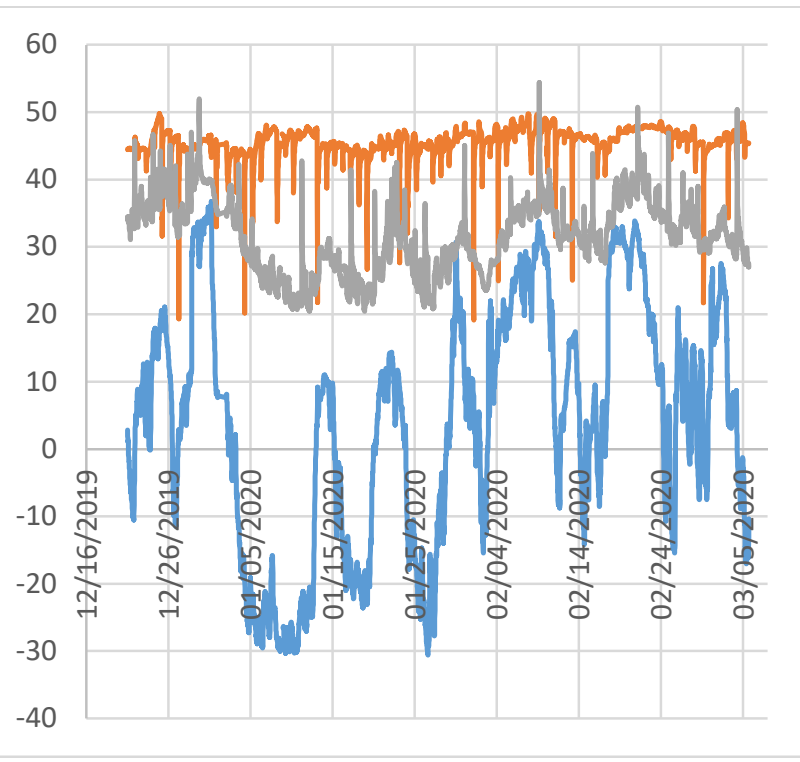

Figure 108: Winter 2019 DP 


\subsection{Natural Gas Utility Bills}

\begin{tabular}{|l|c|c|c|c|c|}
\hline & $\mathbf{f t}^{\mathbf{2}}$ & Occupied T & SRE T/STUD T & Unoccupied T & SRE T/STUD T \\
\hline SRE & 1788 & 71 & 1 & 71 & 1 \\
\hline STUD & 2774 & 65 & 1.092 & 60 & 1.183 \\
\hline
\end{tabular}

Table 13: Misc. Information for Calcs

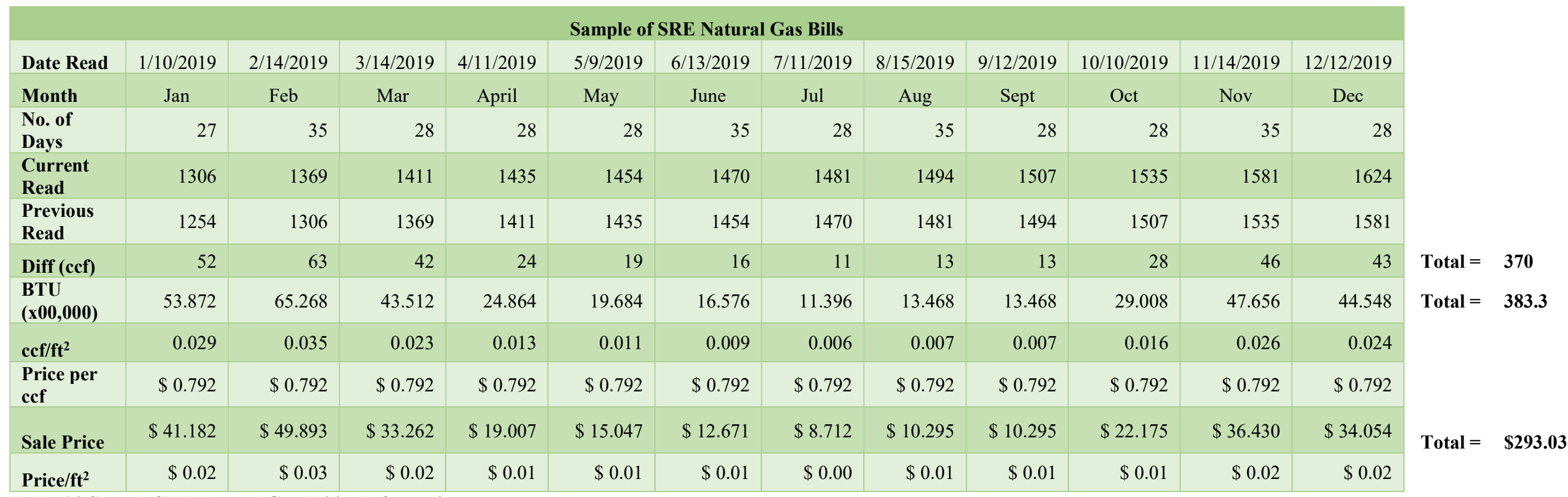

Table 14:Sample SRE Natural Gas Utility Information 


\begin{tabular}{|c|c|c|c|c|c|c|c|c|c|c|c|c|}
\hline Date Read & $1 / 10 / 2019$ & $2 / 14 / 2019$ & $3 / 14 / 2019$ & $4 / 11 / 2019$ & $5 / 9 / 2019$ & $6 / 13 / 2019$ & $7 / 11 / 2019$ & $8 / 15 / 2019$ & 9/12/2019 & $10 / 10 / 2019$ & $11 / 14 / 2019$ & $12 / 12 / 2019$ \\
\hline Month & Jan & Feb & Mar & April & May & June & Jul & Aug & Sept & Oct & Nov & Dec \\
\hline $\begin{array}{l}\text { NO. of } \\
\text { Days }\end{array}$ & 27 & 35 & 28 & 28 & 28 & 35 & 28 & 35 & 28 & 28 & 35 & 28 \\
\hline $\begin{array}{l}\text { Current } \\
\text { Read }\end{array}$ & 2147 & 2351 & 2495 & 2569 & 2630 & 2674 & 2697 & 2731 & 2764 & 2822 & 2958 & 3091 \\
\hline $\begin{array}{l}\text { Previous } \\
\text { Read }\end{array}$ & 1959 & 2147 & 2351 & 2495 & 2569 & 2630 & 2674 & 2697 & 2731 & 2764 & 2822 & 2958 \\
\hline Diff (ccf) & 188 & 204 & 144 & 74 & 61 & 44 & 23 & 34 & 33 & 58 & 136 & 133 \\
\hline $\begin{array}{l}\text { BTU } \\
(\mathbf{x 0 0 , 0 0 0 )}\end{array}$ & 194.768 & 211.344 & 149.184 & 76.664 & 63.196 & 45.584 & 23.828 & 35.224 & 34.188 & 60.088 & 140.896 & 137.788 \\
\hline $\operatorname{ccf} / \mathbf{f t}^{2}$ & 0.068 & 0.074 & 0.052 & 0.027 & 0.022 & 0.016 & 0.008 & 0.012 & 0.012 & 0.021 & 0.049 & 0.048 \\
\hline $\begin{array}{l}\operatorname{ccf} / \mathrm{ft}^{2} \mathrm{w} / \\
\Delta \mathrm{T}\end{array}$ & 0.076 & 0.083 & 0.058 & 0.030 & 0.025 & 0.018 & 0.009 & 0.014 & 0.013 & 0.023 & 0.055 & 0.054 \\
\hline Diff $w / \Delta T$ & 211.058 & 229.021 & 161.662 & 83.076 & 68.482 & 49.397 & 25.821 & 38.170 & 37.047 & 65.114 & 152.680 & 149.312 \\
\hline $\begin{array}{l}\text { Price per } \\
\text { cef }\end{array}$ & $\$ 0.79$ & $\$ 0.79$ & $\$ 0.79$ & $\$ 0.79$ & $\$ 0.79$ & $\$ 0.79$ & $\$ 0.85$ & $\$ 0.85$ & $\$ 0.85$ & $\$ 0.85$ & $\$ 0.85$ & $\$ 0.85$ \\
\hline Sale Price & $\$ 148.89$ & $\$ 161.56$ & $\$ 114.04$ & $\$ 58.61$ & $\$ 48.31$ & $\$ 34.85$ & $\$ 19.61$ & $\$ 28.99$ & $\$ 28.14$ & $\$ 49.45$ & $\$ 115.96$ & $\$ 113.40$ \\
\hline $\begin{array}{l}\text { Price w/ } \\
\Delta T\end{array}$ & $\$ 167.15$ & $\$ 181.38$ & $\$ 128.03$ & $\$ 65.79$ & $\$ 54.23$ & $\$ 39.12$ & $\$ 22.02$ & $\$ 32.54$ & $\$ 31.59$ & $\$ 55.52$ & $\$ 130.18$ & $\$ 127.31$ \\
\hline $\begin{array}{l}\text { Price } / \mathbf{f t}^{2} \\
w / \Delta T\end{array}$ & $\$ 0.06$ & $\$ 0.07$ & $\$ 0.05$ & $\$ 0.02$ & $\$ 0.02$ & $\$ 0.01$ & $\$ 0.01$ & $\$ 0.01$ & $\$ 0.01$ & $\$ 0.02$ & $\$ 0.05$ & $\$ 0.05$ \\
\hline
\end{tabular}

\section{Total $=944$}

Total $=\mathbf{1 1 7 2 . 7 5}$

Table 15: Sample of STUD Natural Gas Utility Information 